FEDERAL RESERVE BANK OF SAN FRANCISCO

WORKING PAPER SERIES

\title{
Banks, Maturity Transformation, and Monetary Policy
}

\author{
Pascal Paul \\ Federal Reserve Bank of San Francisco
}

October 2022

Working Paper 2020-07

https://www.frbsf.org/economic-research/publications/working-papers/2020/07/

\section{Suggested citation:}

Paul, Pascal. 2022. "Banks, Maturity Transformation, and Monetary Policy," Federal Reserve Bank of San Francisco Working Paper 2020-07.

https://doi.org/10.24148/wp2020-07

The views in this paper are solely the responsibility of the authors and should not be interpreted as reflecting the views of the Federal Reserve Bank of San Francisco or the Board of Governors of the Federal Reserve System. 


\title{
Banks, Maturity Transformation, and Monetary Policy
}

\author{
Pascal Paul \\ Federal Reserve Bank of San Francisco*
}

First version: February 2020

This version: September 2022

\begin{abstract}
Banks engage in maturity transformation and the term premium compensates them for bearing the associated interest rate risk. Consistent with this view, I show that banks' net interest margins and term premia have comoved in the United States over the last decades. On monetary policy announcement days, bank equity falls more sharply than nonbank equity following an increase in expected future short-term rates, but also responds more positively if term premia increase. These effects are reflected in bank cash-flows and amplified for banks with a larger maturity mismatch. The results reveal that banks are not immune to interest rate risk.
\end{abstract}

Keywords: Banks, Maturity Transformation, Monetary Policy, Term Premium, Interest Rate Risk, Bank Profitability

JEL Codes: E43, E44, E52, E58, G21, G32

*I thank Michael Bauer, Juliane Begenau, Markus Brunnermeier, Anna Cieslak, Simon Gilchrist, Valentin Haddad, Benjamin Hébert, Arvind Krishnamurthy, Monika Piazzesi, Glenn Rudebusch, João Santos, David Sraer, Eric Swanson, and an anonymous referee for their comments; Miguel Ampudia, Falko Fecht, and Skander van den Heuvel for their discussions; Jens Christensen, Richard Crump, and Andrew Meldrum for sharing their codes and data; seminar participants at the Bank of England, the Bank of Finland, Danmarks Nationalbank, the International Monetary Fund, the Federal Reserve Bank of San Francisco, the Office of Financial Research, Sveriges Riksbank, and conference participants at the SED conference, the SITE workshop on "Banks and Financial Frictions," the 28th Finance Forum, the OFCE/Science Po Workshop "Empirical Monetary Economics," the Annual Meeting of the Swiss Society for Financial Market Research, the Day-ahead conference on Financial Markets and Institutions, the Winter Meetings of the Econometric Society, the World Congress of the Econometric Society, the EEA-ESEM Congress, the Econometrics Workshop at the Federal Reserve Bank of St. Louis, and the Royal Economic Society Annual Conference for their insights. I also thank Colton Merrill, Benjamin Shapiro, and Simon Zhu for excellent research assistance. All errors are my own. The views expressed herein are solely those of the author and do not necessarily reflect the views of the Federal Reserve Bank of San Francisco or the Federal Reserve System. Email: pascal.paul@sf.frb.org. 


\section{Introduction}

An inherent feature of financial intermediation is maturity transformation: banks invest in longterm assets, funded by short-term liabilities. Due to this institutional characteristic, the typical textbook view is that banks are strongly exposed to interest rate risk. When short-term rates increase, banks' cost of funding rises, and with fixed-rate assets, their profit margins shrink, which drags down their stock prices. Accordingly, the business model of banking is highly sensitive to conventional monetary policy.

However, banks can structure their balance sheets to reduce their interest rate risk exposure. On one hand, interest rates of banks' assets are not necessarily fixed but can change with short-term rates. For example, banks frequently issue business loans or household mortgages with adjustable rates (e.g., Ippolito, Ozdagli and Perez-Orive, 2018; Foà et al., 2019). On the other hand, banks' cost of funding does not necessarily move one-for-one with changes in short-term rates. In particular, it has been shown that deposit rates are inherently rigid (e.g., Hannan and Berger, 1991; Neumark and Sharpe, 1992; Driscoll and Judson, 2013). Especially when short-term rates move up, the spread to deposit rates widens, such that deposits resemble long-term debt. Banks' market power in deposit markets can explain both the lower level and the behavior of deposit rates vis-à-vis short-term rates (e.g., Drechsler, Savov and Schnabl, 2017). Banks also actively manage their maturity profile. For example, it has been shown that banks shorten the maturity of their corporate loans when they increase their use of short-term wholesale funding (e.g., Paligorova and Santos, 2017). Given all of these features, bank profit margins may remain unchanged or even increase when the policy rate rises.

The classic view that banks are strongly exposed to interest rate risk has therefore been questioned recently. For example, Drechsler, Savov and Schnabl (2021) provide appealing evidence that banks do not take on interest rate risk, despite having a large maturity mismatch. First, they show that net interest margins of U.S. banks have been insensitive to changes in the federal funds rate, the policy target rate of the Federal Reserve, or Fed for short, as replicated in Appendix Figure A.1. Second, the reaction of banks' stock prices to plausibly exogenous changes in interest rates is relatively small, and not substantially different than the typical market response. Third, in the cross-section, banks match the short-run sensitivity of their interest income and expenses to changes in the federal funds rate (see also, e.g., Hellwig, 1994; Kirti, 2020). That is, if deposits behave like long-term liabilities, it is in fact optimal to invest in long-term fixed-rate assets.

These contradictory predictions about banks' interest rate risk exposure have vastly different implications. On one hand, the real effects of a policy rate change may be amplified by altering bank net worth if bank profit margins are sensitive to changes in monetary policy. Such a prediction is consistent with recent models in which the effective risk-bearing capacity of the financial sector plays a role for the transmission of shocks (Gertler and Kiyotaki, 2010; He and Krishnamurthy, 2013; Brunnermeier and Sannikov, 2014). On the other hand, if banks are insulated from interest 
rate risk, practitioners, policymakers, and academics could largely ignore the effects of policy rate changes on the financial sector, as well as its net worth for the propagation of monetary policy to the real economy.

In this paper, I provide new evidence on banks' interest rate risk exposure for the United States. I document four main findings, all of which result from taking into account changes in the term premium, the missing puzzle piece compared with previous empirical studies. The term premium is a natural starting point to study banks' exposure to interest rate risk, since it reflects the compensation for bearing such risk, as illustrated with a few stylized examples in the next section and standard asset pricing theory.

My first finding is that banks' net interest margins have comoved with term premia over the past few decades. Since the early 1990s, both series have been steadily declining. Over this period, banks' net interest margins fell around 2 p.p., with the relevant term premia accounting for a similar decline. The close relation is not only visible for longer-term trends, but also for high-frequency changes. Further, I show that the comovement between term premia and net interest margins is also not specific to this sample period-it equally holds for longer samples that start around the 1960s with steady increases initially. Hence, the relation between term premia and banks' net interest margins suggests that banks have historically been compensated for taking on interest rate risk. Put differently, if banks were not exposed to interest rate risk, then term premia and net interest margins should be fairly unrelated, and the evidence speaks against such a view.

Second, I analyze how banks' stock prices respond to yield changes on days of monetary policy announcements by the Federal Open Market Committee (FOMC). The identifying assumption is that monetary policy news dominates on such days (e.g., Kuttner, 2001; Gürkaynak, Sack and Swanson, 2005; Bernanke and Kuttner, 2005). As shown previously, banks' stock prices respond only weakly to longer-term government bond yield changes. In fact, comparing the response of a bank stock index with that of a typical market index shows that the two responses are not substantially different. If anything, the bank stock index responds more positively to an increase in long-term yields, suggesting that banks are not strongly exposed to interest rate risk.

However, once such yield changes are decomposed into variations in expected short-term rates and term premia, the findings change substantially. Relative to a typical market index, banks' stock prices respond more negatively to increases in expected short-term rates but more positively to a rise in term premia. For example, bank equity falls by around 17 percent to a 100-basis-point level-increase in expected short-term rates with respect to a 2-year government bond. In comparison, nonbank equity falls by 30 percent or 4 p.p. less, and even larger differences are found for the responses to term premia. These results show that bank equity is highly sensitive to interest rate risk, a finding that is hidden when ignoring changes in term premia.

Two identification concerns surround these results. First, term premia respond endogenously to 
monetary policy news and other shocks on monetary policy announcement days. Second, omitted shocks such as information releases by the Fed about the economic outlook can bias the estimates since they are correlated with the interest rate surprises as well as stock prices (e.g., Nakamura and Steinsson, 2018). To address these concerns, I show analytically that the identification approach gives consistent estimates in the absence of such omitted shocks, even if term premia endogenously adjust to monetary policy news. In the presence of correlated but omitted shocks, I show that the differential responses between bank and nonbank equity can still be consistently estimated, reinforcing the empirical results. The same holds for non-FOMC days and I show that my findings are largely unchanged if I include such observations, which increases the sample size substantially.

I show that these findings are also supported by asset pricing theory. Accordingly, bank equity should respond more negatively than nonbank equity to an increase in expected future short-term rates, but more positively to an increase in term premia. Intuitively, banks' expected cash-flow rises after an increase in term premia, and their equity response is therefore more positive relative to typical nonfinancial companies. In contrast, banks' net interest margins on legacy assets sharply decline to an increase in short-term rates, leading to a stronger fall in bank equity, even after taking into account the reduced pass-through to deposit rates and variable-rate loans. Based on a numerical example, I show that asset pricing predicts similar quantitative differences between the responses of bank and nonbank equity to a change in short-term rates as in the data, and that banks' maturity mismatch can account for them as opposed to heterogeneity in leverage between banks and nonfinancial companies.

In a third exercise, I test whether the stock price reactions are also reflected in the response of bank profit margins to term premia and expected short-term interest rate surprises. Consistent with the differential equity responses and the asset pricing predictions, I find that banks' net interest margins increase if term premia rise but decrease if expected future short-term rates increase. These responses are not offset by a reaction of noninterest income, but translate into similar movements in banks' net income. Again, such heterogeneity is hidden without a decomposition of long-term yields.

To obtain the fourth and final result, I turn to the cross-section of banks. Specifically, I analyze whether banks' stock prices respond differently to yield changes depending on their business model. Using alternative measures of banks' maturity mismatch, I show that stock prices of banks with a larger maturity mismatch respond more positively to a rise in term premia. Intuitively, banks that engage more heavily in maturity transformation benefit relatively more if the compensation for interest rate risk increases. I show that the results based on stock prices survive various robustness checks: using alternative estimates for term premia, excluding particular unscheduled FOMC meetings, using different measures for banks' maturity mismatch, controlling for other bank characteristics, and restricting the sample along several dimensions.

Taken all pieces of evidence together, my results support a view that lies in between the classic textbook case and the one that banks are not exposed to interest rate risk. While banks engage 
in active risk management to reduce their interest rate risk exposure, such a risk transfer is not perfect and banks are unable to offload all of the interest rate risk that they are naturally exposed to. Three immediate implications arise from my findings. First, policy rate changes can affect bank net worth and thereby amplify the real effects of monetary policy. Second, the recent decline in bank net interest margins can largely be accounted for by a reduction in interest rate risk and the associated compensation for such risk. Third, while working through a number of channels, quantitative easing may have unwanted side-effects by distorting term premia. That is because lower term premia can reduce bank profitability, bank lending, and ultimately affect the real economy.

Related Literature. This paper relates to a literature on banks' exposure to interest rate risk, dating back at least to Samuelson (1945) (see Vuillemey, 2016, for a survey of the literature). A seminal contribution to the empirical literature on this topic is Flannery and James (1984). They consider the response of banks' stock returns to changes in interest rates and find that those responses depend on banks' characteristics, in particular on banks' maturity mismatch. Relative to this early contribution, English, van den Heuvel and Zakrajšek (2018) consider the response of U.S. banks' stock prices to monetary policy surprises on FOMC announcement days, thereby focusing on responses to monetary policy news. They find that banks' stock prices are negatively exposed to surprise increases in the level and the slope of the yield curve, and both reactions are mitigated for banks with a larger maturity mismatch. However, Drechsler, Savov and Schnabl (2021) highlight that the reaction of bank equity to monetary policy surprises is not substantially different from that of other nonfinancial companies.

In comparison, the key insight from my analysis is that long-term bond yield changes may have opposing implications for banks, depending on whether they are due to changes in future expected short-term rates or changes in term premia. Once bond yield changes are decomposed in this way, I show that bank equity is substantially more exposed to interest rate risk relative to nonbank equity, and in comparison with the estimates by English, van den Heuvel and Zakrajšek (2018). In the cross-section of banks, the underlying change in long-term bond yields also matters: banks with a larger maturity mismatch respond more positively to an increase in term premia, but more negatively if the yield curve steepens because of an increase in expected short-term rates.

While I study how changes in term premia affect bank profit margins and their stock prices, Haddad and Sraer (2020) show that changes in banks' interest rate exposure predicts one-period bond excess returns, consistent with the view that banks remain exposed to interest rate risk. ${ }^{1}$ Intuitively, banks are marginal investors in various fixed income markets and determine asset prices in those markets according to their own interest rate exposure (see also, e.g., Hanson, 2014). While my analysis is silent on which agents price term premia, they could possibly be driven by banks' investing behavior.

\footnotetext{
${ }^{1}$ The expected annual term premium of a long-term bond is equal to the average expected one-period bond excess returns with declining maturity.
} 
Begenau, Piazzesi and Schneider (2020) also study U.S. banks' exposure to interest rate risk and credit risk by constructing a small number of spanning bonds that capture those risks. They show that banks' balance sheets have been substantially exposed to both risks. In addition, they find that banks by and large do not use derivatives to reduce their interest rate exposure. ${ }^{2}$ Gomez, Landier, Sraer and Thesmar (2021) investigate the relation between interest rate risk exposure and bank lending, showing that U.S. banks with a larger income gap-that is, more short-term interest rate sensitive assets than liabilities-reduce their lending by less following an increase in the federal funds rate. Hoffmann, Langfield, Pierobon and Vuillemey (2019) use data for several Euro area countries and find that banks' exposure to interest rate risk is heterogeneous in the cross-section, with net worth increasing to higher interest rates for a substantial fraction of banks. Apart from these empirical contributions, Di Tella and Kurlat (2020) build a model in which banks' maturity mismatch and exposure to interest rate risk emerges as an equilibrium outcome. Their model predicts bank equity responses to interest rate shocks in the range of the numbers that I obtain.

My findings can also shed light on the discussion about bank profitability within a low or negative interest rate environment. ${ }^{3}$ I show that low net interest margins of banks are not a recent phenomenon, but have been falling over the past three decades. I associate this pattern to the simultaneous decrease in interest rate risk and the associated compensation for it. Nonetheless, I also show that banks' return on assets is relatively stable at around 1 percent outside of financial crises over the last decades.

Overview. The next section uses several stylized examples to build intuition for the results in this paper. Section 3 provides descriptive evidence for the historical relation between banks' net interest margins and term premia. Sections 4 and 5 consider event-study approaches, estimating the responses of stock prices to changes in interest rates. Section 6 considers theoretical asset pricing predictions. Section 7 estimates impulse responses of banks' profit margins to interest rate surprises. Section 8 collects evidence on stock price responses from the cross-section of banks. Finally, Section 9 concludes and highlights several avenues and challenges for future research.

\section{$2 \quad$ Stylized Examples}

To build intuition for the findings in this paper, I start out with a few stylized examples. Imagine a bank that borrows one dollar at the short-term market rate and invests this dollar in a safe longterm government bond, rolling over its debt until the bond matures. In expectation, the bank's profit is given by the term premium, that is, by the difference between the annual yield of an $m$-period zero-coupon government bond at the time of investment in period $t$, denoted $y_{t}^{m}$, and the

\footnotetext{
${ }^{2}$ See also, e.g., Purnanandam (2007) and Vuillemey (2019).

${ }^{3}$ See, e.g., Altavilla, Boucinha and Peydró (2018), Ampudia and van den Heuvel (2019), Balloch and Koby (2020), Borio, Gambacorta and Hofmann (2017), Brei, Borio and Gambacorta (2019), Brunnermeier and Koby (2019), Claessens, Coleman and Donnelly (2018), Heider, Saidi and Schepens (2019), Lopez, Rose and Spiegel (2018), Ulate (2021), and Wang (2018).
} 
average expected short-term rates over this horizon, denoted $E H_{t}^{m}$ for "expectation hypothesis,"

$$
y_{t}^{m}=\underbrace{\frac{1}{m} E_{t}\left\{\sum_{k=0}^{m-1} y_{t+k}\right\}}_{E H_{t}^{m}}+\underbrace{\tau_{t}^{m}}_{\text {Term Premium }},
$$

where $y_{t+k}$ denotes the short-term rate in period $t+k$. Interest rate risk is the risk of fluctuations in short-term rates (the bank's cost of funding) which affect the bank's profits. The expected term premium $\tau_{t}^{m}$ compensates the bank for taking on interest rate risk-a risk compensation for engaging in an arbitrage of investing long-term, financed by borrowing short-term. In Appendix F, I use a similar example to show how the term premium is priced in equilibrium using standard consumption-based asset pricing. The theoretical nature of the term premium is the same. It compensates an investor for taking on interest rate risk. In practice, the term premium is priced by various investors that trade government bonds directly or indirectly, including banks, money market funds, pension funds, arbitrageurs, and households, for example.

In the above example, the term premium is also equal to the bank's expected net interest margin (NIM) - the difference between interest income and interest expenses per unit of (interest-earning) assets. Equation (2.1) illustrates that a change in long-term yields can have opposing implications for banks' cash-flows depending on what drives this change. For example, after the bank invested, higher-than-expected short-term rates imply an increase in the cost of funding and therefore a fall in profits. In contrast, before a bank invests, a higher term premium that also raises long-term yields actually implies higher future profits, while also reflecting a risk compensation. ${ }^{4}$ Given these opposing effects, it is therefore important to disentangle changes in long-term yields. This simple example also highlights that there is an important difference between the term spread (current long-term yield minus current short-term yield) and the term premium (current long-term yield minus average expected future short-term rates). For example, an elevated term spread does not necessarily imply that the bank in this simple example can expect a high profit margin, since it may simply reflect an expectation that future short-term rates will increase. Hence, the distinction between term spread and term premium is particularly important for banks that need to evaluate how future short-term rates evolve when making an investment decision.

As the discussion in the introduction demonstrates, banks are not so simple in practice. In particular, banks typically borrow at rates below short-term market rates and largely invest in risky loans, as opposed to safe government bonds. To account for these additional features, consider a bank that invests in an $m$-period risky fixed-rate loan. The expected annual rate $E_{t}\left(r_{t}^{m}\right)$ on such

\footnotetext{
${ }^{4}$ All else equal, an increase in the term premium after investment actually has no effect on the profits for this bank if it intends to hold its long-term bond until maturity. In contrast, if the bank holds the long-term bond with the intention to resell it at a later point in time, an increase in the term premium is associated with a fall in the price of the bond and can therefore imply lower profits. As explained in Section 6, the current market value of future profits or dividends also decreases following an increase in the term premium due to a standard discounting effect.
} 
a loan that is issued in period $t$ can be expressed as

$$
E_{t}\left(r_{t}^{m}\right)=y_{t}^{m}+\underbrace{\eta_{t}^{m}}_{\text {External Finance Premium }}
$$

where $\eta_{t}^{m}$ gives the expected external finance premium, which compensates the bank for taking on credit risk (e.g., Bernanke, Gertler and Gilchrist, 1999). Further taking into account (2.1) and assuming that the bank borrows at a deposit rate $r_{t+k}$ in period $t+k$ with $r_{t+k}<y_{t+k}$, equation (2.2) can be extended to

$$
E_{t}\left(r_{t}^{m}\right)=\underbrace{\overbrace{\frac{1}{m} E_{t}\left\{\sum_{k=0}^{m-1} r_{t+k}\right\}+\underbrace{\mu_{t}^{m}}_{\text {Deposit Premium }}}^{E H_{t}^{m}}}_{y_{t}^{m}}+\tau_{t}^{m}+\eta_{t}^{m}
$$

where $\mu_{t}^{m}$ denotes the expected deposit premium. The bank earns this premium due to its deposit franchise, which allows the bank to pay a deposit rate that is lower than the short-term market rate (e.g., Drechsler, Savov and Schnabl, 2017). The expected deposit premium is given by the difference between $E H_{t}^{m}$ and the average expected deposit rates over the same horizon. For this more sophisticated bank, the expected net interest margin at time $t$ is

$$
E_{t}\left(N I M_{t}^{m}\right)=\mu_{t}^{m}+\tau_{t}^{m}+\eta_{t}^{m}
$$

Hence, the bank earns a profit from three distinct premia in expectation: (i) $\mu_{t}^{m}$ due to its deposit franchise, (ii) $\tau_{t}^{m}$ for taking on interest rate risk, and (iii) $\eta_{t}^{m}$ for taking on credit risk. Based on equation (2.4), one can quantify the relative importance of each premium. According to the classic view about banking mentioned in the introduction, $\tau_{t}^{m}$ should account for a substantial fraction of banks' overall margin. In contrast, if banks are not exposed to interest rate risk, $\tau_{t}^{m}$ should be negligible, since their assets would be priced without such a risk compensation. ${ }^{5}$

\section{Descriptive Evidence}

Unfortunately, none of the three premia in (2.4) are directly observable. In particular, the term premium is unknown due to the lack of direct data on the expected path of future short-term rates. In this paper, I therefore rely on estimates for $\tau_{t}^{m}$ from term structure models. To understand the importance of $\tau_{t}^{m}$ for bank profit margins, I consider data on realized net interest margins. Intuitively, if changes in term premia are priced into rates on new loans and securities, then such movements should be reflected in variations in realized net interest margins, if banks are in fact exposed to interest rate risk. Also note that such a risk exposure should still be reflected in bank

\footnotetext{
${ }^{5}$ For example, a hypothetical adjustable-rate long-term government bond with a yield that moves one-for-one with the current short-term rate has a zero term premium. Similarly, a bank that issues an adjustable-rate loan with the same feature only earns the deposit premium $\mu_{t}^{m}$ and the credit risk premium $\eta_{t}^{m}$ in expectation according to equation (2.3).
} 


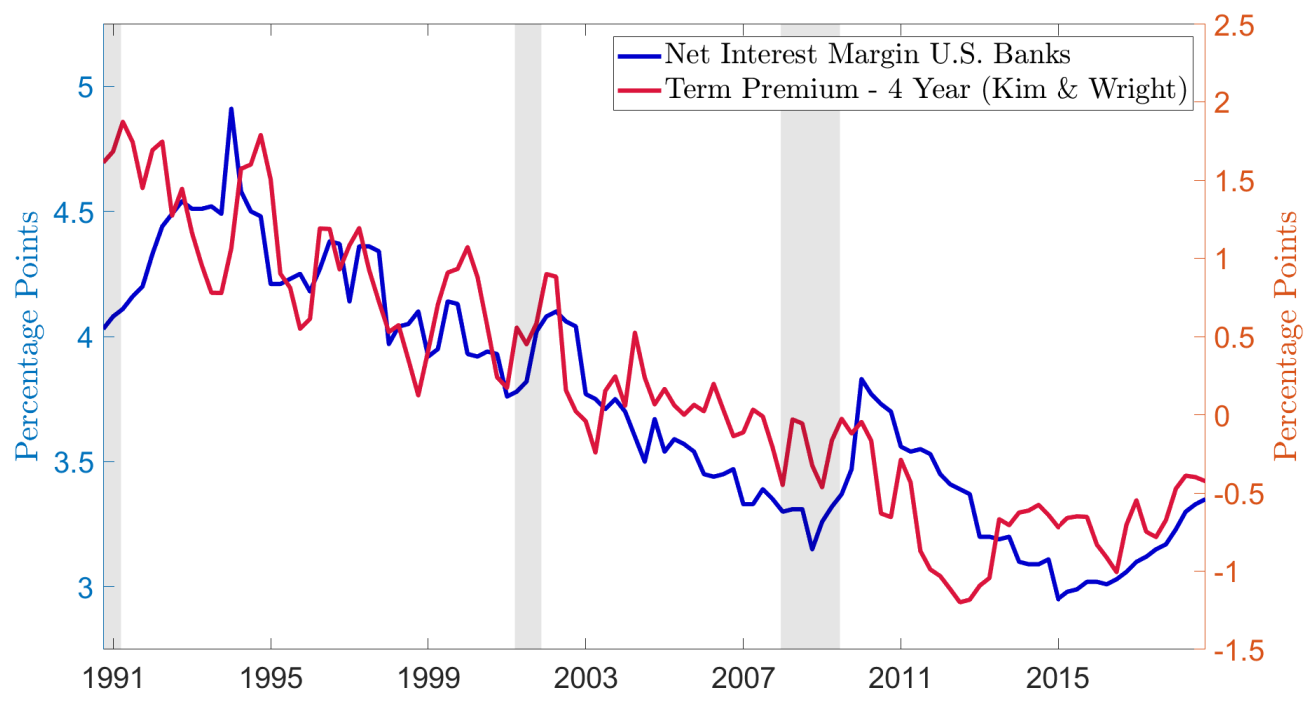

Figure 3.1: Banks' Net Interest Margins and the Term Premium - Levels.

Notes: The net interest margin is given by the difference between interest income and interest expenses divided by total interest-earning assets. The figure shows the net interest margin for U.S. commercial banks and is taken from St. Louis Fed's FRED database based on data from the Call Reports (left axis). The term premium is based on estimates by Kim and Wright (2005) (right axis, see Section 4.1 for details).

profit margins, even if banks price term premia in equilibrium or respond to term premium changes by altering their asset allocations.

Figure 3.1 provides such a comparison, using data for U.S. commercial banks and a term premium estimate based on the model by Kim and Wright (2005), which is employed by the Federal Reserve Board (see Section 4.1 for details). ${ }^{6}$ The two series have followed each other closely over the past three decades. Over the sample, the average net interest margin for U.S. commercial banks declined from around 5 percent at its peak in the early 1990s to around 3 percent by 2015 . This decline can be explained by the fall in the term premium over the same period. In fact, the term premium declined by slightly more, from around 1.8 percent to -1.2 percent, with the other components in (2.3) potentially moving in an offsetting direction over the sample. The fraction of the net interest margin that can be explained by the term premium also declined over the considered sample, from around 40 percent in the mid-1990s to close to zero around the onset of the Great Recession. The negative term premium in recent years can be explained by the absence of a lower bound on the short-term interest rate within the term structure model by Kim and Wright (2005) (see Section 4.1 for a discussion) or by the preference of certain investors, such as pension funds, for longer-maturity bonds.

\footnotetext{
${ }^{6}$ The 4-year term premium is used since such a horizon roughly corresponds to the typical maturity mismatch of banks in the data (see Section 8.1 and Appendix Figure H.2). As a measure of banks' net interest margins, I take a historical series directly from St. Louis Fed's FRED database, which is based on data from the Call Reports. Replicating this series with the data described in Section 8.1 yields similar estimates. In unreported work, I verify that these trends hold for banks that are active throughout the sample, the ones that are entering, and the ones that are dropping out.
} 


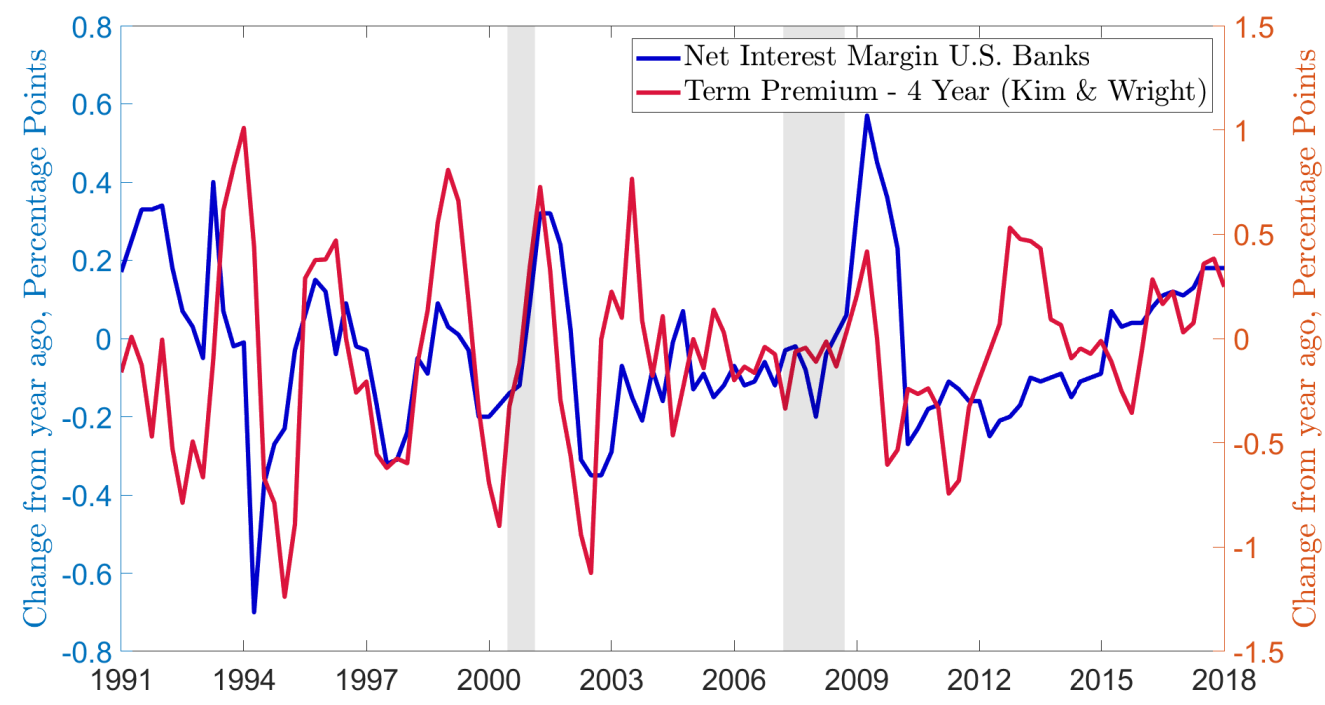

Figure 3.2: Banks' Net Interest Margins and the Term Premium - Differences.

Notes: The net interest margin is given by the difference between interest income and interest expenses divided by total interest-earning assets. The figure shows the net interest margin for U.S. commercial banks and is taken from St. Louis Fed's FRED database based on data from the Call Reports (left axis). The term premium is based on estimates by Kim and Wright (2005) (right axis, see Section 4.1 for details).

Figure 3.2 uses the same series as Figure 3.1, but illustrates them as percentage point changes from a year ago. Again, the two series follow each other closely, with the term premium change often leading that of the net interest margin. An exception is the recent lower bound episode, possibly due to the feature that the Kim and Wright (2005) model does not account for such a constraint. Thus, term premia and net interest margins not only show similar trends over the last decades, but also move in tandem at higher frequencies. ${ }^{7}$

Additional evidence on the relation between term premia and net interest margins is shown in Appendix A. Figure A.3 replicates the evidence in Figures 3.1 and 3.2, using an alternative estimate for the term premium based on the model by Adrian, Crump and Moench (2013) (see Section 4.1 for details). Again, the two series show similar movements. The evidence in Figures 3.1, 3.2, and Appendix A suggests that changes in term premia feed into subsequent changes in net interest margins relatively quickly, which can be explained by the fact that the rates on new loans and other assets can incorporate such changes at issuance, impacting a bank's interest income stream thereafter.

The estimates by Adrian, Crump and Moench (2013) reach back further than the ones by Kim and Wright (2005), starting in 1961. Figure A.4 makes use of this longer time series, comparing a term premium estimate by Adrian, Crump and Moench (2013) with annual historical data on bank net interest margins from the Federal Deposit Insurance Corporation (FDIC). In contrast to the

\footnotetext{
${ }^{7}$ Similar patterns are visible when comparing net interest margins with long-term government yields instead, as those are strongly driven by changes in term premia. However, the comovements are less precise due to the influence of future expected short-term rates as shown in Appendix Figure A.2.
} 
sample in Figure 3.1, the term premium has not been in steady decline, but increased from 1961 until around the early 1980s and fell thereafter. While there are some episodes during which the term premium and the net interest margin diverge for this extended sample, for the most part, the two series show similar patterns. ${ }^{8}$

While there are many reasons why term premia and net interest margins change, the strong comovement between the two series over short and long windows, high and low interest rates, with changing time trends, provides evidence that they are related, as opposed to other factors explaining all of these comovements. For example, changes in just the level of interest rates, which also occurred over the sample period, cannot explain movements in banks' net interest margins, leaving aside considerations such as a lower bound on interest rates. That is because what matters for banks is not the level per se but the margin between different interest rates. Moreover, while a decline in the cost of providing banking services over recent years may be an explanation for the downward trend in net interest margins, it is an unlikely explanation for all of the comovements given the previous rise in net interest margins that is shown in Figure A.4 and the high-frequency relations between term premia and net interest margins in Figures 3.2 and A.3.

While banks' net interest margins have been falling since the early 1990s, their return on assets (net income over total assets) has been relatively stable at around 1 percent outside of financial recessions, such as the one associated with the financial crisis of 2007-09 (see Figure A.6). ${ }^{9}$ Based on a longer time series reaching back to the mid-1930s, Figure A.7 shows a similar pattern, though banks' return on assets leveled below 1 percent before $1990 .{ }^{10}$ The noticeable exceptions are three episodes of severe financial distress: the Great Depression at the beginning of the sample, the Savings and Loans Crisis in the mid-1980s, and the 2007-09 financial crisis.

Banks may have responded to the falling term premia over the last years in two ways. First, they may have reacted by increasing their maturity mismatch, since longer-term bonds typically earn a higher premium. Appendix Figure H.2 shows such a trend. Based on the maturity gap (see Section 8.1 for details), the typical bank raised its duration mismatch by around 1.5 years over the past two decades. ${ }^{11}$ Second, with term premia and deposit premia $\mu_{t}^{m}$ in equation (2.4)

\footnotetext{
${ }^{8}$ While the term premium and banks' net interest margin show a strong relation, the same cannot be said about the term spread and banks' net interest margins (see Appendix Figure A.5).

${ }^{9}$ The sharp fall of banks' return on assets during financial crises is largely explained by an increase in "provision for loan and lease losses" (see Appendix Figure A.6) and a rise in "goodwill impairment losses" that are part of banks' noninterest expenses in the income statement of the Call Reports. In contrast, banks' net interest income is not strongly affected (see Figures 3.1 and A.6).

${ }^{10}$ Figure A.6 shows that the stability of banks' return on assets over the past few decades has been due to the fact that banks' net noninterest income has been increasing in parallel. Splitting net noninterest income into noninterest income and expenses, Figure A.8 illustrates that this trend is driven by a fall in banks' noninterest expenses. While banks' noninterest income also increased throughout the 1990s, it has been on a downward trend since then. Note that fees associated with loan originations are generally part of banks' interest income in the income statement in the Call Reports. They therefore enter banks' net interest margin. A range of other fees, such as servicing and securitization fees, are part of banks' noninterest income. Source: https://www.ffiec.gov/forms031.htm

${ }^{11}$ At the same time, the declining term premium may have been the reason why a large share of smaller (community) banks that relied more heavily on maturity transformation went out of business or were consolidated under the roof of bank holding companies. Over the past three decades, the number of commercial banks in the U.S. declined from
} 
declining close to the lower bound, banks may have attempted to stabilize their net interest margins by increasing external finance premia. Wang (2018) finds evidence for such a trend, as the difference between bank loan income and a replicating treasury portfolio increased in recent years. ${ }^{12}$

Taken together, the evidence suggests that changes in term premia have historically been reflected in banks' net interest margins, despite the fact that their return on assets has been fairly stable outside of financial crises. The remainder of the paper takes these descriptive patterns as a motivation to analyze the behavior of banks' stock prices and income margins in response to changes in interest rates and term premia.

\section{Evidence from Stock Indices}

In this section, I show how the returns of stock indices respond to yield changes on FOMC announcement days. I compare the response of an index that represents the U.S. banking sector, the so-called KBW Bank Index, with the response of the Standard and Poor's (S\&P) 500 Index, adjusted to exclude all commercial banks. To various surprise changes in government bond yields of different maturities, the response of both indices is relatively small in absolute terms and the KBW Bank Index does not respond more strongly than the adjusted S\&P 500. Based on these results, banks and other large corporations do not seem particularly exposed to interest rate risk, and if anything, banks are less exposed. However, I show that these conclusions change once yield changes are decomposed. Bank equity responds more negatively to surprise increases in short-term rates, but more positively to a rise in term premia, and these differences are masked by looking at simple yield changes only.

\subsection{Data and Sample}

I focus on changes in yields, term premia, and stock returns at the daily frequency because that is the highest frequency for which term premia estimates are available. All changes are based on closing-day prices on the day of the FOMC announcement relative to the previous trading day. ${ }^{13}$

Treasury Yield Data. The analysis requires data on financial markets' expectations of nearby short-term rates, which are targeted by the Federal Reserve, and data on longer-term government bond yields. I approximate the former using secondary market rates for 3-month Treasury bills (Tbills). These indicate the market's expectations of short-term rates over the coming three months, and term premia are generally negligible at this horizon. In comparison with expected rates on even shorter maturities, for example as extracted from futures prices on the current month's federal funds rate, the 3-month T-bills have the following advantage: they are less affected by policy actions that

around 12,500 to around 4,500 (Source: Call Reports).

${ }^{12}$ Note that such a trend is not visible for corporate bond spreads, as illustrated in Figure B.1 which shows the credit spread and excess bond premium series by Gilchrist and Zakrajsek (2012).

${ }^{13}$ Typically, the previous trading day is the day just before the announcement. In two instances, 4/18/1994 and $11 / 12 / 1997$, the windows are larger, covering two- and three-day changes, respectively. All of the following results are robust to excluding those two meetings. As stated in the text, the FOMC announcement on 9/17/2001 is excluded from all estimations, since financial markets were closed from 9/11/2001 until 9/17/2001. 
reflect only the timing of rate changes from one meeting to the next, but rather represent actual level changes in nearby short-term rates (see also Bernanke and Kuttner, 2005). The longer-term government bond yield data are taken from Gürkaynak, Sack and Wright (2007). In particular, I use yield data for the 2-year, 5-year, and 10-year Treasury bonds. These maturities are chosen because they correspond to the range of banks' maturity mismatch, as explained in more detail in Section 8.1, and because they allow for a comparison with the estimates in English, van den Heuvel and Zakrajšek (2018).

Term Premia Estimates. For the United States, two estimates for daily term premia are publicly available that cover the entire sample period that I consider and that are commonly used in the literature: those of the term structure model by Kim and Wright (2005) and the ones by Adrian, Crump and Moench (2013). ${ }^{14}$ The publicly available estimates by Adrian, Crump and Moench (2013) are based on yield data starting in 1961. To account for structural changes over time, I reestimate their model, starting the sample at the same time as the one by Kim and Wright (2005) (1990:M7) and ending it before the financial crisis in 2008/09 (2007:M12). The term premia estimates of the two models are shown in Appendix Figures B.2 and B.3. All series show a declining trend over the past three decades. For the main analysis, I rely on the estimates by Kim and Wright (2005) and check the robustness of my findings to using the data by Adrian, Crump and Moench (2013) instead. ${ }^{15}$ The underlying term structure models for these two estimates differ according to their estimation method, the yield data employed, the number of factors extracted from the yield data, the sample starting period, and the use of survey data to discipline expected short-term rates. Li, Meldrum and Rodriguez (2017) provide a comparison and show that the use of survey data explains most of the differences for the final term premia estimates.

Stock Returns. I obtain daily stock prices for the KBW Bank Index from Yahoo Finance. ${ }^{16}$ The KBW Bank Index is a benchmark stock index of the banking sector. The index was developed by the investment bank Keefe, Bruyette and Woods. It includes a weighting of 24 banking stocks, mainly including large financial institutions as opposed to smaller regional banks. As a comparison group representing other large nonfinancial firms, I use the S\&P 500 Index but exclude all commercial banks to avoid the possibility that any price movements reflect the behavior of the banking sector. ${ }^{17}$

\footnotetext{
${ }^{14}$ The data from Kim and Wright (2005) and Adrian, Crump and Moench (2013) are available at:

https://www.federalreserve.gov/pubs/feds/2005/200533/200533abs.html

https://www.newyorkfed.org/research/data_indicators/term_premia.html

${ }^{15}$ The model by Kim and Wright (2005) is a latent three-factor Gaussian term structure model. The estimation includes 3- and 6-months T-bill rates, 12-, 24-, 48-, 84-, and 120-months Treasury yields from Gürkaynak, Sack and Wright (2007), and the model is augmented with Blue Chip surveys of the 3-month T-bill yield expected in 6 months, 1 year, and 6-11 years. The survey data improves identification of the latent factors and reduces small-sample problems (see also Kim and Orphanides, 2012). While beneficial for the decomposition into term premia and average expected future short-term rates, the inclusion of survey data comes at the cost of computational speed. In contrast, the model by Adrian, Crump and Moench (2013) allows for a computationally fast estimation and does not rely on history-dependent survey data, and I make use of these differences and obtain bootstrap estimates based on the model by Adrian, Crump and Moench (2013) (see Appendices C and D for details).

${ }^{16}$ The data are available at: https://finance.yahoo.com/quote/\%5Ebkx/

${ }^{17}$ To this end, I gather data for historical constituents of the S\&P 500 and their stock prices from the Wharton Research Data Services. Commercial banks with SIC Codes that start with 60 or 61 and 6712 are excluded and the index is recomputed by adding up all of the individual firm market values on any given day. To ensure that
} 
While the companies in those two indices still differ across a number of characteristics apart from their maturity mismatch, which may drive some of the differences of the stock prices responses, the following results show that the relative reactions substantially change across regressions setups, specifically, once yield changes are decomposed into movements in term premia and expected shortterm rates. For both indices, I exclude dividends to compute daily stock returns.

Sample Period. Throughout, I focus on the sample period 1994:M1-2007:M12 for three reasons. First, I choose the sample start because, from 1994 onward, the Fed released a statement immediately after each FOMC meeting. Until 1994, changes to the target rate had to be inferred by the size and type of open market operations. Hence, it might have taken market participants some time to absorb the relevant information and the daily trading-day windows to extract the surprises might be too restrictive. Second, I choose the end of the sample to exclude the period of financial distress in 2008/09 and the effective-lower bound (ELB) episode that followed. The ELB period is particularly problematic when using the term premia estimates by Kim and Wright (2005) and Adrian, Crump and Moench (2013), since these models do not explicitly account for a lower bound on the short-term interest rate. Therefore, 2007:M12 is chosen as an end date. ${ }^{18}$ Third, for the period 1994:M1-2007:M12, employment reports were rarely released on FOMC announcement days, as opposed to the time before 1994 (see, e.g., Bernanke and Kuttner, 2005, and Gürkaynak, Sack and Swanson, 2005). Such macroeconomic news releases would imply a threat to the identification given the daily trading windows (see also Gürkaynak, Sack and Swanson, 2005). In fact, only the FOMC announcement on February 18, 1994, took place on the same day as an employment report release. All of the following results are robust to excluding this meeting from the sample.

Specific FOMC Announcements. For the main analysis, I consider all FOMC meetings between 1994:M1 and 2007:M12, apart from the announcement on September 17, 2001. That is because all financial markets in New York were closed from September 11, 2001, to September 17, 2001, hence, the identifying assumption that monetary policy news dominates over these days seems unreasonable. Below, I show that my results are robust to excluding other unscheduled FOMC meetings-August 10, 2007, and August 17, 2007-because these FOMC announcements focused on providing details about liquidity policies (e.g., the Term Auction Facility) or communicated awareness of ongoing economic events and did not announce policy changes. The announcement on October 15, 1998, followed unusual developments in financial markets associated with the deteriorating situations in Russia and Asia and the near collapse of Long-term Capital Management. Hence, the associated 25 basis points cut can be understood as pure signal to financial markets. I

this procedure reflects the actual index, I also compute an index that leaves in commercial banks. For the FOMC announcements days in the following section, the correlation of the returns of the original S\&P 500 and the "bottomup" calculation is 0.9989. However, after excluding commercial banks, this correlation only changes to 0.9951, implying that the exclusion of banks does not make a substantial difference. In contrast, the correlation coefficient between the KBW Index and the S\&P 500 is 0.86 , but 0.98 between the KBW Index and the excluded banks in the S\&P 500.

${ }^{18} \mathrm{~A}$ potential concern is that markets expected the ELB to bind in the future at the end of the sample. However, based on the estimates from Kim and Wright (2005), I find that average expected future short-term rates were well above 3 percent for the 1 - to 10-year maturities on 12/31/2007 and always above 1 percent throughout the estimation sample (1994:M1-2007:M12). 
therefore exclude this meeting as well for the robustness checks.

\subsection{Results}

As a first pass, I compute the response of the returns of the KBW Bank Index and the adjusted S\&P 500 Index on day $t$ of an FOMC announcement, denoted by $R_{t}$, to daily yield changes. Since the distinction between level and slope changes is particularly relevant for banks, I estimate the regression

$$
R_{t}=\alpha+\beta_{1} \Delta Y_{t}^{3 M}+\beta_{2}\left(\Delta Y_{t}^{m}-\Delta Y_{t}^{3 M}\right)+u_{t}
$$

where $\Delta Y_{t}^{3 M}$ denotes the yield change of the 3-month T-bill and $\Delta Y_{t}^{m}$ is the yield change of a government bond with maturity $m$. The regression coefficients have the following interpretation. The coefficient $\beta_{2}$ captures the return response to a slope surprise, that is, an increase in $\Delta Y_{t}^{m}$ holding $\Delta Y_{t}^{3 M}$ constant. In turn, $\beta_{1}$ represents an increase in $\Delta Y_{t}^{3 M}$, holding $\left(\Delta Y_{t}^{m}-\Delta Y_{t}^{3 M}\right)$ constant, that is, a level shift in the yield curve that changes $Y_{t}^{3 M}$ and $Y_{t}^{m}$ by the same amount. Importantly, the slope surprise in (4.1) represents a slope change in the term spread: the difference between current long-term yields and current short-term yields.

The estimation results are shown in Table 4.1. Several observations stand out. First, all of the estimated coefficients are not statistically different from zero at conventional confidence levels. ${ }^{19}$ Second, the $R^{2}$ are relatively low. Third, the response of the $\mathrm{S} \& \mathrm{P} 500$ is more negative compared with the response of the KBW Bank Index at various maturities. To slope surprises, these results suggest that the banking sector may benefit from an increase in the term spread, in particular with respect to longer maturities, given the positive $\beta_{2}$ coefficients for the 5 -year and the 10-year maturities. However, the more positive responses to level surprises indicate that the banking sector is actually less exposed to interest rate risk compared with other nonbank firms in the S\&P 500 . And fourth, for both indices, the responses to a level surprise become more positive the longer the maturity, a puzzling finding since one would expect the opposite: if interest rates remain elevated for longer, stock prices should be more negatively affected.

Next, I show that the previous regression setup misses a key distinction: long-term yields move either because of changes in future expected short-term rates or because of changes in term premia, that is,

$$
\Delta Y_{t}^{m}=\Delta E H_{t}^{m}+\Delta T P_{t}^{m}
$$

where $\Delta E H_{t}^{m}$ denotes the change in the expectation-hypothesis component, or the average expected future short-term rates over horizon $m$, and $\Delta T P_{t}^{m}$ denotes the change in the expected term premium for a government bond of maturity $m$ (see equation 2.1). Regression (4.1) can therefore

\footnotetext{
${ }^{19}$ The quantitative results and statistical significance in Table 4.1 depend on the daily frequency. Appendix Table C.1 replicates regression (4.1), but uses high-frequency changes for $\Delta Y_{t}^{3 M}$ and $\Delta Y_{t}^{m}$ based on 30-minute windows (10 minutes before and 20 minutes after an announcement). In comparison with Table 4.1, the estimated coefficients $\hat{\beta}_{1}$ are statistically significant at conventional confidence levels. However, in comparison with Table 4.2 that separates out term premium changes, the estimated coefficients are still smaller in absolute terms, suggesting that term premia play a role even at higher frequencies.
} 
Table 4.1: Response of Stock Returns to Level and Slope Surprises.

\begin{tabular}{lcccccc}
\hline & & \multicolumn{3}{c}{ KBW Index } & & \multicolumn{2}{c}{ S\&P 500 } & \\
$\mathrm{m}=$ & 2-year & 5-year & 10-year & 2-year & 5-year & 10-year \\
\hline \multirow{2}{*}{$\Delta Y_{t}^{3 M}$} & -3.29 & -2.12 & -0.75 & -4.14 & -3.46 & -3.35 \\
\multirow{2}{*}{$\Delta\left(Y_{t}^{m}-Y_{t}^{3 M}\right)$} & $(3.94)$ & $(4.19)$ & $(4.81)$ & $(2.54)$ & $(2.67)$ & $(3.06)$ \\
& -0.30 & 1.38 & 2.71 & -0.73 & 0.39 & 0.45 \\
& $(3.60)$ & $(3.80)$ & $(4.25)$ & $(2.29)$ & $(2.64)$ & $(2.98)$ \\
\hline $\mathrm{R}^{2}$ & & & & & & \\
Meetings & 0.01 & 0.02 & 0.02 & 0.05 & 0.05 & 0.05 \\
\hline
\end{tabular}

Notes: Estimation results for regression (4.1), where $R_{t}$ is given by the return of the KBW Bank Index or the S\&P 500 (excluding banks). Sample: 1994:M1-2007:M12, excluding FOMC announcement on $9 / 17 / 2001$. White standard errors in parentheses. ${ }^{* * *} p<0.01,{ }^{* *} p<0.05$, ${ }^{*} p<0.1$.

be adapted to

$$
R_{t}=\alpha+\beta_{1} \Delta Y_{t}^{3 M}+\beta_{2}\left(\Delta E H_{t}^{m}-\Delta Y_{t}^{3 M}\right)+\beta_{3} \Delta T P_{t}^{m}+u_{t}
$$

In (4.2), $\beta_{1}$ and $\beta_{2}$ represent the responses to level and slope increases in expected future short-term rates, and $\beta_{3}$ gives the response to an increase in term premia. ${ }^{20}$ Using the estimates by Kim and Wright (2005), Table 4.2 shows the results based on the regression setup in (4.2). Strikingly, the estimated coefficients $\hat{\beta}_{1}$ and $\hat{\beta}_{2}$ have opposite signs compared with $\hat{\beta}_{3}$, and all are statistically different from zero at standard confidence levels for various maturities. In comparison with the estimation results in Table 4.1, the magnitudes of all coefficients and the $R^{2}$ increase substantially for both indices.

A level or slope increase in future expected short-term rates lowers stock returns for both indices. In contrast, a rise in expected term premia is associated with higher stock returns. The absolute responses of bank equity are larger to each of those yield changes. For example, a 100-basis-points increase in the level of future expected short-term rates over the next 2 years leads to a drop in equity prices of around 17 percent for the banking sector and around 13 percent for the adjusted S\&P 500. Hence, bank equity shows a roughly 30 percent or 4 p.p. stronger response. ${ }^{21}$ At the same maturity, to a 100-basis-points increase in the term premium, the bank equity response is

\footnotetext{
${ }^{20}$ In contrast to Hanson and Stein (2015) and Nakamura and Steinsson (2018), changes in the expected path of future short-term rates and term premia are used as regressors instead of dependent variables in the regression (4.2), and treated as data. As it is well known, there is substantial model and estimation uncertainty attached to such estimates. However, in the case that the estimates that I use contain classical measurement error, the estimated coefficients are biased towards zero, less precise, and can be seen as conservative lower bound estimates. My results are also unaffected if the estimates of the level of expected future short-term rates and term premia are biased but their changes around FOMC announcements are not. Appendix D also considers bootstrapped estimates using the Adrian, Crump and Moench (2013) model.

${ }^{21}$ In comparison, English, van den Heuvel and Zakrajšek (2018) find that bank stock returns fall by less, around 8 percent to a 100-basis-point level-increase of the 2-year government bond yield, without the decomposition into future expected short-term rates and term premia (see Table 1 therein).
} 
Table 4.2: Response of Stock Returns to Level, Slope, and Term Premia Surprises.

\begin{tabular}{lcccccc}
\hline & & \multicolumn{2}{c}{ KBW Index } & & \multicolumn{2}{c}{ S\&P 500 } \\
\cline { 6 - 7 } $\mathrm{m}=$ & 2-year & 5-year & 10-year & 2-year & 5-year & 10-year \\
\hline \multirow{2}{*}{$\Delta Y_{t}^{3 M}$} & $-16.65^{* *}$ & $-31.00^{* *}$ & $-41.20^{* *}$ & $-12.77^{* *}$ & $-24.05^{* *}$ & $-33.47^{* *}$ \\
& $(7.16)$ & $(13.78)$ & $(19.66)$ & $(5.26)$ & $(9.51)$ & $(13.06)$ \\
$\Delta\left(E H_{t}^{m}-Y_{t}^{3 M}\right)$ & $-20.99^{* *}$ & $-36.26^{* *}$ & $-46.26^{* *}$ & $-14.09^{* *}$ & $-26.46^{* *}$ & $-36.04^{* *}$ \\
& $(9.23)$ & $(16.74)$ & $(22.78)$ & $(6.53)$ & $(11.26)$ & $(14.87)$ \\
$\Delta T P_{t}^{m}$ & $21.12^{* *}$ & $23.45^{* *}$ & $25.14^{* *}$ & $13.11^{*}$ & $15.82^{* *}$ & $17.75^{* *}$ \\
& $(10.19)$ & $(10.18)$ & $(10.95)$ & $(7.80)$ & $(7.57)$ & $(7.99)$ \\
& & & & & & \\
\hline $\mathrm{R}^{2}$ & 0.08 & 0.09 & 0.08 & 0.11 & 0.13 & 0.13 \\
Meetings & 118 & 118 & 118 & 118 & 118 & 118 \\
\hline
\end{tabular}

Notes: Estimation results for regression (4.2), where $R_{t}$ is given by the return of the KBW Bank Index or the S\&P 500 (excluding banks), and $\Delta E H_{t}^{m}$ and $\Delta T P_{t}^{m}$ are based on estimates from Kim and Wright (2005). Sample: 1994:M1-2007:M12, excluding FOMC announcement on 9/17/2001. White standard errors in parentheses. ${ }^{* * *} p<0.01,{ }^{* *} p<0.05,{ }^{*} p<0.1$.

61 percent or 8 p.p. larger than the nonbank equity response (21 vs. 13 percent). The estimated coefficients $\hat{\beta}_{1}$ and $\hat{\beta}_{2}$ therefore suggest that bank cash-flows are more sensitive to interest rate risk, and the coefficients $\hat{\beta}_{3}$ indicate that bank profits respond more to changes in the compensation for interest rate risk. The following sections discuss under which conditions these estimates are well identified, the economic interpretation of the results, and whether they are supported by asset pricing theory. Appendix $\mathrm{C}$ reports robustness checks to alternative term premia estimates and the exclusion of specific emergency FOMC meetings.

\section{Identification}

Under which conditions does regression (4.2) identify the true causal effects? In Appendix E, I derive the following propositions to address this question. Changes in average expected future short-term rates are driven by monetary policy news and plausibly exogenous on FOMC announcement days. However, term premia are endogenous and may even reflect a response to expected future short-term rates. Nonetheless, regression (4.2) can still give consistent estimates even if one allows for such an endogenous response of term premia. The necessary condition is that the exogenous variation in term premia, that is unrelated to short-term rates, does not move stock prices through another channel. This condition is equivalent to the absence of an omitted variable bias, as summarized in Proposition 1. Also note that the estimates still have a causal interpretation under the conditions in Proposition 1, even if banks partly price term premia or respond to term premium changes. That is because rational equity investors can take term premium changes as given and understand future bank behavior, pricing equity according to both.

Proposition 1. The effects of future expected short-term rates and term premia on stock returns are consistently estimated based on regression (4.2) using ordinary least squares, in the absence of 
omitted shocks that are correlated with stock returns and the regressors in (4.2).

A particular reason why regression (4.2) may be subject to an omitted variable bias is due to the information effect of monetary policy. On announcement days, the Fed may release private information about its economic outlook and stock prices may respond to the information release in addition to the interest rate shock (e.g., Nakamura and Steinsson, 2018). An omitted Fed "information shock" may have a direct effect on stock prices, while also moving bond prices and term premia. In fact, such an omitted shock can explain the positive effect of term premia on the S\&P 500 in Table (4.2). To positive news about growth prospects, investors move out of longer-maturity bonds into shorter-maturity bonds or stocks, thereby raising term premia on longer-maturity bonds. Stock prices increase due to the additional demand for equity or because they reflect changes in growth expectations, giving rise to a positive relation between equity and term premia.

Such an omitted shock may not only be a Fed "information shock" but could also represent some other macroeconomic news release or changes in investors' risk-attitudes. In Appendix E, I show that regression (4.2) gives biased estimates in the presence of such omitted shocks, which cannot be immediately resolved without direct observations of those shocks or instruments for the endogenous regressors. However, if the omitted shock has a homogeneous direct effect on stock prices of two companies or indices, a reasonable assumption with respect to the mentioned macroeconomic shocks which likely affect financial and nonfinancial companies similarly through non-interest rate channels, then the bias is the same for the two companies or indices. Intuitively, when taking the difference of the two estimates, the bias cancels out, giving a consistent estimate of the difference and allowing for heterogeneous responses to term premia and short-term rates, as summarized in Proposition 2. I therefore reestimate regression (4.2) using the difference in the return of the KBW Index and the adjusted S\&P 500 as a dependent variable. Table 5.1 shows the results. For the 2 -year maturity, $\hat{\beta}_{1}, \hat{\beta}_{2}$, and $\hat{\beta}_{3}$ are all statistically different from zero at typical confidence levels. ${ }^{22}$

Proposition 2. The difference in the effects of future expected short-term rates and term premia on stock returns of two companies or indices are consistently estimated based on regression (4.2) using ordinary least squares, even in the presence of omitted shocks that are correlated with stock returns and the regressors in (4.2), if these omitted shocks have a homogeneous direct effect on the stock returns of the two companies or indices.

A remaining concern is that the three regressors in (4.2) are fairly strongly correlated, potentially giving biased estimates for the relatively small sample of FOMC announcement days in Tables 4.2 and 5.1. For example, the correlation coefficients at the 2-year maturity are -0.75 between $\Delta Y_{t}^{3 M}$ and $\left(\Delta E H_{t}^{m}-\Delta Y_{t}^{3 M}\right), 0.44$ between $\left(\Delta E H_{t}^{m}-\Delta Y_{t}^{3 M}\right)$ and $\Delta T P_{t}^{m}$, and 0.10 between $\Delta Y_{t}^{3 M}$

\footnotetext{
${ }^{22}$ An alternative approach to account for the Fed information effect is to exclude observations with nonstandard stock price responses. Following Jarocinski and Karadi (2020), I omit meetings with positive (negative) equity reactions of the S\&P 500 following a monetary policy tightening (easing). Appendix Tables C.4 and C.5 show that the results not only remain but intensify with this additional restriction.
} 
Table 5.1: Response of Stock Returns - Differences between KBW and S\&P 500.

\begin{tabular}{lccc}
\hline & & \multicolumn{2}{c}{ KBW-S\&P 500 } \\
\cline { 3 - 3 } $\mathrm{m}=$ & 2-year & 5 -year & 10-year \\
\hline \multirow{2}{*}{$\Delta Y_{t}^{3 M}$} & $-3.88^{*}$ & -6.94 & -7.73 \\
& $(0.08)$ & $(0.12)$ & $(0.20)$ \\
$\Delta\left(E H_{t}^{m}-Y_{t}^{3 M}\right)$ & $-6.90^{* *}$ & -9.79 & -10.22 \\
& $(0.05)$ & $(0.10)$ & $(0.18)$ \\
$\Delta T P_{t}^{m}$ & $8.01^{* *}$ & $7.62^{* *}$ & $7.39^{*}$ \\
& $(0.02)$ & $(0.03)$ & $(0.05)$ \\
& & & \\
\hline $\mathrm{R}^{2}$ & 0.03 & 0.02 & 0.02 \\
Meetings & 118 & 118 & 118 \\
\hline
\end{tabular}

Notes: Estimation results for regression (4.2), where $R_{t}$ is given by the return of the KBW Bank Index minus the return of the S\&P 500 (excluding banks), and $\Delta E H_{t}^{m}$ and $\Delta T P_{t}^{m}$ are based on estimates from Kim and Wright (2005). Sample: 1994:M1-2007:M12, excluding FOMC announcement on $9 / 17 / 2001$. P-values in parentheses are based on one-sided tests with the null hypothesis that $\hat{\beta}_{1}>0, \hat{\beta}_{2}>0$, and $\hat{\beta}_{3}<0$, using White standard errors. ${ }^{* * *} p<0.01,{ }^{* *} p<0.05$, ${ }^{*} p<0.1$.

and $\Delta T P_{t}^{m}$, and the ones at the 5- and 10-year maturities are similar. ${ }^{23}$ In Appendix E, I show that the previous identification argument generalizes to non-FOMC days. As long as structural shocks affect bank and nonbank equity heterogeneously through future expected short-term rates and term premia, but not through another channel, the difference in the return responses can be consistently estimated based on regression (4.2). Extending the sample in this way yields results that are similar to the benchmark estimates as shown in Table 5.2, which covers 2,878 observations as opposed to the original 118 policy announcement days. ${ }^{24}$ By and large, bank equity responds more negatively to slope and level changes related to future expected short-term rates, but more positively to changes in term premia, and the statistical significance largely improves for this extended sample.

What do the results in Tables 4.2 and 5.1 reveal about banks' exposure to interest rate risk, and how do they compare to the small and insignificant estimates in Table 4.1? The stronger absolute responses of bank equity relative to nonbank equity in Table 5.1 suggest that banks' cash-flow is particularly sensitive to a change in short-term rates or term premia. The next section shows that such relative responses are also supported by asset pricing theory. Intuitively, higher-than-expected short-term rates imply a reduction of net interest margins on banks' legacy assets-exposing banks to interest rate risk. Moreover, counterfactuals show that the stronger equity responses are quantitatively too large to be explained by the fact that banks are simply more leveraged compared with nonfinancial firms. In contrast, higher term premia raise net interest margins on newly acquired

\footnotetext{
${ }^{23}$ Appendix Table H.7 provides summary statistics of different variables on FOMC announcement days.

${ }^{24}$ Combining FOMC and non-FOMC days, the correlation coefficients at the 2-year maturity are -0.72 between $\Delta Y_{t}^{3 M}$ and $\left(\Delta E H_{t}^{m}-\Delta Y_{t}^{3 M}\right), 0.37$ between $\left(\Delta E H_{t}^{m}-\Delta Y_{t}^{3 M}\right)$ and $\Delta T P_{t}^{m}$, and 0.21 between $\Delta Y_{t}^{3 M}$ and $\Delta T P_{t}^{m}$, and the ones at the 5- and 10-year maturities are similar.
} 
Table 5.2: Differences between KBW and S\&P 500 (Including non-FOMC days).

\begin{tabular}{lccc}
\hline & & KBW-S\&P 500 & \\
\cline { 3 - 3 } $\mathrm{m}=$ & 2-year & 5 -year & 10 -year \\
\hline \multirow{2}{*}{$\Delta Y_{t}^{3 M}$} & $-2.03^{* *}$ & $-6.53^{* * *}$ & $-11.63^{* * *}$ \\
& $(0.05)$ & $(0.00)$ & $(0.00)$ \\
$\Delta\left(E H_{t}^{m}-Y_{t}^{3 M}\right)$ & $-2.95^{* *}$ & $-8.12^{* * *}$ & $-13.56^{* * *}$ \\
& $(0.01)$ & $(0.00)$ & $(0.00)$ \\
$\Delta T P_{t}^{m}$ & -0.70 & $1.93^{*}$ & $3.68^{* *}$ \\
& $(0.28)$ & $(0.09)$ & $(0.01)$ \\
& & & \\
\hline $\mathrm{R}^{2}$ & 0.01 & 0.01 & 0.01 \\
Observations & 2,878 & 2,878 & 2,878 \\
\hline
\end{tabular}

Notes: Estimation results for regression (4.2), where $R_{t}$ is given by the return of the KBW Bank Index minus the return of the $\mathrm{S} \& \mathrm{P} 500$ (excluding banks), and $\Delta E H_{t}^{m}$ and $\Delta T P_{t}^{m}$ are based on estimates from Kim and Wright (2005). The sample covers all one-day changes in returns and interest rates (FOMC and non-FOMC days) from 1993:M2 to 2007:M12, where the start of the sample is determined by the beginning of the KBW-index. P-values in parentheses are based on one-sided tests with the null hypothesis that $\hat{\beta}_{1}>0, \hat{\beta}_{2}>0$, and $\hat{\beta}_{3}<0$, using White standard errors. ${ }^{* * *} p<0.01,{ }^{* *} p<0.05,{ }^{*} p<0.1$.

loans (see equation 2.3). These predictions are also confirmed based on impulse responses of bank profit margins in Section 7. Regression (4.1) masks the heterogeneous effects of $\Delta E H_{t}^{m}$ and $\Delta T P_{t}^{m}$ since the two offset each other in this regression setup. ${ }^{25}$

\section{Asset Pricing Predictions}

Are the results so far supported by asset pricing theory? In Appendix F, I derive several theoretical predictions on the relation between stock prices, term premia, and short-term rates, which reinforce the previous empirical findings.

Prediction \#1. To an increase in the term premium, bank stock returns respond more positively compared with typical nonfinancial companies.

As illustrated in Appendix F.1, term premia affect stock prices through three distinct channels: (i) discounting, (ii) cash-flow, and (iii) risk-compensation. The relative response of bank equity versus nonbank equity is therefore determined by how strongly stock prices react through each of the three channels. The discounting channel is relatively standard: higher term premia imply that future

\footnotetext{
${ }^{25}$ If an unexpected increase in future expected short-term rates also raises term premia, such a channel may provide banks with an additional "hedge" against interest rate risk. While a positive correlation between $\Delta E H_{t}^{m}$ and $\Delta T P_{t}^{m}$ at various maturities indicates such a relation, it may also be due to a correlated Fed information effect shock. A surprise monetary tightening implies positive news about the future path of the economy, investors move out of longer-maturity bonds into shorter-maturity bonds or stocks, thereby raising term premia on longer-maturity bonds. Hence, such a hedge may not exist to a pure monetary policy shock that is orthogonal to a Fed information shock.
} 
dividends are discounted more heavily, depressing current market values. While this channel affects all stock prices in a similar way, banks and nonbanks differ with respect to the cash-flow channel. Intuitively, bank net interest margins increase if the term premium rises as explained in Section 2. In contrast, nonfinancial firms are unlikely to experience higher cash-flows after a rise in the term premium since they do not engage in the same arbitrage as banks. ${ }^{26}$ If anything, higher term premia likely result in higher interest expenses for most firms, dragging down cash-flows. Thus, bank stock returns should respond more positively compared with typical nonfinancial companies following an increase in the term premium through the cash-flow channel. As shown in Appendix F.1, such a differential response persists even after taking into account the discounting and riskcompensation channels, resulting in Prediction \#1, which is confirmed by the results in Tables 4.2 and 5.1.

Prediction \#2. To an increase in short-term rates, bank stock returns respond more negatively compared with typical nonfinancial companies.

In Appendix F.2, I derive a standard decomposition of the response of stock prices to a monetary policy shock into news about future real rates, dividends, and equity risk premia. Using a numerical example to a 100-basis-points increase of short-term real rates over 2 years allows for a comparison of the response of bank and nonbank equity as predicted by theory. To obtain an estimate of the banks' dividend response, I match the relevant parameters to the data on banks' net interest margins, their maturity mismatch that accounts for variable-rate loans, their typical leverage, and the pass-through of policy rate changes to banks' interest expenses, taking into account the stickiness of deposit rates. Even under various conservative assumptions, the response of bank dividends is substantially more negative than that of nonbank dividends typically observed in the data. Intuitively, since banks borrow using short-term liabilities, their net interest margin on legacy assets strongly declines after an increase in short-term rates, impacting stock prices through lower dividends. The dividend reactions translate in stock price responses with a comparable difference as found in Table 4.2, resulting in Prediction \#2.

The theoretical decomposition also allows to consider two counterfactuals. First, even if banks have a similar leverage as nonbanks, their stock price response is substantially stronger, suggesting that the observed differences can be accounted for by banks' maturity mismatch. Second, assuming that deposit rates respond one-for-one with policy rate changes-as suggested by the "textbook view" mentioned in the introduction-roughly doubles the percentage difference between the responses of bank and nonbank equity. While a substantial increase, it is not an outsized value, indicating that the estimated differences already reveal a sizeable interest rate exposure of banks.

\footnotetext{
${ }^{26}$ The term premium compensates banks for engaging in an arbitrage, buying long-term bonds financed by rolling over short-term bonds. If such an arbitrage can be executed at no extra costs, then the present discounted value of it should be zero in equilibrium and remain unchanged when term premia move. A positive relation between bank equity and term premia as in Table 4.2 can be reconciled by portfolio rebalancing and the Fed information effect as explained in Appendix F.1.
} 


\section{Banks' Income Responses to Interest Rate Surprises}

The empirical evidence on banks' stock price responses and the theoretical asset pricing predictions suggest that bank profit margins decline to an increase in future expected short-term rates, but rise if term premia increase. In this section, I test whether that is the case by estimating impulse responses of banks' profit margins to interest rate surprises. To this end, I construct quarterly shock series for term premia and short-term rates. This is achieved by adding up the individual interest rate surprises around FOMC announcement days that occur within a particular quarter, as in Romer and Romer (2004). Given these shock series, I estimate a set of local projections that corresponds to the regression setup (4.2) following Jordà (2005),

$$
\operatorname{Margin}_{t+h}-\operatorname{Margin}_{t-1}=\alpha^{h}+\beta_{1}^{h} Y_{t}^{3 M}+\beta_{2}^{h}\left(E H_{t}^{m}-Y_{t}^{3 M}\right)+\beta_{3}^{h} T P_{t}^{m}+u_{t}^{h} \text { for } \mathrm{h}=0,1, \ldots,
$$

where $T P_{t}^{m}$ denotes the quarterly term premium shock for maturity $m, E H_{t}^{m}$ is the shock to the expectation-hypothesis component of long-term yields in period $t$ for maturity $m$, and $Y_{t}^{3 M}$ is the shock to the 3-month Treasury bill. The dependent variable denotes the change in a profit margin from $t-1$ to $t+h$. I consider aggregate series for the net interest margin and net income. The net interest margin is given by the difference between interest income and interest expenses divided by total interest-earning assets. Net income is the return on total assets. Both series are taken from St. Louis Fed's FRED database based on data from the Call Reports for all U.S. commercial banks.

The results for regression (7.1) at the 5-year maturity are shown in Figure 7.1. In response to a positive level or slope shock to expected future short-term rates, banks' net interest margins fall and these responses are statistically different from zero at the 95 percent confidence level several quarters after the shock. The net interest margin responses translate into similar net income reactions, though the absolute responses are slightly smaller due to the alternative denominator (total assets vs. total interest-earning assets) and possibly due to offsetting responses of noninterest income. In contrast, in response to a positive term premium shock, banks' net interest margins rise. Again, the response manifests itself into a similar net income reaction. ${ }^{27}$ These findings are consistent with the previous stock price responses and the asset price predictions. The typical bank experiences lower cash flows when expected future short-term rates rise, but the opposite after an increase in the term premium.

In Appendix G, I test again how the responses differ when ignoring the decomposition of longterm bond yields. Figure G.1 shows the responses to level and slope shocks in long-term yields, resembling regression (4.1). The profit margins decline to a positive level yield surprise, but they are substantially smaller and less precise compared with the ones in Figure 7.1. The responses to slope surprises are close to zero and largely insignificant, illustrating again the importance of the decomposition. Besides the documented margin responses, stock prices also react to changes in

\footnotetext{
${ }^{27}$ I find that the results equally hold for the 2-year and 10-year maturities, when using bank-level data as described in Section 8.1, and remain similar when including additional controls in regression (7.1). In particular, I check and confirm the robustness of the results to including up to three previous quarters of term premium shocks, expected future short-term rate shocks, and the one-year change in the respective dependent variable.
} 

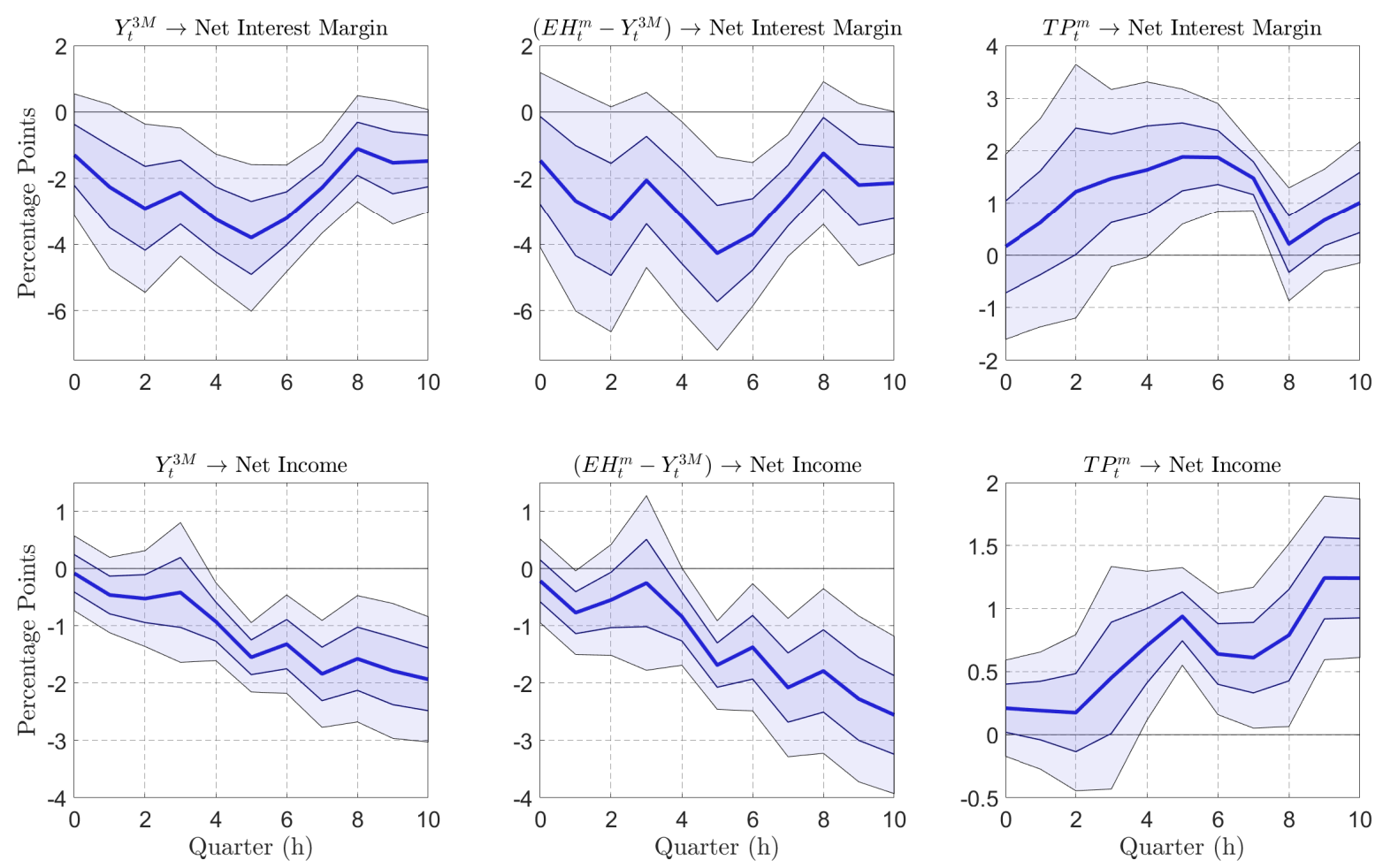

Figure 7.1: Impulse Responses of Bank Profit Margins.

Notes: Estimation results for regressions (7.1), where $E H_{t}^{m}$ and $T P_{t}^{m}$ are based on estimates from Kim and Wright (2005) for $m=5$-year. Sample: 1994:Q1-2007:Q4, excluding FOMC announcement on $9 / 17 / 2001.95$ and 68 percent confidence bands shown, using Newey and West (1987) standard errors.

loan quantities. Appendix Figure G.2 shows that bank loans decrease following a level or slope surprise to expected short-term rates, but increase following a rise in the term premium, thereby reinforcing the margin effects. These responses are less precise but statistically significant at the one-standard-deviation confidence intervals.

\section{Evidence from Bank-Level Stock Returns}

In Section 4, I have shown that bank equity responds stronger in absolute terms to changes in future expected short-term rates and term premia on FOMC announcement days compared with nonbank equity. This section documents that these effects differ in the cross-section of banks depending on the maturity profile of their balance sheets. In particular, stock returns of banks with a larger maturity mismatch increase more in response to a rise in term premia, but also decline more strongly following an increase in future expected short-term rates. Both of these results are supported by asset pricing theory, as shown in Appendix F. 


\subsection{Data}

I start from a list of U.S. financial institutions provided by the New York Fed that gives a mapping of identifiers; this allows me to link bank-level stock price data with balance sheet information. ${ }^{28}$ For the following analysis, I restrict the sample to bank holding corporations (BHCs). For BHCs, two measures of maturity mismatch are commonly used in the literature: the income gap and the maturity gap. I use both measures since each of them comes with advantages and disadvantages.

Stock Prices. Daily stock price data are obtained from the Wharton Research Data Services, and I exclude dividends to compute daily stock returns. As above, I restrict the sample to all stock returns with one-day trading windows apart from the two exceptions stated in footnote 13.

Income Gap from Y-9C. The Consolidated Financial Statements or FR Y-9C filings for BHCs contain information on the value of book assets (RA) and liabilities (RL) that reprice or mature within the next year. Based on these data, the one-year income gap for bank $i$ at time $t$ can be derived, which is defined as

$$
\text { Income gap }_{\mathrm{i}, \mathrm{t}}=\frac{R A_{i, t}-R L_{i, t}}{\text { Total Assets }_{i, t}}
$$

The advantage of this measure is that the data are available for a relatively long sample (since 1986:Q2) and that it applies to all interest-earning assets and liabilities of a BHC. A disadvantage is that this measure is silent on the maturity or repricing of all balance sheet items beyond the one-year horizon. Gomez et al. (2021) and Haddad and Sraer (2020) use this measure in related work. Appendix $\mathrm{H}$ provides additional information on the data source and the variables that are used.

Maturity Gap from Call Reports. The second measure is the maturity gap, which is based on data from the Call Reports for U.S. banks. The maturity or repricing data in the Call Reports are more detailed than in the $\mathrm{Y}-9 \mathrm{C}$. They allocate various balance sheet items into ranges of maturities beyond the one-year limit. Following English, van den Heuvel and Zakrajšek (2018), I use the midpoint of each range as the maturity $m_{j}$ for the value of all assets or liabilities within category $j .{ }^{29}$ The maturity gap for bank $i$ at time $t$ is defined as the difference between the weighted maturity of all covered assets and liabilities,

$$
\text { Maturity Gap }_{\mathrm{i}, \mathrm{t}}=\sum_{j} m_{A, j} \frac{\text { Asset }_{j, i, t}}{\sum_{j} \text { Asset }_{j, i, t}}-\sum_{j} m_{L, j} \frac{\text { Liability }_{j, i, t}}{\sum_{j} \text { Liability }_{j, i, t}}
$$

and Appendix G considers alternative definitions to check the robustness of the following findings. While the maturity data in the Call Reports are more granular for balance sheet items that are covered, they also have several disadvantages in comparison with the income gap from the Y-9C

\footnotetext{
${ }^{28}$ The list gives a mapping between PERMCO and RSSD identifiers and can be found at: https://www. newyorkfed.org/research/banking_research/datasets.html.

${ }^{29}$ For the open-ended maturity buckets larger than 3 years and larger than 15 years, maturities of 5 and 20 years, respectively, are assumed. See Appendix Tables H.3 and H.4 for details.
} 
filings. First, the data are only available for certain types of assets and liabilities. Second, the data only start in 1997:Q2. Third, to relate the data to the BHCs' stock prices, the balance sheet information of various bank subsidiaries has to be aggregated up to the BHC-level. Appendix $\mathrm{H}$ provides additional information on the data sources and the aggregation. Tables H.3 and H.4 list the variables that are used and the maturity weights $m_{A, j}$ and $m_{L, j}$ in equation (8.2).

Sample and Descriptive Evidence. For the following analysis, I use a sample of BHCs, for which the aggregation based on the Call Report data gives comparable total balance sheet sizes as the Y-9C data (see Appendix H for details). In this regard, I consider domestic data only and exclude all balance sheet and income items from foreign subsidiaries to ensure that the results are not driven by trends from abroad. Appendix Figure H.1 shows the historical evolution of the average income gap and compares it with an equivalent measure based on the Call Report data. The two follow each other closely. Figure H.2 shows the evolution of the typical maturity gap and its distribution over time. Table H.6 reports the correlations of the various maturity mismatch measures. Notably, the income gap and the maturity gap are negatively correlated.

\subsection{Results}

As a first pass, I replicate regressions (4.1) and (4.2) using the bank-level stock price data. The results are shown in Appendix Tables I.1 and I.2. They are similar compared with the ones in Tables 4.1 and 4.2. However, the absolute magnitudes of the coefficients are lower. I find that this is due to the inclusion of BHCs with smaller market capitalization. For example, when restricting the pooled sample to the top 10 percent based on firm market capitalization (see Appendix Table I.3), the coefficients are close to the ones in Table 4.2 .

Next, I use the balance sheet information described in the previous section in combination with the bank-level stock price data. To ensure that the balance sheet variables do not incorporate a response to the announcement itself, I associate all balance sheet variables from the quarter prior to an FOMC meeting with each respective announcement. To test the hypothesis that BHCs are differentially affected by a surprise change in term premia depending on their maturity mismatch, regression (4.2) is extended to

$$
R_{i, t}=\alpha_{i}+\beta_{1} \Delta Y_{t}^{3 M}+\beta_{2}\left(\Delta E H_{t}^{m}-\Delta Y_{t}^{3 M}\right)+\beta_{3} \Delta T P_{t}^{m}+\beta_{4} \Delta T P_{t}^{m} \cdot I G_{i, t}+\beta_{5} I G_{i, t}+u_{i, t},
$$

where $R_{i, t}$ denotes the trading-day window stock return for bank $i, \alpha_{i}$ is a bank-specific fixed effect, and $I G_{i, t}$ denotes bank $i$ 's income gap in the quarter prior to the announcement on day $t$. The income gap variable is normalized to standard deviation one and mean zero for each respective estimation sample, which simplifies the interpretation of the regression coefficients and allows to assess their economic importance easily. The results for regression (8.3) at the 2-, 5-, and 10-year maturities are shown in columns (i)-(iii) of Table 8.1, and the estimation output with respect to the maturity variable itself is omitted for brevity in all following tables. 
Table 8.1: Response of Stock Returns to Level, Slope, and Term Premia Surprises.

\begin{tabular}{lcccccc}
\hline & $(\mathrm{i})$ & $($ ii $)$ & $($ iii $)$ & $(\mathrm{iv})$ & $(\mathrm{v})$ & $(\mathrm{vi})$ \\
$\mathrm{m}=$ & 2 -year & 5 -year & 10 -year & 2 -year & 5 -year & 10 -year \\
\hline \multirow{2}{*}{$\Delta Y_{t}^{3 M}$} & $-6.76^{* *}$ & $-11.27^{*}$ & -13.98 & $-6.93^{* *}$ & $-11.32^{*}$ & -13.66 \\
& $(3.28)$ & $(6.28)$ & $(8.97)$ & $(3.15)$ & $(6.09)$ & $(8.76)$ \\
$\Delta\left(E H_{t}^{m}-Y_{t}^{3 M}\right)$ & $-7.63^{*}$ & -12.33 & -14.92 & $-7.91^{*}$ & $-12.42^{*}$ & -14.59 \\
& $(4.11)$ & $(7.46)$ & $(10.21)$ & $(4.04)$ & $(7.33)$ & $(10.05)$ \\
$\Delta T P_{t}^{m}$ & $9.36^{* *}$ & $9.43^{* *}$ & $9.69^{* *}$ & $9.57^{* *}$ & $9.48^{* *}$ & $9.58^{* *}$ \\
& $(4.36)$ & $(4.48)$ & $(4.87)$ & $(4.21)$ & $(4.32)$ & $(4.69)$ \\
$\Delta T P_{t}^{m} \cdot I G_{i, t}$ & $-1.50^{* *}$ & $-1.24^{* *}$ & $-1.29^{* *}$ & $-1.73^{* * *}$ & $-1.49^{* * *}$ & $-1.63^{* * *}$ \\
& $(0.62)$ & $(0.49)$ & $(0.51)$ & $(0.59)$ & $(0.47)$ & $(0.48)$ \\
& & & & & & \\
\hline Bank Controls & & & & $\checkmark$ & $\checkmark$ & $\checkmark$ \\
R-squared & 0.04 & 0.04 & 0.04 & 0.05 & 0.05 & 0.05 \\
Observations & 34,231 & 34,231 & 34,231 & 34,020 & 34,020 & 34,020 \\
Banks & 852 & 852 & 852 & 852 & 852 & 852 \\
Meetings & 118 & 118 & 118 & 118 & 118 & 118 \\
\hline
\end{tabular}

Notes: Estimation results for regression (8.3), where $\Delta E H_{t}^{m}$ and $\Delta T P_{t}^{m}$ are based on estimates from Kim and Wright (2005). Sample: 1994:M1-2007:M12, excluding FOMC announcement on $9 / 17 / 2001$. $I G_{i, t}$ is normalized to standard deviation one and mean zero for each estimation. Columns (iv)-(vi) include additional control variables: the interactions between $\Delta T P_{t}^{m}$ and various bank characteristics (see text for details). Standard errors in parentheses are two-way clustered by banks and meetings. ${ }^{* * *} p<0.01,{ }^{* *} p<0.05,{ }^{*} p<0.1$.

Positive level and slope surprises in short-term rates affect bank stock returns again negatively. In contrast, an increase in term premia has the opposite sign. However, this effect depends on a bank's maturity mismatch prior to an FOMC announcement day. Stock returns of banks with a smaller income gap, that is, fewer assets relative to liabilities that reprice over the next year, respond more to an increase in term premia. The coefficient $\hat{\beta}_{4}$ is estimated to be statistically significant at the 5 percent confidence level for various maturities and economically sizable. For the 2-year maturity, a 100-basis-points increase in the term premium is associated with 1.5 p.p. higher stock return for a bank with an income gap that is one standard deviation smaller within the estimation sample. Going from the 5th to 95th percentile in the sample distribution of the income gap implies a return difference of around 4.5 p.p., that is, around 50 percent of the stock return response for a bank with an average income gap based on Table 8.1. ${ }^{30}$ Thus, heterogeneity in banks' maturity profile explains a sizeable fraction of the response of their stock prices to changes in term premia.

Columns (iv)-(vi) test whether these results may driven by other bank characteristics. To this end, I interact $\Delta T P_{t}^{m}$ with a number of additional bank controls and include each as a separate regressor in (8.3). The bank-specific variables are the loan-to-asset share, demand and savings deposits, time deposits (both relative to total liabilities), market leverage, and bank size measured

\footnotetext{
${ }^{30}$ Appendix Table H.7 provides summary statistics for the maturity variables on FOMC announcement days.
} 
Table 8.2: Response of Stock Returns to Level, Slope, and Term Premia Surprises.

\begin{tabular}{lcccccc}
\hline & $(\mathrm{i})$ & $(\mathrm{ii})$ & $(\mathrm{iii})$ & $(\mathrm{iv})$ & $(\mathrm{v})$ & $(\mathrm{vi})$ \\
$\mathrm{m}=$ & 2 -year & 5 -year & 10 -year & 2 -year & 5 -year & 10 -year \\
\hline \multirow{2}{*}{$\Delta Y_{t}^{3 M}$} & $-7.63^{* *}$ & $-12.61^{*}$ & -14.91 & $-7.49^{* *}$ & $-12.20^{*}$ & -14.13 \\
& $(3.44)$ & $(6.96)$ & $(10.58)$ & $(3.30)$ & $(6.68)$ & $(10.13)$ \\
$\Delta\left(E H_{t}^{m}-Y_{t}^{3 M}\right)$ & $-9.48^{* *}$ & $-14.53^{*}$ & -16.56 & $-9.35^{* *}$ & $-14.11^{*}$ & -15.82 \\
& $(4.37)$ & $(8.41)$ & $(12.17)$ & $(4.30)$ & $(8.17)$ & $(11.75)$ \\
$\Delta T P_{t}^{m}$ & $12.82^{* * *}$ & $12.18^{* *}$ & $12.21^{* *}$ & $12.45^{* * *}$ & $11.70^{* *}$ & $11.55^{* *}$ \\
& $(4.61)$ & $(4.69)$ & $(5.17)$ & $(4.47)$ & $(4.55)$ & $(5.04)$ \\
$\Delta T P_{t}^{m} \cdot M G_{i, t}$ & $1.14^{* *}$ & $0.92^{* *}$ & $0.77^{*}$ & $1.30^{* *}$ & $0.96^{*}$ & 0.70 \\
& $(0.44)$ & $(0.37)$ & $(0.44)$ & $(0.57)$ & $(0.50)$ & $(0.56)$ \\
& & & & & & \\
\hline Bank Controls & & & & $\checkmark$ & $\checkmark$ & $\checkmark$ \\
R-squared & 0.04 & 0.04 & 0.04 & 0.04 & 0.05 & 0.05 \\
Observations & 27,938 & 27,938 & 27,938 & 27,760 & 27,760 & 27,760 \\
Banks & 731 & 731 & 731 & 731 & 731 & 731 \\
Meetings & 90 & 90 & 90 & 90 & 90 & 90 \\
\hline
\end{tabular}

Notes: Estimation results for regression (8.4), where $\Delta E H_{t}^{m}$ and $\Delta T P_{t}^{m}$ are based on estimates from Kim and Wright (2005). Sample: 1997:M4-2007:M12, excluding FOMC announcement on 9/17/2001. $M G_{i, t}$ is normalized to standard deviation one and mean zero for each estimation. Columns (iv)-(vi) include additional control variables: the interactions between $\Delta T P_{t}^{m}$ and various bank characteristics (see text for details). Standard errors in parentheses are two-way clustered by banks and meetings. ${ }^{* * *} p<0.01,{ }^{* *} p<0.05,{ }^{*} p<0.1$.

by the natural log of total real assets. The estimations show that the absolute size of the coefficient and its significance actually strengthen with the additional controls. Taken together, these results suggest that banks with a larger maturity mismatch-a smaller income gap-benefit more from an increase in term premia. The next regression repeats the previous one,

$$
R_{i, t}=\alpha_{i}+\beta_{1} \Delta Y_{t}^{3 M}+\beta_{2}\left(\Delta E H_{t}^{m}-\Delta Y_{t}^{3 M}\right)+\beta_{3} \Delta T P_{t}^{m}+\beta_{4} \Delta T P_{t}^{m} \cdot M G_{i, t}+\beta_{5} M G_{i, t}+u_{i, t},
$$

but uses the maturity gap (MG) instead of the income gap. The results for (8.4) are shown in Table 8.2. The estimated coefficients $\hat{\beta}_{1}, \hat{\beta}_{2}$, and $\hat{\beta}_{3}$ are similar compared with the ones in Table 8.1. In contrast, the coefficient $\hat{\beta}_{4}$ on the interaction term $\Delta T P_{t}^{m} \cdot M G_{i, t}$ is estimated to be positive. The opposite sign is explained by the fact that the income gap and the maturity gap are negatively correlated (see Appendix Table H.6). Again, the effects are economically sizable. To a 100-basis-points higher term premium at the 2-year maturity, a one-standard-deviation larger maturity gap is associated with a higher stock return of around 1.1-1.3 p.p., depending on the inclusion of various interactions of $\Delta T P_{t}^{m}$ with other bank controls. A disadvantage of the maturity gap is that it does not cover maturity data on all assets and liabilities. Based on estimates of the missing information, Appendix Table I.8 shows that $\hat{\beta}_{4}$ in regression (8.4) increases to 1.9-2.1 for the various maturities and is statistically different at the 1 percent confidence level, with the P5P95 sample difference of the maturity gap again accounting for around 50 percent of the response 
of a bank with an average maturity gap. Thus, whether one uses the income gap or the maturity gap, the results remain much the same, both in quantitative importance and statistical significance.

Appendix I collects further evidence and robustness checks: (i) comparisons with the regressions and maturity gap definition by English, van den Heuvel and Zakrajšek (2018), (ii) alternative term premia estimates, and (iii) excluding specific unscheduled FOMC meetings. One additional finding is that the stock price of banks with larger maturity mismatch responds more negatively to an increase in future expected short-term rates. Intuitively, such banks are locked in for longer when their cost of funding increases.

\section{Conclusion}

Through active risk management, banks structure their balance sheets to offload the interest rate risk that they are naturally exposed to. In this paper, I provide new evidence for the United States to show that this risk transfer to banks' creditors and borrowers is not perfect. Part of the aggregate interest rate risk remains with the banking sector.

In support of this view, I show that (i) banks' net interest margins have historically comoved with term premia; (ii) their stock prices fall more sharply in response to an increase in expected future short-term rates compared with the typical market response, but also responds more positively if term premia increase; (iii) both of these responses are amplified for banks that engage more heavily in maturity transformation; and (iv) banks' net interest margins rise following term premium shocks, but fall in reaction to an increase in future expected short-term rates.

Several fascinating avenues and challenges for future research emerge from this paper. First, as documented throughout, the term premium is quantitatively important for bank profitability. The term premium was also the focus of quantitative easing that central banks around the world have used over the past several years. While quantitative easing works through various channels, one side effect is that it may reduce bank profit margins by lowering term premia. In turn, suppressed bank

profitability can reduce bank lending and thereby affect overall economic activity. Understanding the quantitative importance of these channels is key to assess the overall effectiveness of quantitative easing. Second, it would be useful to build a structural model of financial intermediation, in which the term premium is an endogenous general equilibrium outcome, and subsequently use the model to replicate the findings in this paper. Related to the first point, such a model could shed light on the question of whether quantitative easing may have the mentioned unwanted effects.

Last, my results highlight the importance of differentiating between average expected short-term rates and term premia when analyzing the effects of long-term interest rate changes on stock prices. Future research that aims to apply such decompositions faces at least two challenges. First, the state of the art within the high-frequency identification literature is to use 30-minute event windows, but the highest frequency at which term premia estimates are available is at the daily frequency. 
Second, I rely on term premia estimates from term structure models that are publicly available. It is well-known that the estimation of term premia is challenging. Existing models often produce different level estimates and considerable uncertainty remains around any estimate. Understanding these differences and their importance for the response of stock prices remains a difficult but important challenge for future research.

\section{References}

Adrian, Tobias, Richard K. Crump and Emanuel Moench. 2013. "Pricing the term structure with linear regressions." Journal of Financial Economics 110(1):110-138.

Altavilla, Carlo, Miguel Boucinha and José Luis Peydró. 2018. "Monetary policy and bank profitability in a low interest rate environment." Economic Policy 33(96):531-586.

Ampudia, Miguel and Skander J. van den Heuvel. 2019. "Monetary Policy and Bank Equity Values in a Time of Low and Negative Interest Rates." Finance and Economics Discussion Series, Board of Governors of the Federal Reserve System (U.S.) (064).

Balloch, Cynthia and Yann Koby. 2020. "Low Rates and Bank Loan Supply: Theory and Evidence from Japan." Unpublished Manuscript .

Begenau, Juliane, Monika Piazzesi and Martin Schneider. 2020. "Banks' Risk Exposures." NBER Working Paper (21334).

Bernanke, Ben, Mark Gertler and Simon Gilchrist. 1999. "The Financial Accelerator in a Quantitative Business Cycle Framework." Handbook of Macroeconomics, in: J. B. Taylor \&3 M. Woodford (ed.), Handbook of Macroeconomics, edition 1, volume 1, chapter 21, pages 1341-1393 Elsevier. (6455).

Bernanke, Ben S. and Kenneth N. Kuttner. 2005. "What Explains the Stock Market's Reaction to Federal Reserve Policy?" Journal of Finance 60(3):1221-1257.

Borio, Claudio, Leonardo Gambacorta and Boris Hofmann. 2017. "The influence of monetary policy on bank profitability." International Finance 20(1):48-63.

Brei, Michael, Claudio Borio and Leonardo Gambacorta. 2019. "Bank intermediation activity in a low interest rate environment." BIS Working Papers (807).

Brunnermeier, Markus K. and Yuliy Sannikov. 2014. "A Macroeconomic Model with a Financial Sector." American Economic Review 104(2):379-421.

Brunnermeier, Markus and Yann Koby. 2019. "The Reversal Interest Rate." Unpublished Manuscript, Princeton University .

Claessens, Stijn, Nicholas Coleman and Michael Donnelly. 2018. "Low-For-Long interest rates and banks interest margins and profitability: Cross-country evidence." Journal of Financial Intermediation 35:1-16.

Cochrane, John. 2005. Asset Pricing. Princeton University Press.

Di Tella, Sebastian and Pablo Kurlat. 2020. "Why are banks exposed to monetary policy?" AEJ:Macroeconomics, forthcoming . 
Drechsler, Itamar, Alexi Savov and Philipp Schnabl. 2017. "The Deposits Channel of Monetary Policy." The Quarterly Journal of Economics 132(4):1819-1876.

Drechsler, Itamar, Alexi Savov and Philipp Schnabl. 2021. "Banking on Deposits, Maturity Transformation without Interest Rate Risk." Journal of Finance 76(3):1091-1143.

Driscoll, John C. and Ruth Judson. 2013. "Sticky deposit rates." Finance and Economics Discussion Series, Board of Governors of the Federal Reserve System (U.S.) (2013-80).

English, William B., Skander J. van den Heuvel and Egon Zakrajšek. 2018. "Interest Rate Risk and Bank Equity Valuations." Journal of Monetary Economics 98:80-97.

Flannery, Mark J. and Christopher M. James. 1984. "The Effect of Interest Rate Changes on the Common Stock Returns of Financial Institutions." The Journal of Finance 39(4):1141-1153.

Foà, Gabriele, Leonardo Gambacorta, Luigi Guiso and Paolo Emilio Mistrulli. 2019. "The Supply Side of Household Finance." The Review of Financial Studies 32(10):3762-3798.

Gertler, Mark and Nobuhiro Kiyotaki. 2010. "Financial Intermediation and Credit Policy in Business Cycle Analysis." Handbook of Monetary Economics 3:547-599.

Gilchrist, Simon and Egon Zakrajsek. 2012. "Credit Spreads and Business Cycle Fluctuations." American Economic Review 102(4):1692-1720.

Gomez, Matthieu, Augustin Landier, David Sraer and David Thesmar. 2021. "Banks Exposure to Interest Rate Risk and the Transmission of Monetary Policy." Journal of Monetary Economics 117:543-570.

Gürkaynak, Refet S, Brian Sack and Eric Swanson. 2005. "Do Actions Speak Louder Than Words? The Response of Asset Prices to Monetary Policy Actions and Statements." International Journal of Central Banking 1(1):55-93.

Gürkaynak, Refet S., Brian Sack and Jonathan H. Wright. 2007. "The U.S. Treasury Yield Curve: 1961 to the Present." Journal of Monetary Economics 54(8):2291-2304.

Haddad, Valentin and David Sraer. 2020. "The Banking View of Bond Risk Premia." Journal of Finance $75(5): 2465-2502$.

Hannan, Timothy H. and Allen N. Berger. 1991. "The Rigidity of Prices: Evidence from the Banking Industry." The American Economic Review 81(4):938-945.

Hanson, Samuel G. 2014. "Mortgage convexity." Journal of Financial Economics 113(2):270-299.

Hanson, Samuel G. and Jeremy C. Stein. 2015. "Monetary Policy and Long-Term Real Rates." Journal of Financial Economics 115(3):429-448.

He, Zhiguo and Arvind Krishnamurthy. 2013. "Intermediary Asset Pricing." American Economic Review 103(2):732-70.

Heider, Florian, Farzad Saidi and Glenn Schepens. 2019. "Life below Zero: Bank Lending under Negative Policy Rates." The Review of Financial Studies 32(10):3728-3761.

Hellwig, Martin. 1994. "Liquidity provision, banking, and the allocation of interest rate risk." European Economic Review 38(7):1363-1389. 
Hoffmann, Peter, Sam Langfield, Federico Pierobon and Guillaume Vuillemey. 2019. "Who bears interest rate risk?" Review of Financial Studies 32(8):2921-2954.

Ippolito, Filippo, Ali K. Ozdagli and Ander Perez-Orive. 2018. "The transmission of monetary policy through bank lending: The floating rate channel." Journal of Monetary Economics 95:49 - 71.

Jarocinski, Marek and Peter Karadi. 2020. "Deconstructing monetary policy surprises: the role of information shocks." AEJ:Macroeconomics 12(2):1-43.

Jordà, Oscar. 2005. "Estimation and Inference of Impulse Responses by Local Projections." American Economic Review 95(1):161-182.

Kekre, Rohan and Moritz Lenel. 2020. "Monetary Policy, Redistribution, and Risk Premia." Unpublished Manuscript .

Kim, D. H. and A. Orphanides. 2012. "Term Structure Estimation With Survey Data on Interest Rate Forecasts." Journal of Financial and Quantitative Analysis 47:241-272.

Kim, Don H. and Jonathan H. Wright. 2005. "An Arbitrage-Free Three-Factor Term Structure Model and the Recent Behavior of Long-Term Yields and Distant-Horizon Forward Rates." Finance and Economics Discussion Series, Board of Governors of the Federal Reserve System (U.S.) (2005-33).

Kirti, Divya. 2020. "Why Do Bank-Dependent Firms Bear Interest-Rate Risk?" Journal of Financial Intermediation 41.

Kuttner, Kenneth N. 2001. "Monetary policy surprises and interest rates: Evidence from the Fed funds futures market." Journal of Monetary Economics 47(3):523-544.

Li, Canlin, Andrew Meldrum and Marius Rodriguez. 2017. "Robustness of long-maturity term premium estimates." FEDS Notes. Washington: Board of Governors of the Federal Reserve System, April 3.

Lopez, Jose A., Andrew Rose and Mark Spiegel. 2018. "Why Have Negative Nominal Interest Rates Had Such a Small Effect on Bank Performance? Cross Country Evidence." Federal Reserve Bank of San Francisco (07).

Nakamura, Emi and Jón Steinsson. 2018. "High Frequency Identification of Monetary Non-Neutrality: The Information Effect." Quarterly Journal of Economics 133(3):1283-1330.

Neumark, David and Steven Sharpe. 1992. "Market Structure and the Nature of Price Rigidity: Evidence from the Market for Consumer Deposits." The Quarterly Journal of Economics 107(2):657-680.

Newey, W. K. and K. D. West. 1987. "A Simple, Positive-Definite, Heteroskedasticity and Autocorrelation Consistent Covariance Matrix." Econometrica 55:703-708.

Paligorova, Teodora and JoãoSantos.2017. "BanksâExposuretoRolloverRiskandtheMaturityofCorporateLoans." ReviewoJ

Paul, Pascal. 2020. "The Time-Varying Effect of Monetary Policy on Asset Prices." Review of Economics and Statistics 102(4):690-704.

Purnanandam, Amiyatosh. 2007. "Interest rate derivatives at commercial banks: An empirical investigation." Journal of Monetary Economics 54(6):1769-1808.

Romer, Christina D. and David H. Romer. 2004. "A New Measure of Monetary Shocks: Derivation and Implications." American Economic Review 94(4):1055-1084. 
Samuelson, Paul A. 1945. "The Effect of Interest Rate Increases on the Banking System." The American Economic Review 35(1):16-27.

Ulate, Mauricio. 2021. "Going Negative at the ZLB: The Effects of Negative Nominal Interest Rates." American Economic Review 111(1):1-40.

Vuillemey, Guillaume. 2016. "Interest Rate Risk in Banking: A Survey." Unpublished Manuscript .

Vuillemey, Guillaume. 2019. "Bank Interest Rate Risk Management." Management Science 65(12):5449-5956.

Wang, Olivier. 2018. "Banks, Low Interest Rates, and Monetary Policy Transmission." Unpublished Manuscript 


\section{Appendix: For Online Publication}

\section{A Banks' Income and Expenses}

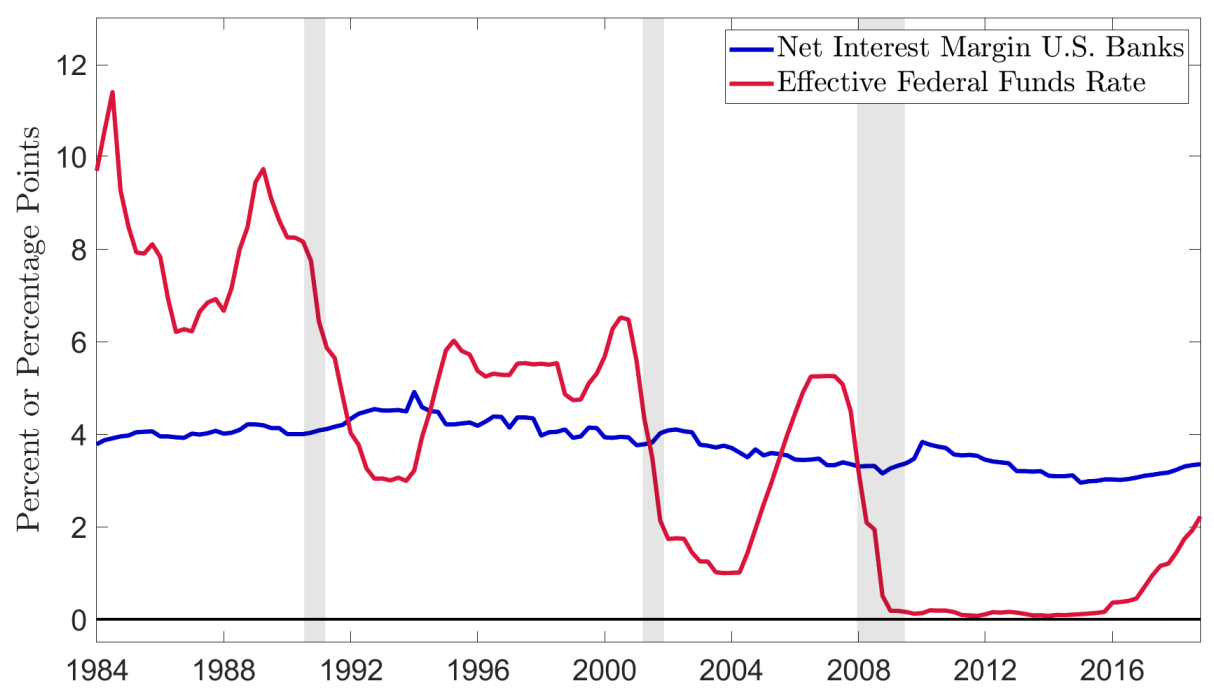

Figure A.1: Banks' Net Interest Margins and the Federal Funds Rate.

Notes: The net interest margin for U.S. commercial banks and the effective federal funds rate are taken from the St. Louis Fed's FRED database. 

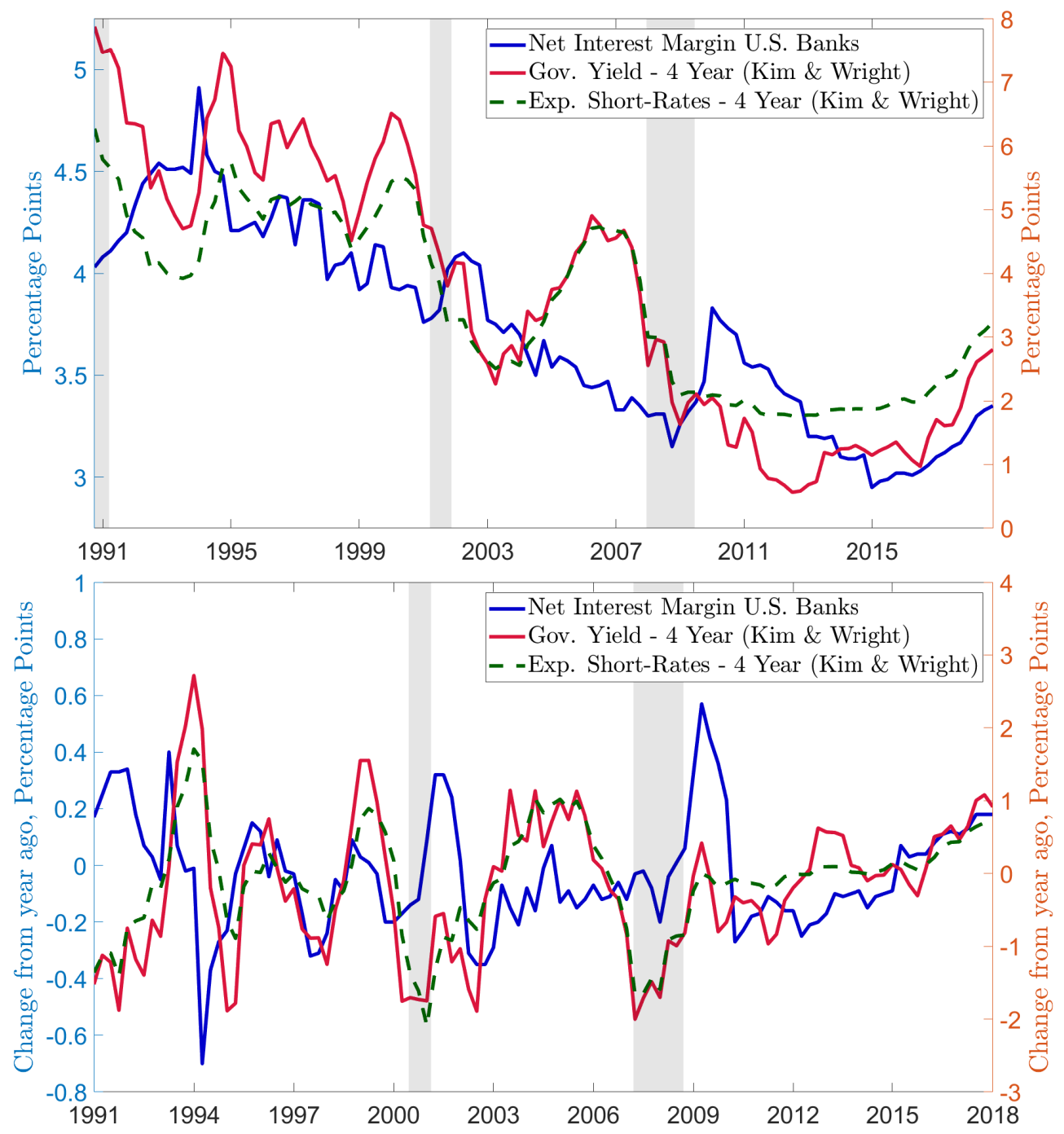

Figure A.2: Banks' Net Interest Margins and Long-term Yields.

Notes: The net interest margin for U.S. commercial banks is taken from the St. Louis Fed's FRED database based on data from the Call Reports (left axis). The government bond yield (fitted yield) and expected future short-term rates are taken from the Kim and Wright (2005) model (right axis, see Section 4.1 for details). 

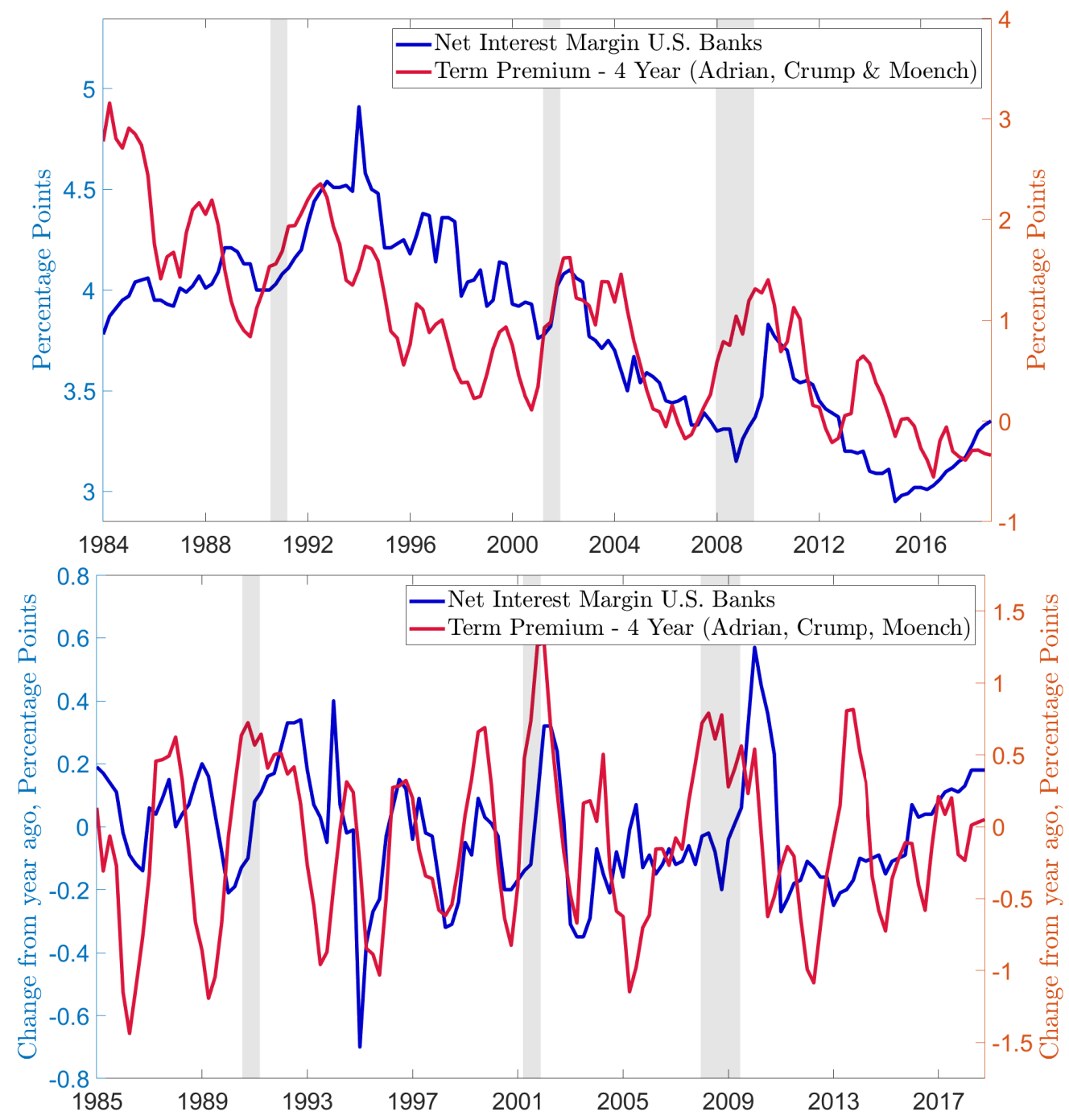

Figure A.3: Banks' Net Interest Margins and the Term Premium - ACM-Model. Notes: The net interest margin for U.S. commercial banks is taken from the St. Louis Fed's FRED database based on data from the Call Reports (left axis). The term premium is based on estimates by Adrian, Crump and Moench (2013) (right axis, see Section 4.1 for details). 


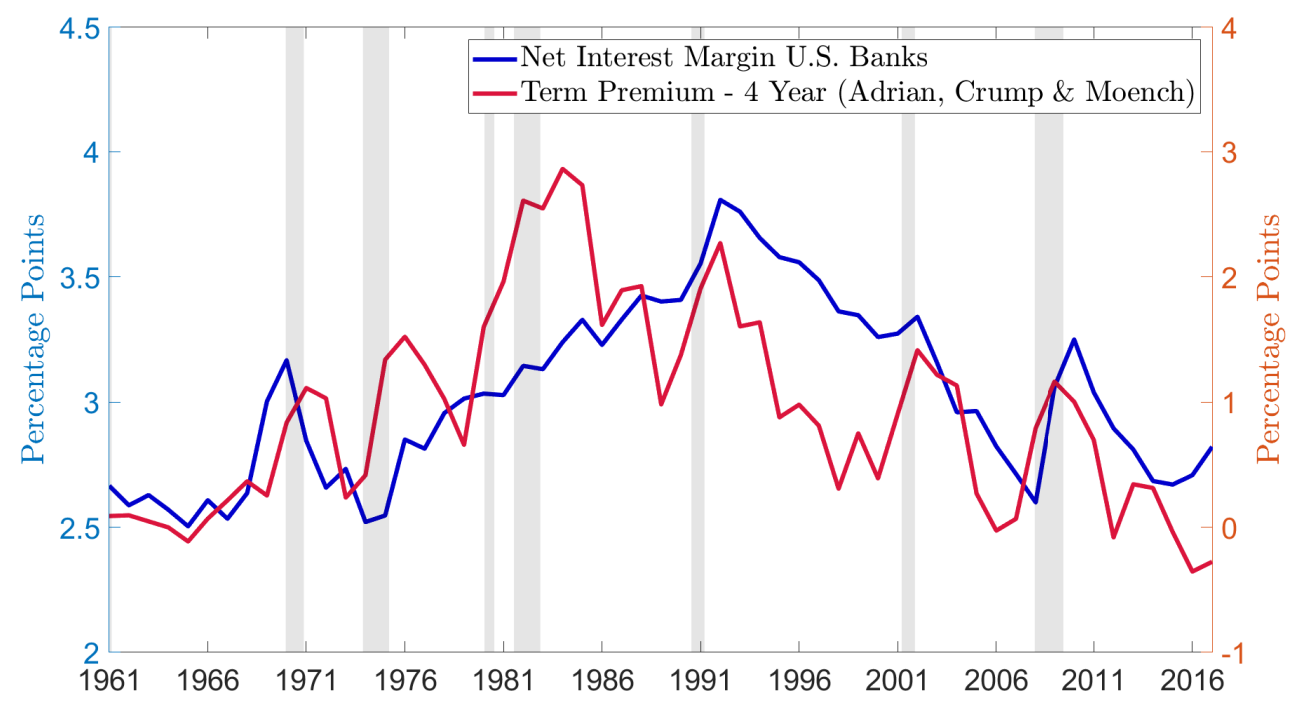

Figure A.4: Banks' Net Interest Margins and the Term Premium - Long View.

Notes: The net interest margin for U.S. banks is based on the Historical Bank Data from the FDIC (left axis). The term premium is based on estimates by Adrian, Crump and Moench (2013) (right axis, see Section 4.1 for details).

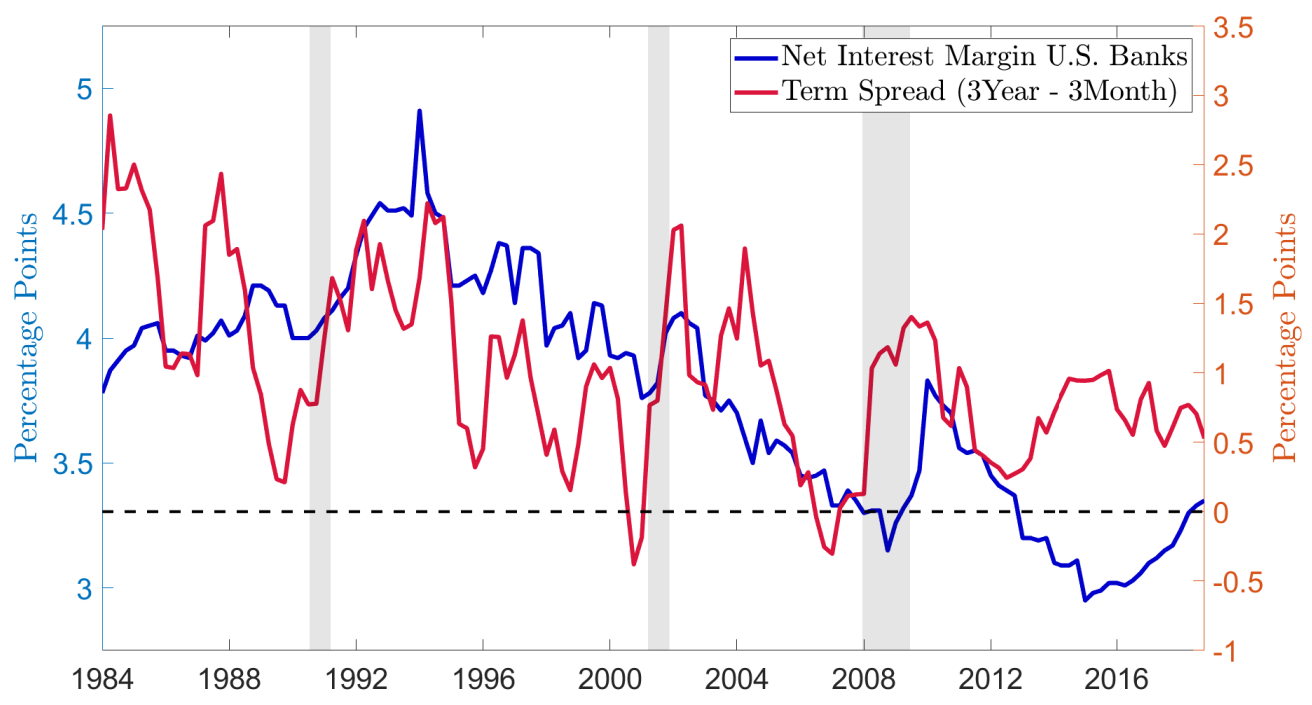

Figure A.5: Banks' Net Interest Margins and the Term Spread.

Notes: The net interest margin for U.S. commercial banks is taken from the St. Louis Fed's FRED database (left axis). The term spread is the difference between the 3-year government yield and the 3-month T-Bill (right axis, see Section 4.1 for details). 


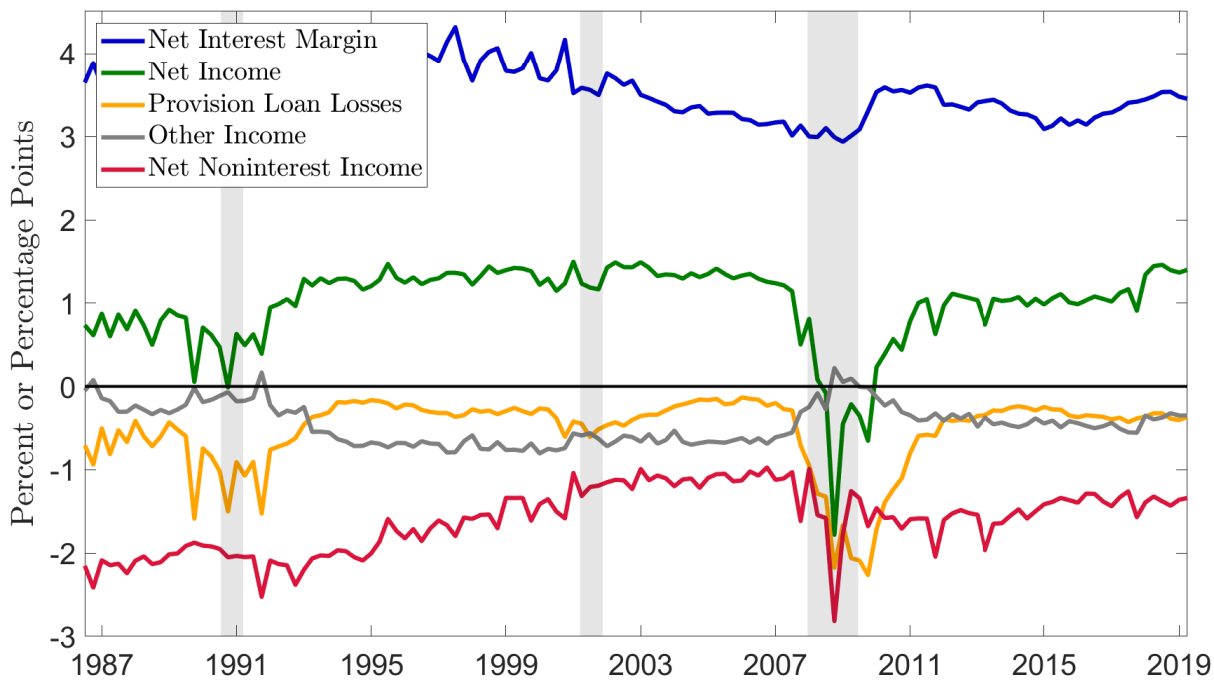

Figure A.6: Banks' Net Income.

Notes: Net income, net interest margin, net noninterest income, provision for loan losses, and other income (residual) as a fraction of total assets based on data from the Call Reports. Sample restricted to BHCs within the list of U.S. financial institutions described in Section 8.1, income and assets from foreign subsidiaries are excluded. See Tables H.2 and H.5 for details on the variable definitions.

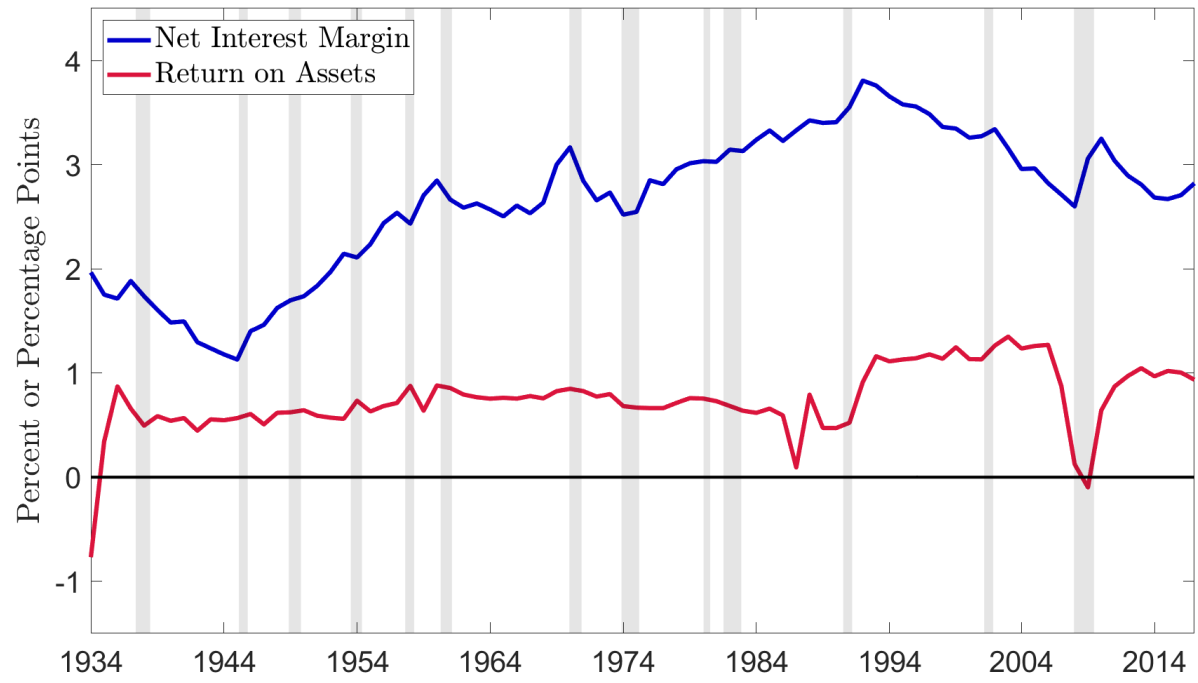

Figure A.7: Banks' Net Interest Margins and Return on Assets.

Notes: The net interest margin and return on assets for U.S. banks are based on the Historical Bank Data from the FDIC. 


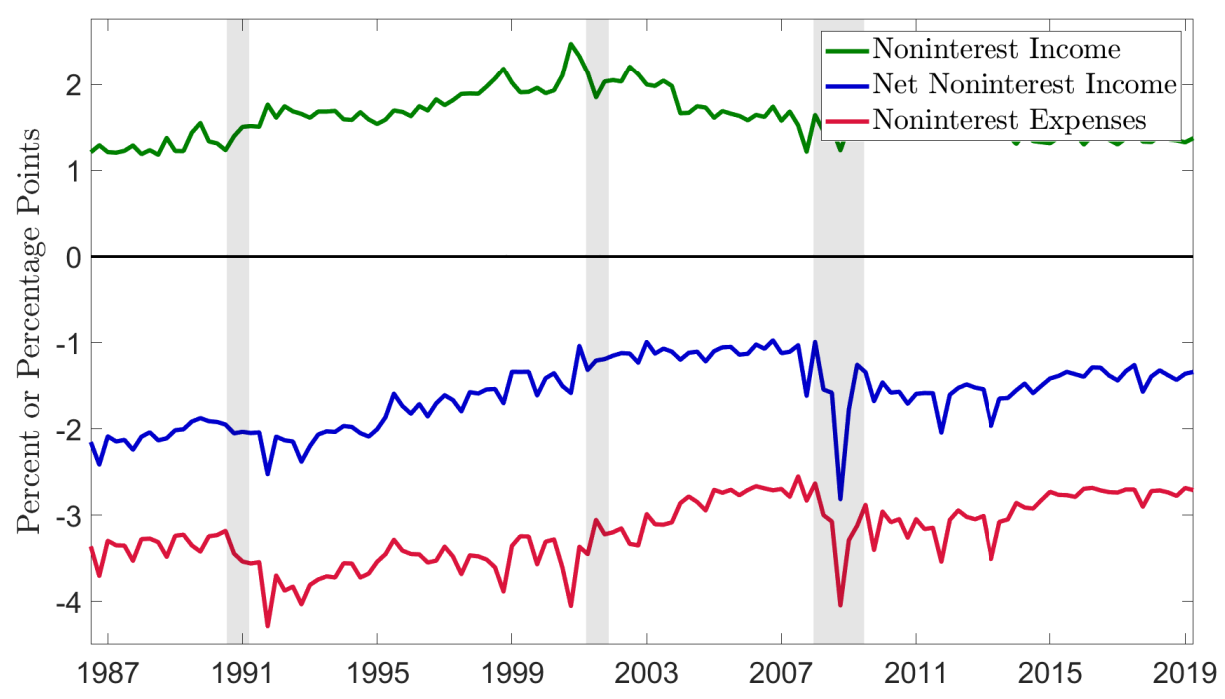

Figure A.8: Banks' Noninterest Income and Expenses.

Notes: Noninterest income, noninterest expenses, and net noninterest income as a fraction of total assets based on data from the Call Reports. Sample restricted to BHCs within the list of U.S. financial institutions described in Section 8.1, income and assets from foreign subsidiaries are excluded. See Tables H.2 and H.5 for details on the variable definitions.

\section{B Credit Spreads and Term Premia Estimates}

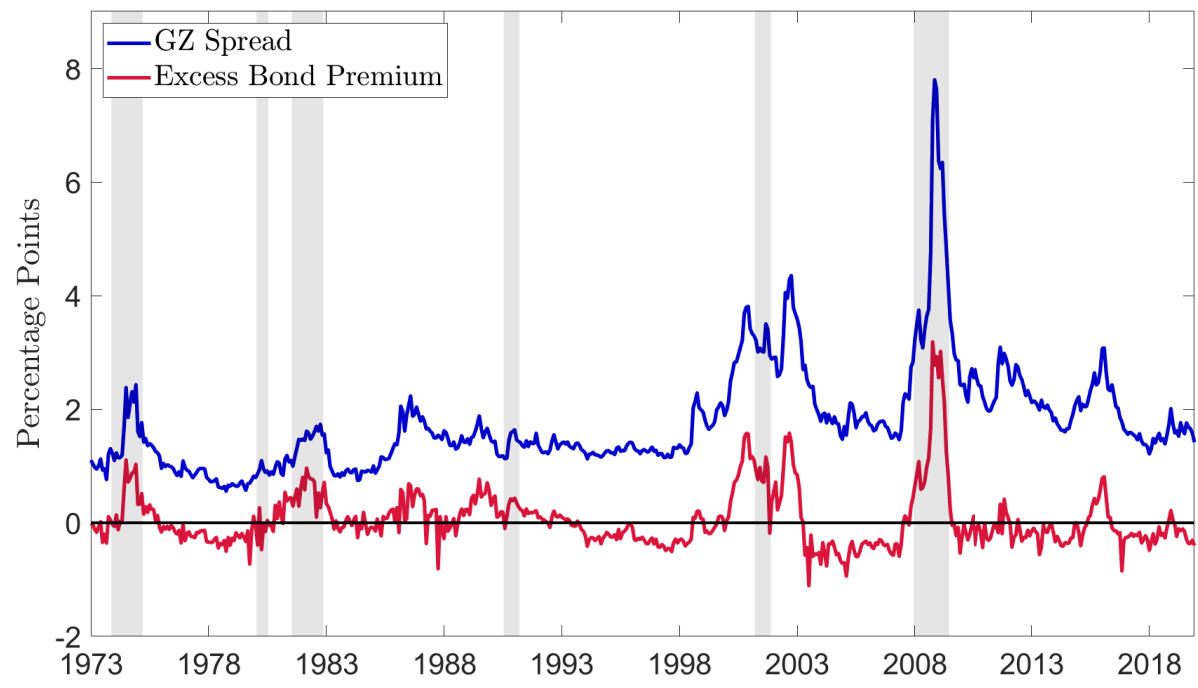

Figure B.1: Credit Spread and Excess Bond Premium by Gilchrist and Zakrajsek (2012). 


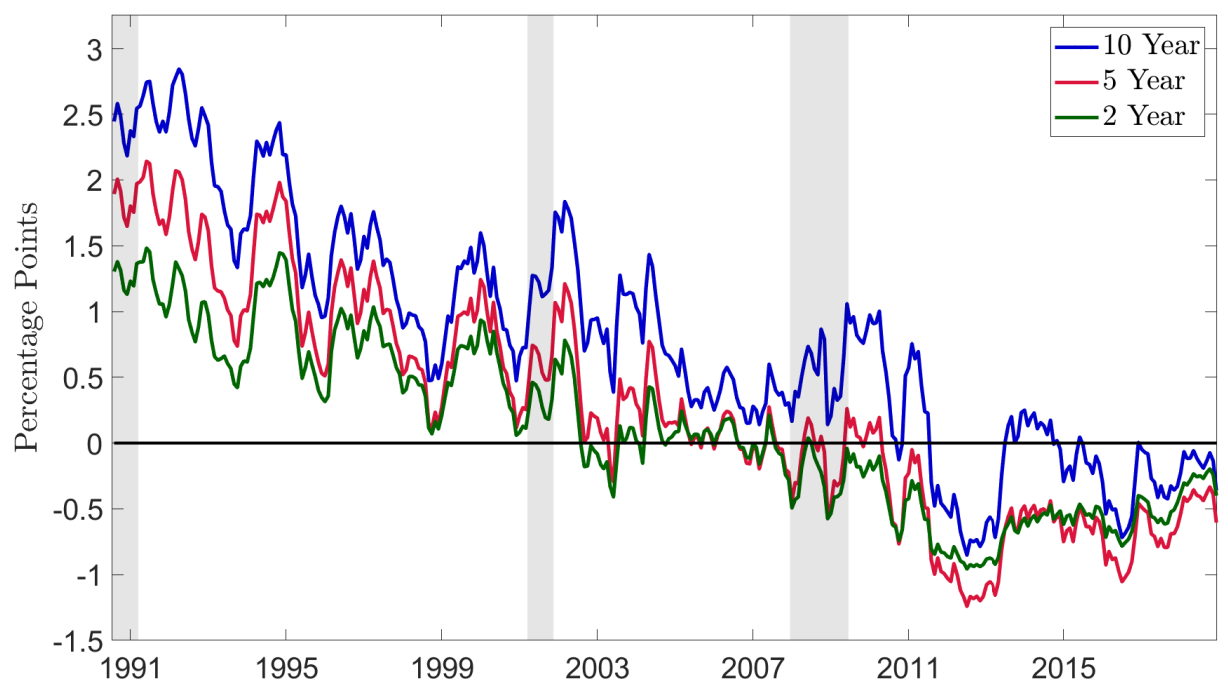

Figure B.2: Term Premia - Kim and Wright (2005).

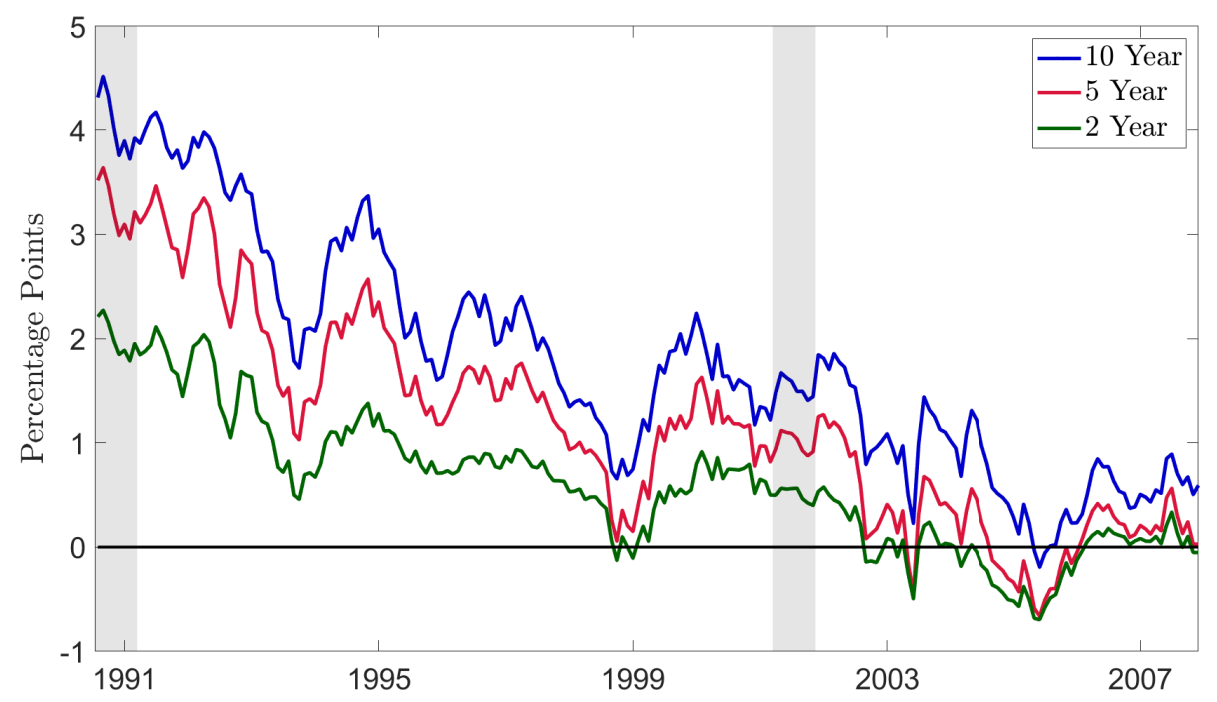

Figure B.3: Term Premia - Adrian, Crump and Moench (2013). Based on a reestimation of the model by Adrian, Crump and Moench (2013) for the sample 1990:M7-2007:M12.

\section{Additional Evidence for Stock Indices}

I check the robustness of the results from Section 4 along two additional dimensions. First, instead of the term premia estimates by Kim and Wright (2005), I use the ones by Adrian, Crump and Moench (2013). I make use of the computationally fast estimation of their model and obtain bootstrap estimates. Appendix D summarizes the procedure. Given the bootstrapped estimates, I rerun 
regression (4.2) and the results are shown in Table C.2. Compared with Table 4.2, the estimated coefficients have the same sign and qualitative patterns across the maturities and between the two stock indices. However, the absolute magnitudes of the responses and the statistical significance are lower. These differences can be explained by the use of survey data on expected future short-term rates within the term structure model of Kim and Wright (2005) that are absent in the model by Adrian, Crump and Moench (2013). As shown by Li, Meldrum and Rodriguez (2017), this additional information accounts for the majority of the differences in the term premia estimates of the two models. The use of survey data aligns the Kim and Wright (2005) estimates with financial market's expectations, which can explain why the equity price response with respect to their estimates show a higher statistical significance. Second, I exclude several FOMC announcements following emergency meetings that are listed in Section 4.1. Reestimating regression (4.2) gives the results that are shown in Table C.3. The findings remain largely unchanged, though the absolute magnitudes of the estimated coefficients and their statistical significance are somewhat lower.

Table C.1: Response of Stock Returns to High-Frequency Yield Surprises.

\begin{tabular}{|c|c|c|c|c|c|c|}
\hline \multirow[b]{2}{*}{$\mathrm{m}=$} & \multicolumn{3}{|c|}{ S\&P $500 \mathrm{HF}$} & \multicolumn{3}{|c|}{ S\&P 500 Daily } \\
\hline & 2-year & 5-year & 10-year & 2-year & 5-year & 10-year \\
\hline$\Delta Y_{t}^{3 M}$ & $-7.05^{* * *}$ & $-7.34^{* * *}$ & $-7.38^{* * *}$ & $-10.73^{* * *}$ & $-11.18^{* * *}$ & $-11.54^{* * *}$ \\
\hline \multirow{2}{*}{$\Delta\left(Y_{t}^{m}-Y_{t}^{3 M}\right)$} & -2.18 & -1.33 & -0.86 & -2.11 & -1.75 & -1.60 \\
\hline & $(2.33)$ & $(2.37)$ & (2.49) & (3.19) & (3.03) & (3.36) \\
\hline $\mathrm{R}^{2}$ & 0.29 & 0.28 & 0.27 & 0.22 & 0.21 & 0.21 \\
\hline Meetings & 118 & 118 & 118 & 118 & 118 & 118 \\
\hline
\end{tabular}

Notes: Estimation results for regression (4.1), where $\Delta Y_{t}^{3 M}$ and $\Delta Y_{t}^{m}$ are given by yield changes based on 30-minute windows around FOMC announcements and $R_{t}$ is given by the return of the S\&P 500 based on a 30-minute window (S\&P $500 \mathrm{HF}$ ) or a daily window (S\&P 500 Daily). Sample: 1994:M1-2007:M12, excluding FOMC announcement on 9/17/2001. White standard errors in parentheses. ${ }^{* * *} p<0.01,{ }^{* *} p<0.05,{ }^{*} p<0.1$. 
Table C.2: Response of Stock Returns - Adrian, Crump and Moench (2013).

\begin{tabular}{lcccccc}
\hline & \multicolumn{3}{c}{ KBW Index } & \multicolumn{3}{c}{ S\&P 500 } \\
$\mathrm{m}=$ & 2-year & 5-year & 10-year & 2-year & 5-year & 10-year \\
$\Delta Y_{t}^{3 M}$ & -4.31 & -5.06 & -9.93 & $-4.64^{* *}$ & $-6.10^{*}$ & -8.92 \\
& $(0.14)$ & $(0.20)$ & $(0.22)$ & $(0.04)$ & $(0.07)$ & $(0.14)$ \\
$\Delta\left(E H_{t}^{m, b}-Y_{t}^{3 M}\right)$ & -2.20 & -3.11 & -7.96 & -1.96 & -3.20 & -6.11 \\
& $(0.31)$ & $(0.35)$ & $(0.29)$ & $(0.27)$ & $(0.26)$ & $(0.25)$ \\
$\Delta T P_{t}^{m, b}$ & 4.32 & $3.22^{*}$ & $3.91^{* *}$ & 2.28 & 1.62 & 1.18 \\
& $(0.13)$ & $(0.09)$ & $(0.03)$ & $(0.18)$ & $(0.12)$ & $(0.10)$ \\
& & & & & & \\
\hline$R^{2}$ & 0.04 & 0.04 & 0.04 & 0.07 & 0.07 & 0.06 \\
Meetings & 118 & 118 & 118 & 118 & 118 & 118 \\
\hline
\end{tabular}

Notes: Estimation results for regression (D.2), where $\hat{R}_{t}^{b}$ is given by the predicted return of the KBW Bank Index or the S\&P 500 (excluding banks), and $\Delta E H_{t}^{m, b}$ and $\Delta T P_{t}^{m, b}$ are bootstrapped estimates based on a reestimation of the model by Adrian, Crump and Moench (2013) for the sample 1990:M7-2007:M12 (see Appendix D for details). The table shows the median of the estimated parameters, the cumulative probability $(c p)$ above zero (for $\hat{\beta}_{1}$ and $\hat{\beta}_{2}$ ) and below zero (for $\hat{\beta}_{3}$ ) is shown in parentheses. Sample: 1994:M1-2007:M12, excluding FOMC announcement on 9/17/2001. ${ }^{* * *} c p<0.01,{ }^{* *} c p<0.05,{ }^{*} c p<0.1$.

Table C.3: Response of Stock Returns - Excluding Unscheduled Meetings.

\begin{tabular}{|c|c|c|c|c|c|c|}
\hline \multirow[b]{2}{*}{$\mathrm{m}=$} & \multicolumn{3}{|c|}{ KBW Index } & \multicolumn{3}{|c|}{ S\&P 500} \\
\hline & 2-year & 5-year & 10-year & 2-year & 5-year & 10 -year \\
\hline \multirow[t]{2}{*}{$\Delta Y_{t}^{3 M}$} & $-15.11^{* *}$ & $-24.32^{*}$ & -29.06 & $-11.72^{* *}$ & $-19.47^{*}$ & $-25.49^{*}$ \\
\hline & $(7.56)$ & $(14.29)$ & $(20.29)$ & $(5.55)$ & $(9.89)$ & $(13.60)$ \\
\hline \multirow{2}{*}{$\Delta\left(E H_{t}^{m}-Y_{t}^{3 M}\right)$} & $-15.83^{*}$ & -25.22 & -29.28 & -10.28 & -18.71 & -24.71 \\
\hline & $(9.35)$ & $(16.91)$ & (23.09) & $(6.56)$ & $(11.39)$ & $(15.22)$ \\
\hline \multirow[t]{2}{*}{$\Delta T P_{t}^{m}$} & 15.57 & 16.68 & 17.08 & 9.29 & 11.23 & 12.49 \\
\hline & (10.91) & (10.90) & (11.63) & $(8.40)$ & $(8.18)$ & $(8.58)$ \\
\hline $\mathrm{R}^{2}$ & 0.08 & 0.08 & 0.07 & 0.13 & 0.13 & 0.13 \\
\hline Meetings & 115 & 115 & 115 & 115 & 115 & 115 \\
\hline
\end{tabular}

Notes: Estimation results for regression (4.2), where $R_{t}$ is given by the return of the KBW Bank Index or the S\&P 500 (excluding banks), and $\Delta E H_{t}^{m}$ and $\Delta T P_{t}^{m}$ are based on estimates from Kim and Wright (2005). White standard errors in parentheses. Sample: 1994:M1-2007:M12, excluding FOMC announcements on 10/15/1998, 9/17/2001, 08/10/2007, and 08/17/2007. ${ }^{* * *} p<0.01$, ${ }^{* *} p<0.05,{ }^{*} p<0.1$. 
Table C.4: Response of Stock Returns - Jarocinski and Karadi (2020)-Approach.

\begin{tabular}{|c|c|c|c|c|c|c|}
\hline \multirow[b]{2}{*}{$\mathrm{m}=$} & \multicolumn{3}{|c|}{ KBW Index } & \multicolumn{3}{|c|}{ S\&P 500} \\
\hline & 2-year & 5-year & 10-year & 2-year & 5-year & 10-year \\
\hline$\Delta Y_{t}^{3 M}$ & $\begin{array}{c}-22.97^{* * *} \\
(5.50)\end{array}$ & $\begin{array}{c}-48.49^{* * *} \\
(9.81)\end{array}$ & $\begin{array}{c}-73.02^{* * *} \\
(15.06)\end{array}$ & $\begin{array}{c}-14.66^{* * *} \\
(3.56)\end{array}$ & $\begin{array}{c}-29.43^{* * *} \\
(6.32)\end{array}$ & $\begin{array}{c}-43.43^{* * *} \\
(9.86)\end{array}$ \\
\hline$\Delta\left(E H_{t}^{m}-Y_{t}^{3 M}\right)$ & $\begin{array}{c}-26.21^{* * *} \\
(6.83)\end{array}$ & $\begin{array}{c}-53.50 * * * \\
(11.67)\end{array}$ & $\begin{array}{c}-77.79 * * * \\
(17.45)\end{array}$ & $\begin{array}{c}-15.02^{* * *} \\
(4.02)\end{array}$ & $\begin{array}{c}-30.56^{* * *} \\
(7.06)\end{array}$ & $\begin{array}{c}-44.07^{* * * *} \\
(10.98)\end{array}$ \\
\hline$\Delta T P_{t}^{m}$ & $\begin{array}{l}3.23 \\
(7.84)\end{array}$ & $\begin{array}{c}16.59^{* *} \\
(8.07)\end{array}$ & $\begin{array}{c}24.25^{* *} \\
(9.38)\end{array}$ & $\begin{array}{l}-3.48 \\
(4.45)\end{array}$ & $\begin{array}{c}5.46 \\
(4.73)\end{array}$ & $\begin{array}{c}10.12^{*} \\
(5.67)\end{array}$ \\
\hline $\mathrm{R}^{2}$ & 0.43 & 0.45 & 0.42 & 0.56 & 0.55 & 0.50 \\
\hline Meetings & 71 & 71 & 71 & 71 & 71 & 71 \\
\hline
\end{tabular}

Notes: Estimation results for regression (4.2), where $R_{t}$ is given by the return of the KBW Bank Index or the S\&P 500 (excluding banks), and $\Delta E H_{t}^{m}$ and $\Delta T P_{t}^{m}$ are based on estimates from Kim and Wright (2005). White standard errors in parentheses. Sample: 1994:M1-2007:M12, excluding FOMC announcements on 9/17/2001 and meetings with positive (negative) responses of S\&P 500 to increase (decrease) of two-year government bond yield. ${ }^{* * *} p<0.01,{ }^{* *} p<0.05,{ }^{*} p<0.1$.

Table C.5: Response of Stock Returns - Jarocinski and Karadi (2020)-Approach.

\begin{tabular}{lccc}
\hline & & KBW-S\&P 500 & \\
\cline { 3 - 3 } $\mathrm{m}=$ & 2 -year & 5 -year & 10 -year \\
\hline \multirow{2}{*}{$\Delta Y_{t}^{3 M}$} & $-8.31^{* * *}$ & $-19.07^{* * *}$ & $-29.59^{* * *}$ \\
& $(0.01)$ & $(0.00)$ & $(0.00)$ \\
$\Delta\left(E H_{t}^{m}-Y_{t}^{3 M}\right)$ & $-11.19^{* * *}$ & $-22.94^{* * *}$ & $-33.72^{* * *}$ \\
& $(0.01)$ & $(0.00)$ & $(0.00)$ \\
$\Delta T P_{t}^{m}$ & $6.72^{*}$ & $11.13^{* *}$ & $14.13^{* *}$ \\
& $(0.10)$ & $(0.02)$ & $(0.01)$ \\
\hline $\mathrm{R}^{2}$ & & & \\
Meetings & 0.08 & 0.10 & 0.10 \\
\hline
\end{tabular}

Notes: Estimation results for regression (4.2), where $R_{t}$ is given by the return of the KBW Bank Index minus the return of the $\mathrm{S} \& \mathrm{P} 500$ (excluding banks), and $\Delta E H_{t}^{m}$ and $\Delta T P_{t}^{m}$ are based on estimates from Kim and Wright (2005). Sample: 1994:M1-2007:M12, excluding FOMC announcement on 9/17/2001 and meetings with positive (negative) responses of S\&P 500 to increase (decrease) of two-year government bond yield. P-values in parentheses are based on one-sided tests with the null hypothesis that $\hat{\beta}_{1}>0, \hat{\beta}_{2}>0$, and $\hat{\beta}_{3}<0$, based on White standard errors. ${ }^{* * *} p<0.01,{ }^{* *} p<0.05,{ }^{*} p<0.1$. 


\section{Bootstrapping Procedure}

This section describes the bootstrapping procedure that is used for the estimations with respect to Tables C.2, I.9, and I.10. Bootstrapped estimates for term premia and expected future short-term rates based on the model by Adrian, Crump and Moench (2013) (ACM) are obtained as follows:

1. Estimate the ACM-model for the sample 1990:M7-2007:M12 based on the data by Gürkaynak, Sack and Wright (2007) (using the same set of yields and 5 principal components as in ACM).

2. Given the estimated model parameters obtained in step 1, reestimate series for the principal components recursively based on equation (1) in Adrian, Crump and Moench (2013). This is achieved by drawing with replacement from the set of estimated residuals from step 1 (denoted $v_{t+1}$ in equation (1) in Adrian, Crump and Moench, 2013). Rerun the model using the new series of factors and obtain the fitted yield series. Construct a new set of yield series by adding estimated errors to the fitted yield series. These innovations are drawn with replacement from the set of estimated errors between the original yields and the fitted yields based on step 1.

3. Given the new set of yield series produced in step 2, rerun the model and produce estimates for term premia and expected future short-term rates.

4. Repeat steps 2 and 3 a large number of times, giving a large set of estimated term premia and expected future short-term rates.

Using the estimates from step 1, run regression (4.2)

$$
R_{t}=\alpha+\beta_{1} \Delta Y_{t}^{3 M}+\beta_{2}\left(\Delta E H_{t}^{m}-\Delta Y_{t}^{3 M}\right)+\beta_{3} \Delta T P_{t}^{m}+u_{t}
$$

and save the estimated coefficients $\hat{\alpha}, \hat{\beta}_{1}, \hat{\beta}_{2}$, and $\hat{\beta}_{3}$, as well as the estimated residuals. Given the bootstrapped estimates from steps 1-4, obtain trading window changes around FOMC announcements for expected future short-term rates and term premia, denoted $\Delta E H_{t}^{m, b}$ and $\Delta T P_{t}^{m, b}$ for maturity $m$ and bootstrap $b$. Given those estimates, construct predicted returns associated with bootstrap $b$ according to

$$
\hat{R}_{t}^{b}=\hat{\alpha}+\hat{\beta}_{1} \Delta Y_{t}^{3 M}+\hat{\beta}_{2}\left(\Delta E H_{t}^{m, b}-\Delta Y_{t}^{3 M}\right)+\hat{\beta}_{3} \Delta T P_{t}^{m, b}+\bar{u}_{t}
$$

where $\bar{u}_{t}$ is randomly drawn with replacement from the set of estimated residuals based on regression (D.1) and $\hat{\alpha}, \hat{\beta}_{1}, \hat{\beta}_{2}$, and $\hat{\beta}_{3}$ are the saved coefficients from regression (D.1). Given the predicted returns, rerun regression (D.1),

$$
\hat{R}_{t}^{b}=\widetilde{\alpha}+\widetilde{\beta}_{1} \Delta Y_{t}^{3 M}+\widetilde{\beta}_{2}\left(\Delta E H_{t}^{m, b}-\Delta Y_{t}^{3 M}\right)+\widetilde{\beta}_{3} \Delta T P_{t}^{m, b}+\widetilde{u}_{t}
$$

Replicating these steps for each bootstrap estimate $b$ gives a set of estimated coefficients $\widetilde{\beta}_{1}, \widetilde{\beta}_{2}$, and $\widetilde{\beta}_{3}$. The set of parameters for regressions (8.3) and (8.4) are obtained similarly, estimating 
$\hat{R}_{i, t}^{b}=\widetilde{\alpha}_{i}+\widetilde{\beta}_{1} \Delta Y_{t}^{3 M}+\widetilde{\beta}_{2}\left(\Delta E H_{t}^{m, b}-\Delta Y_{t}^{3 M}\right)+\widetilde{\beta}_{3} \Delta T P_{t}^{m, b}+\widetilde{\beta}_{4} \Delta T P_{t}^{m, b} \cdot G a p_{i, t}+\widetilde{\beta}_{5} G a p_{i, t}+\widetilde{u}_{i, t}$,

where $G a p_{i, t}$ denotes firm $i$ 's maturity or income gap.

\section{E Identification}

In this appendix, I derive two propositions with respect to the identification of the effects of future expected short-term rates and term premia based on regression (4.2). For simplicity, I do not distinguish between level and slope changes in future expected short-term rates.

Proposition 1. The effects of future expected short-term rates and term premia on stock returns are consistently estimated based on regression (4.2) using ordinary least squares, in the absence of omitted shocks that are correlated with stock returns and the regressors in (4.2).

Assuming linear relations, the causal effect of a shock to future expected short-term rates, denoted by $\epsilon_{t}^{E H}$, on the stock return $R_{i, t}$ of a company or index $i$ and term premia, denoted by $T P_{t}$, is given by

$$
\begin{aligned}
& R_{i, t}=\alpha_{i, 1} \epsilon_{t}^{E H}+\alpha_{i, 2} \epsilon_{t}^{R}, \\
& T P_{t}=\delta_{1} \epsilon_{t}^{E H}+\delta_{2} \epsilon_{t}^{T P}
\end{aligned}
$$

where $\epsilon_{t}^{R}$ and $\epsilon_{t}^{T P}$ are vectors of other structural shocks besides $\epsilon_{t}^{E H}$. For simplicity, I omit notation regarding the maturity of $\epsilon_{t}^{E H}$ and $T P_{t}$, but both are assumed to correspond to the same bond maturity. Next, assume that $R_{i, t}$ responds to changes in term premia, such that

$$
R_{i, t}=\beta_{i, 1} \epsilon_{t}^{E H}+\beta_{i, 2} T P_{t}+\beta_{i, 3} \widetilde{\epsilon}_{t}^{R}
$$

where $\widetilde{\epsilon}_{t}^{R}$ is again a vector of other structural shocks. Assume that $\epsilon_{t}^{E H}, \widetilde{\epsilon}_{t}^{R}$, and $\epsilon_{t}^{T P}$ are distinct shocks and uncorrelated, excluding the possibility of an omitted variable bias, an assumption that is relaxed in Proposition 2. Without loss of generality, assume that all shocks have a zero mean and variance of one. Similar to Sections 4 and 8, using ordinary least squares, one estimates

$$
R_{i, t}=\widetilde{\beta}_{i, 1} E H_{t}+\widetilde{\beta}_{i, 2} T P_{t}+u_{i, t}
$$

where $E H_{t}$ denotes the change in the expectation hypothesis and is equivalent to $\epsilon_{t}^{E H}$ on FOMC days. In large samples, the estimated coefficients converge to

$$
\hat{\widetilde{\beta}}=\left(\begin{array}{c}
\hat{\widetilde{\beta}}_{i, 1} \\
\tilde{\widetilde{\beta}}_{i, 2}
\end{array}\right) \stackrel{p}{\longrightarrow}\left(\begin{array}{cc}
1 & \delta_{1} \\
\delta_{1} & \delta_{1}^{2}+\delta_{2} \delta_{2}^{\prime}
\end{array}\right)^{-1}\left(\begin{array}{c}
\beta_{1, i}+\beta_{2, i} \delta_{1} \\
\beta_{1, i} \delta_{1}+\beta_{2, i} \delta_{1}^{2}+\beta_{2, i} \delta_{2} \delta_{2}^{\prime}
\end{array}\right)=\left(\begin{array}{c}
\beta_{i, 1} \\
\beta_{i, 2}
\end{array}\right)
$$


and the effects in (E.3) are therefore consistently estimated based on regression (E.4). It is straightforward to show that these results extend to regression setups as in (4.2).

Proposition 2. The difference in the effects of future expected short-term rates and term premia on stock returns of two companies or indices are consistently estimated based on regression (4.2) using ordinary least squares, even in the presence of omitted shocks that are correlated with stock returns and the regressors in (4.2), if these omitted shocks have a homogeneous direct effect on the stock returns of the two companies or indices.

Continuing the example from above, Proposition 2 relaxes the assumption that regression (E.4) is not subject to an omitted variable bias. A particular concern is that on days of monetary policy announcements, the central bank also releases private information about the economic outlook. In what follows, denote such information shocks by $\epsilon_{t}^{I E}$, assumed to be a single shock without loss of generality, and changing the processes from above to

$$
\begin{aligned}
& R_{i, t}=\beta_{i, 1} \epsilon_{t}^{E H}+\beta_{i, 2} T P_{t}+\beta_{3} \epsilon_{t}^{I E} \\
& T P_{t}=\delta_{1} \epsilon_{t}^{E H}+\delta_{2} \epsilon_{t}^{I E}
\end{aligned}
$$

where I omit the above vectors of other structural shocks $\widetilde{\epsilon}_{t}^{R}$ and $\epsilon_{t}^{T P}$ for simplicitly. Without loss of generality, $\epsilon_{t}^{I E}$ is assumed to be correlated with $\epsilon_{t}^{E H}$ and to have mean zero and variance one. Intuitively, the information shock affects all stock returns directly if $\beta_{3} \neq 0$ by altering financial markets' views about the economic outlook and it is assumed that $\beta_{3}$ is not specific to company or index $i$. However, the aggregate information shock may also change the pricing of bonds and term premia if $\delta_{2} \neq 0$, which in turn affects stock returns if $\beta_{i, 2} \neq 0$. Since such information shocks $\epsilon_{t}^{I E}$ are unobserved, one estimates again regression (E.4). Note that such a regression now suffers from an omitted variable bias since the information shock is correlated with $\epsilon_{t}^{E H}$ and $T P_{t}$ given (E.6), while also affecting stock returns $R_{i, t}$ directly according to (E.5). Using ordinary least squares, the estimated coefficients for (E.4) now converge to

$$
\hat{\widetilde{\beta}}=\left(\begin{array}{c}
\hat{\widetilde{\beta}}_{i, 1} \\
\tilde{\widetilde{\beta}}_{i, 2}
\end{array}\right) \stackrel{p}{\longrightarrow}\left(\begin{array}{c}
\beta_{i, 1}-\frac{\delta_{1} \beta_{3}}{\delta_{2}} \\
\beta_{i, 2}+\frac{\beta_{3}}{\delta_{2}}
\end{array}\right),
$$

Note that the estimates are biased but that the bias is independent of company or index $i$ since $\beta_{3}$ is common to all $i$. Hence, when estimating (E.4) for two companies $i$ and $j$, differences in the parameters converge to their true values

$$
\begin{aligned}
& \hat{\widetilde{\beta}}_{i, 1}-\hat{\widetilde{\beta}}_{j, 1} \stackrel{p}{\longrightarrow} \beta_{i, 1}-\beta_{j, 1}, \\
& \hat{\widetilde{\beta}}_{i, 2}-\hat{\widetilde{\beta}}_{j, 2} \stackrel{p}{\longrightarrow} \beta_{i, 2}-\beta_{j, 2},
\end{aligned}
$$

as the biases cancel out, and these results again extend to regression setups as in (4.2).

Non-FOMC days. The identification argument generalizes to non-FOMC days. To illustrate this point, assume that the data generating process is 


$$
\begin{aligned}
R_{i, t} & =\beta_{i, 1} E H_{t}+\beta_{i, 2} T P_{t}+\beta_{3} \epsilon_{1, t}+\beta_{4} \epsilon_{2, t}, \\
E H_{t} & =\delta_{1} \epsilon_{1, t}+\delta_{2} \epsilon_{2, t} \\
T P_{t} & =\alpha_{1} \epsilon_{1, t}+\alpha_{2} \epsilon_{2, t}
\end{aligned}
$$

where $\epsilon_{1, t}$ and $\epsilon_{2, t}$ are two structural shocks that impact stock returns directly if $\beta_{3} \neq 0$ and $\beta_{4} \neq 0$ and indirectly by changing expected future short-term rates and term premia (e.g., a TFP shock). For two companies or indices $i$ and $j$, the difference between the stock returns is

$$
R_{i, t}-R_{j, t}=\left(\beta_{i, 1}-\beta_{j, 1}\right) E H_{t}+\left(\beta_{i, 2}-\beta_{j, 2}\right) T P_{t}
$$

where the direct effects cancel out as long as $\beta_{3}$ and $\beta_{4}$ are not specific to $i$ and $j$. Hence, one can again estimate the differences consistently even if $E H_{t}$ is not taken to be exogenous and the result of monetary policy announcements.

\section{F Asset Pricing Predictions}

In this appendix, I derive testable predictions for the response of stock prices to term premia and short-term rates.

\section{F.1 Stock Prices and Term Premia}

Prediction \#1. To an increase in the term premium, bank stock returns respond more positively compared with typical nonfinancial companies.

To illustrate the first prediction, consider the basic asset pricing equation

$$
p_{t}=E_{t}\left(m_{t, t+j} d_{t+j}\right)
$$

where $p_{t}$ denotes the price of an asset, $m_{t, t+j}$ is some stochastic discount factor from period $t$ to $t+j$, and $d_{t+j}$ denotes the payoff of the asset at time $t+j$. For the following derivations, a useful reformulation of equation (F.1) is (see, e.g., Cochrane, 2005, Chapter 1)

$$
p_{t}=\frac{E_{t} d_{t+j}}{R_{t, t+j}}+\operatorname{cov}_{t}\left(d_{t+j}, m_{t, t+j}\right)
$$

where $R_{t, t+j}=E_{t}\left(m_{t, t+j}\right)^{-1}$. As in Section 2, consider a bank that engages in an arbitrage: the bank invests in a long-term government bond at time $t$ and finances this investment by rolling over a series of short-term bonds until maturity of the long-term bond at time $t+j$. Under the assumption that such a trade can be done at no extra costs, it must be the case that the price at time $t$ is zero in equilibrium. That is, if $d_{t+j}$ denotes the payoff of the arbitrage at time $t+j$, then

$$
p_{t}=0=E_{t}\left(m_{t, t+j} d_{t+j}\right)
$$


The arbitrage argument applies to all assets acquired from $t$ onward and any bond maturity. To provide intuition for these arguments, consider a specific example. A bank invests in a two-period government bond with return $R_{t, t+2}$, known at time $t$, financed by rolling over one-period bonds with returns $R_{t, t+1}$ and $R_{t+1, t+2}$, where the latter is uncertain at time $t$. The payoff from investing one unit at time $t$ is given by

$$
d_{t+2}=R_{t, t+2}-R_{t, t+1} R_{t+1, t+2}
$$

Pricing this payoff at time $t$ gives

$$
\begin{aligned}
p_{t}^{\text {Bank }} & =E_{t}\left(m_{t, t+2}\left(R_{t, t+2}-R_{t, t+1} R_{t+1, t+2}\right)\right) \\
& =1-R_{t, t+1} E_{t}\left(m_{t, t+2} R_{t+1, t+2}\right),
\end{aligned}
$$

where the second line follows from the fact that $R_{t, t+2}=E_{t}\left(m_{t, t+2}\right)^{-1}$. Using equation (F.2), note that $E_{t}\left(m_{t, t+2} R_{t+1, t+2}\right)$ in (F.6) can be written as

$$
E_{t}\left(m_{t, t+2} R_{t+1, t+2}\right)=\frac{E_{t}\left(R_{t+1, t+2}\right)}{R_{t, t+2}}+\operatorname{cov}_{t}\left(m_{t, t+2}, R_{t+1, t+2}\right)
$$

and assume that

$$
R_{t, t+2}=R_{t, t+1} E_{t}\left(R_{t+1, t+2}\right) T P_{t, t+2}
$$

where $T P_{t, t+2}$ denotes the expected excess return from the two-period bond at time $t$ (the "gross" term premium). To obtain an intuition for the role of the term premium, one can use (F.7) and (F.8), together with the arbitrage pricing condition (F.3), in (F.6), which gives

$$
1=\frac{1}{T P_{t, t+2}}+R_{t, t+1} \operatorname{cov}_{t}\left(m_{t, t+2}, R_{t+1, t+2}\right)
$$

Equation (F.9) has an intuitive interpretation. If the covariance between $m_{t, t+2}$ and $R_{t+1, t+2}$ is positive, that is, the marginal utility of consumption in $t+2$ relative to period $t$ is high when $R_{t+1, t+2}$ is elevated, then the gross term premium $T P_{t, t+2}$ is larger than one. Put differently, an investor has to be compensated for engaging in the arbitrage, since the cost of funding tends to be high exactly at the time when the marginal utility of consumption is elevated. The expression (F.9) can also be used to illustrate the various channels through which the term premium affects stock prices. To this end, use again the formulation (F.2) and rewrite (F.5) as

$$
p_{t}^{\text {Bank }}=\frac{E_{t}\left(d_{t+2}\right)}{R_{t, t+2}}+\operatorname{cov}_{t}\left(d_{t+2}, m_{t, t+2}\right)
$$


Using (F.4), (F.8), and (F.9) in (F.10), one obtains

$$
\begin{aligned}
p_{t}^{\text {Bank }} & =\frac{E_{t}\left(R_{t, t+2}-R_{t, t+1} R_{t+1, t+2}\right)}{R_{t, t+2}}+\operatorname{cov}_{t}\left(R_{t, t+2}-R_{t, t+1} R_{t+1, t+2}, m_{t, t+2}\right) \\
& =\frac{\overbrace{T P_{t, t+2}-1}^{\text {Cash-Flow }}}{\underbrace{T P_{t, t+2}}_{\text {Discounting }}}+\underbrace{\frac{1}{T P_{t, t+2}}-1}_{\text {Risk-Compensation }}=0 .
\end{aligned}
$$

Equation (F.11) shows three distinct channels through which the term premium operates. A higher term premium lowers the price $p_{t}^{\text {Bank }}$ because of higher discounting of expected future dividends (through the denominator $R_{t, t+2}$ of the first term in F.10) and because it reflects a necessary riskcompensation arising from the covariance between the stochastic discount factor and the arbitrage payoff (the second term in F.10). However, a higher term premium also reflects higher cash-flows, raising the expected payoff from the arbitrage (the numerator of the first term in F.10). On net, the effects exactly cancel out, such that the price is equal to zero. Further, according to (F.11), any change in the term premium leaves $p_{t}^{B a n k}$ unchanged, that is, $\partial p_{t}^{B a n k} / \partial T P_{t, t+2}=0$.

To illustrate the difference with a typical nonfinancial company, consider the stock price related to some dividend payoff $d_{t+2}^{*}$ at $t+2$,

$$
p_{t}^{N F}=\frac{E_{t}\left(d_{t+2}^{*}\right)}{R_{t, t+2}}+\operatorname{cov}_{t}\left(d_{t+2}^{*}, m_{t, t+2}\right)
$$

Again, a higher term premium lowers the price $p_{t}^{N F}$ due to higher discounting of expected future dividends (through the denominator $R_{t, t+2}$ of the first term in F.10). ${ }^{31}$ In contrast to banks, the impact of the term premium on the dividend payoff of a typical company is likely relatively small. If anything, a higher term premium results in larger interest expenses, dragging down cashflows as opposed to increasing them as for banks. As a conservative approximation, the cash-flow and risk-compensation effects in (F.11) are negligible for a typical nonfinancial company, such that $\partial p_{t}^{N F} / \partial T P_{t, t+2}<0$. For the considered example, it therefore holds that $\partial p_{t}^{B a n k} / \partial T P_{t, t+2}>$ $\partial p_{t}^{N F} / \partial T P_{t, t+2}$, resulting in Prediction \#1.

Positive Relation between Stock Prices and Term Premia. While the above examples show that bank and nonbank equity either show no response or a negative one, the relation between term premia and stock prices can also be positive for the following reason. As discussed in Section 5, if bond investors' outlook for the economy becomes more favorable, as to a positive Fed information shock, stock prices rise and investors may reshuffle their portfolio away from long-term bonds towards short-term bonds and equity. Such portfolio rebalancing may lead to an increase in the term premium and equity prices at the same time, giving rise to a positive correlation between the two. However, such a portfolio rebalancing effect applies to all stock prices, not only to bank equity,

\footnotetext{
${ }^{31}$ A similar argument applies to banks' legacy assets. Following an increase in the term premium, the associated dividends are more heavily discounted, lowering stock prices through that channel. However, all assets acquired after the term premium change are priced according to the arbitrage condition (F.3).
} 
and can therefore explain the positive relation between term premia and the S\&P 500 shown in Section 4.2.

Banks' Maturity Profile. Continuing with the above example, one can also obtain a prediction on the relative stock price responses of banks with different maturity profiles to a change in term premia. Consider two banks $i$ and $j$ that engage in an arbitrage at different maturities, with bank $i$ operating under a larger maturity mismatch than bank $j$. If the associated term premium of bank $i$ 's maturity profile increases, it should experience a positive cash flow effect. In contrast, holding the term premium associated with the maturity profile of bank $j$ constant, the stock price of bank $j$ should decline due to the discounting effect. Hence, stock returns of banks with a larger maturity mismatch are likely to show a more positive response following a rise in the associated term premium.

\section{F.2 Stock Prices and Short-term Rates}

Prediction \#2. To an increase in short-term rates, bank stock returns respond more negatively compared with typical nonfinancial companies.

To arrive at Prediction \#2, it is useful to obtain a linearized expression that relates current stock prices to future dividends and returns. The derivation largely follows Cochrane (2005, page 398). Start with an identity and rearrange

$$
\begin{aligned}
1 & =\tilde{R}_{t+1}^{-1} \tilde{R}_{t+1}=\tilde{R}_{t+1}^{-1}\left(\frac{P_{t+1}+D_{t+1}}{P_{t}}\right) \\
P_{t} & =\tilde{R}_{t+1}^{-1}\left(1+\frac{P_{t+1}}{D_{t+1}}\right) D_{t+1} .
\end{aligned}
$$

Take logs, indicated by small letters,

$$
p_{t}=-\tilde{r}_{t+1}+d_{t+1}+\ln \left(1+e^{p_{t+1}-d_{t+1}}\right) .
$$

Take a Taylor expansion of $\ln \left(1+e^{p_{t+1}-d_{t+1}}\right)$ around $p-d$

$$
p_{t}=-\tilde{r}_{t+1}+d_{t+1}+\ln \left(1+\frac{P}{D}\right)+\frac{\frac{P}{D}}{1+\frac{P}{D}}\left(p_{t+1}-d_{t+1}-(p-d)\right) .
$$

In steady state, the price is $P=D\left(\Lambda+\Lambda^{2}+\Lambda^{3}+\ldots\right)$, where $\Lambda=\frac{\Gamma}{R}, \Gamma$ is the gross real growth rate of dividends, and $R$ is the gross real interest rate. Then, the price-to-dividend ratio is given by $P / D=\Lambda / 1-\Lambda$ and equation (F.13) can be written as

$$
p_{t}=-\tilde{r}_{t+1}+d_{t+1}+\text { const. }+\Lambda\left(p_{t+1}-d_{t+1}\right) .
$$


Assume that the return $\tilde{r}_{t+1}$ is equal to the real interest rate $r_{t}$ plus the risk premium $r p_{t+1}$. Taking this into account and solving the above equation forward gives

$$
p_{t}=\text { const. }+\sum_{j=0}^{\infty} \Lambda^{j}\left[(1-\Lambda) d_{t+j+1}-r_{t+j}-r p_{t+j+1}\right]
$$

The impulse response of $p_{t}$ to a monetary policy shock $\epsilon_{t}^{M P}$ is then

$$
\frac{\partial p_{t}}{\partial \epsilon_{t}^{M P}}=\sum_{j=0}^{\infty} \Lambda^{j}\left[(1-\Lambda) \frac{\partial d_{t+j+1}}{\partial \epsilon_{t}^{M P}}-\frac{\partial r_{t+j}}{\partial \epsilon_{t}^{M P}}-\frac{\partial r p_{t+j+1}}{\partial \epsilon_{t}^{M P}}\right] .
$$

Hence, equation (F.14) illustrates that a stock price rises if future dividends increase or interest rates and risk premia fall. Whether stock prices of banks or typical nonfinancial firms respond more strongly to changes in interest rates is a quantitative question. Based on the following numerical example, I illustrate that bank equity likely responds more strongly. Specifically, I consider a temporary increase in real short-term rates of 100 basis points that lasts for 2 years, resembling the regressions at the two-year maturity in Sections 4 and 8.

News about future real rates. This change in interest rates impacts stock returns of all firms in the same way through the second term in (F.14). Based on a quarterly calibration with $\Lambda=1 / 1.01$, all stock prices decrease by 1.91 percent due to higher future real rates.

News about future dividends for nonbanks. Stock prices of the typical nonfinancial firm are unlikely to change substantially due to dividends. For example, Paul (2020) estimates that the peak fall in dividends to a 100-basis-points increase in real short-term rates is around 3.53 percent. ${ }^{32}$ Even when exaggerating the fall in dividends by assuming that this peak effect actually occurs for every quarter during which interest rates are elevated, I find that nonfinancial firm stock prices still only fall by around 0.27 percent due to dividends.

News about future dividends for banks. To obtain a quantitative estimate for the response of banks' dividends, I make the following assumptions. Assume that banks run a maturity mismatch and renew a constant fraction of their assets each period. Based on the Call Reports data, I find that the typical maturity/next repricing date of assets is around 4.2 years, which takes into account the repricing due to variable-rate loans. Assuming that banks have an equal share of their portfolio within each maturity bucket, the average asset maturity implies that banks renew 3.1 percent of their assets each quarter. ${ }^{33}$ The typical maturity of bank liabilities is around 0.3 years in the data and I normalize it to one quarter for the following calculations.

Further, I assume that banks obtain a net interest margin $(\overline{N I M})$ of 3.5 p.p. prior to the monetary

\footnotetext{
${ }^{32}$ The estimate is based on a proxy-SVAR for the sample 1988:M11-2007:M12 (see Figure 10 in Paul, 2020). Dividends decline by around 0.6 percent to a 17 basis point increase in the real short-term rate. Scaling up this response to a 100 basis points yields the estimate of 3.53 percent.

${ }^{33}$ This is computed by converting the average asset maturity to quarters $(4.2 \times 4=16.8)$ and obtaining the average renewal based on the converted maturity by $1 /(16.8 \times 2-1)=0.031$.
} 
policy shock that occurs at time $t$, corresponding to the average margin for the estimation sample 1994-2007 (see Figure 3.1). In addition, I posit that all newly acquired assets from $t$ onwards price in the interest rate change and always pay a constant spread of 3.5 p.p. Moreover, banks cannot change the quantity of assets that they issue each period. With these assumptions, only legacy assets are affected-a conservative assumption since banks likely obtain less revenue on newly issued assets following a monetary tightening given reductions in loan quantities. Further, assume that only banks' interest expenses on legacy assets are affected but not their interest income, again a conservative assumption, since the interest income on fixed-rate legacy assets likely declines after a monetary tightening due to higher default rates.

Regarding the pass-through of short-term rates to banks' liability costs, I follow Drechsler, Savov and Schnabl (2017) and assume that the average deposit rate increases by around 46 bp to a 100-bp increase in the federal funds rate. They also show that deposits account for around 79 percent of all banks' liabilities and I assume that the rate on the remaining liabilities changes one-for-one with the policy rate. Banks' cost of funding therefore increases by 57 bp to a 100-bp increase in the federal funds rate, and their interest expenses relative to assets by $51.6 \mathrm{bp}$ with a leverage of 10-to-1. The impact on banks' stock prices through dividends over the eight quarter horizon is then given by

$$
\sum_{j=0}^{8} \Lambda^{j}[(1-\Lambda)(1-j \cdot 0.031)(\log (\widetilde{N I M})-\log (\overline{N I M}))]
$$

where $(1-j \cdot 0.031)$ gives the fraction of remaining legacy assets at time $t+j$ that experience a margin reduction due to the higher interest expenses, where $\overparen{N I M}=\overline{N I M}-0.516$. Taken together, I find that banks' stock prices decrease by 1.05 percent due to lower dividends. Relaxing any of the relatively conservative assumptions above is likely to result in larger responses.

News about risk-premia. Previous papers have estimated that risk premia or excess returns typically account for the largest fraction of the total response of stock prices. For example, Kekre and Lenel (2020) estimate that excess returns account for around 58 percent of the total response of stock returns. Scaling up the conservative estimate of a 2.96 percent drop in bank stock prices and the 2.18 percent for nonbank equity to account for the missing response of risk premia gives estimates of 7.05 percent, and 5.19 percent, respectively, as summarized in Table F.1. Hence, in comparison, the fall in bank stock prices is substantially larger than for the typical nonfinancial firm, resulting in Prediction \#2. The magnitude of the difference between the two responses (36 percent or 1.84 p.p.) is also comparable with the difference between the responses in Tables 4.2 and 5.1 (30 percent or 3.88 p.p.).

Counterfactuals. The theoretical decomposition allows to consider two counterfactual scenarios. First, banks differ from nonbanks not only because of their maturity transformation, but also along other dimensions such as their credit risk exposure and their leverage. While the role of credit risk is muted under the mentioned assumptions, the differential responses of bank and nonbank equity may simply be due to differences in leverage. Column (iii) therefore considers the response 
Table F.1: Stock Price Decompositions.

\begin{tabular}{|c|c|c|c|c|}
\hline Counterfactual & $\begin{array}{c}\text { (i) } \\
\text { Nonbanks }\end{array}$ & $\begin{array}{c}\text { (ii) } \\
\text { Banks }\end{array}$ & $\begin{array}{c}\text { (iii) } \\
\text { Banks } \\
\text { (Leverage) } \\
\end{array}$ & $\begin{array}{c}\text { (iv) } \\
\text { Banks } \\
\text { (Deposit Rates) } \\
\end{array}$ \\
\hline $\begin{array}{c}\text { News about real rates } \\
\text { News about dividends } \\
\text { News about risk premia } \\
\text { Total Response }\end{array}$ & $\begin{array}{l}-1.91 \% \\
-0.27 \% \\
-3.01 \% \\
-5.19 \%\end{array}$ & $\begin{array}{l}-1.91 \% \\
-1.05 \% \\
-4.09 \% \\
-7.05 \%\end{array}$ & $\begin{array}{l}-1.91 \% \\
-0.76 \% \\
-3.69 \% \\
-6.36 \%\end{array}$ & $\begin{array}{l}-1.91 \% \\
-1.95 \% \\
-5.33 \% \\
-9.19 \%\end{array}$ \\
\hline
\end{tabular}

Notes: The table shows the numerical results for the stock price decomposition. Column (i) collects the results for nonbank equity and columns (ii)-(iv) for bank equity. Column (iii) assumes that banks have a liabilities-to-assets ratio similar to nonbanks $(2 / 3)$. Column (iv) assumes that banks' cost of funding moves one-for-one with the policy rate.

of bank stock prices under the assumption that banks have a similar leverage as nonbanks. While the response is lower than in column (ii), it is still around 23 percent larger than the response of nonbank equity, suggesting that banks' maturity mismatch accounts for the differential responses in the data. Second, to obtain an upper bound on the role of banks' maturity mismatch, column (iv) considers the "textbook view" that banks are strongly exposed to interest rate risk as deposit rates move one-for-one with policy rates. Under this alternative scenario, bank equity responds by around 77 percent or 4 p.p. more than nonbank equity (9.19 vs. 5.19 percent). This difference is larger compared with the empirical estimates but it is not an outsized value, indicating that the estimated differences already reveal a sizeable interest rate exposure of banks.

Banks' maturity profile. Continuing with the example above, equation (F.15) illustrates that the stock price response directly depends on the ratio of banks' maturity mismatch. A bank with a larger maturity mismatch experiences a sharper fall in its equity price, all else equal. That is because it takes longer until the asset portfolio of such a bank is renewed and all newly acquired assets price in the interest rate change. Intuitively, such a bank is locked in for longer and experiences a sharper fall of its net interest income on legacy assets. 


\section{G Robustness for Banks' Income Responses}
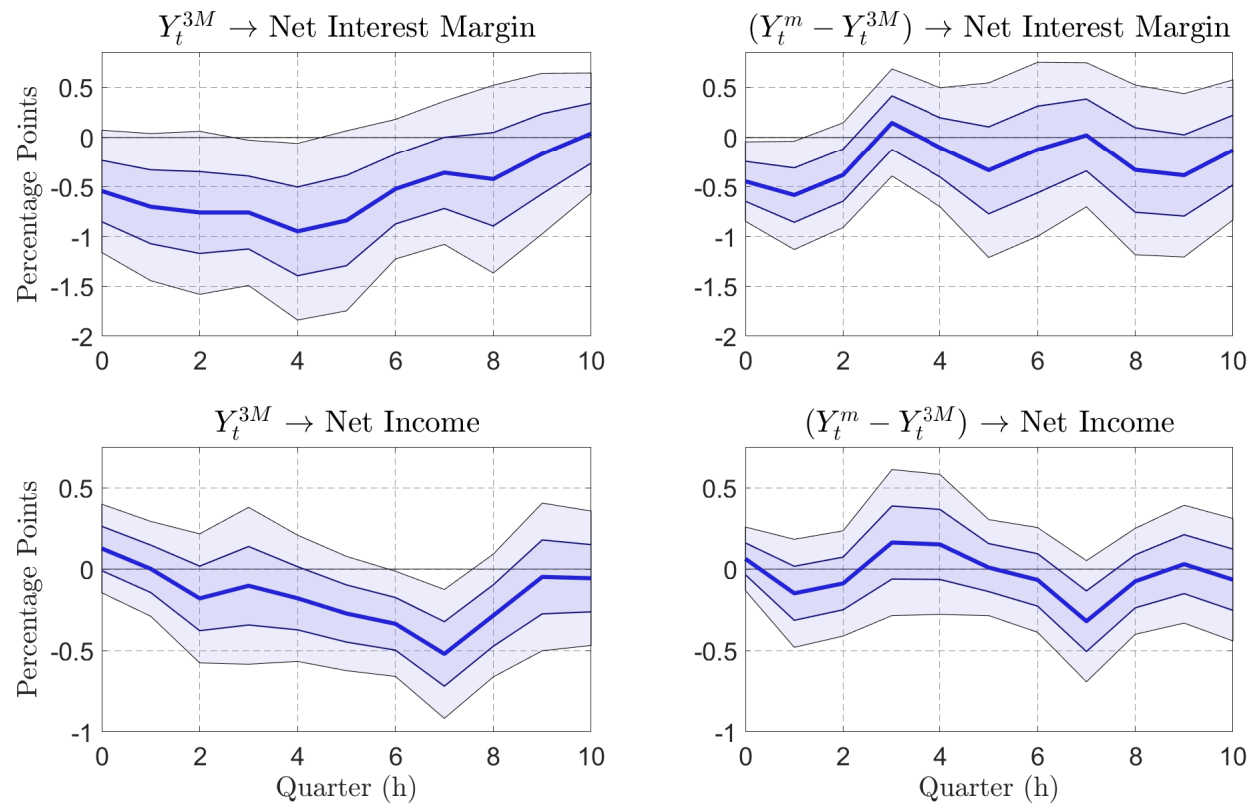

Figure G.1: Impulse Responses of Bank Profit Margins - Yield Changes.

Notes: Estimation results for Margin $_{t+h}-\operatorname{Margin}_{t-1}=\alpha^{h}+\beta_{1}^{h} Y_{t}^{3 M}+\beta_{2}^{h}\left(Y_{t}^{m}-Y_{t}^{3 M}\right)+u_{t}^{h}$, where $Y_{t}^{m}$ denotes the quarterly series for government bond yield changes obtained from the individual surprises on FOMC days for $m=5$-year. Sample: 1994:Q1-2007:Q4, excluding FOMC announcement on 9/17/2001. 95 and 68 percent confidence bands shown, using Newey and West (1987) standard errors.
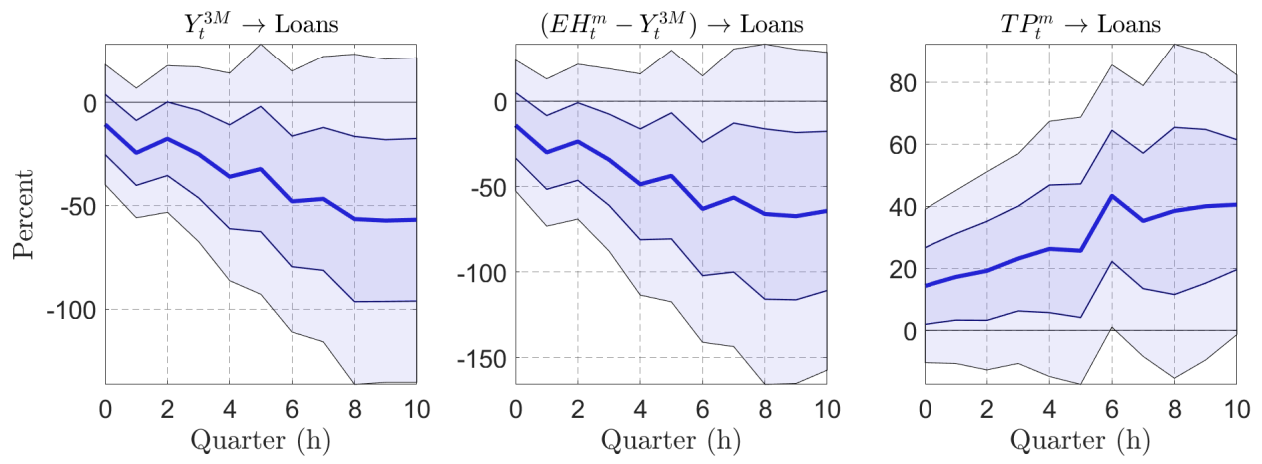

Figure G.2: Impulse Responses of Bank Loans.

Notes: Estimation results for regression (7.1), where the dependent variable is the percentage change in bank loans from $t-1$ to $t+h$. Banks loans are sum of domestic loans and leases across all banks using data from the Call Reports. Sample: 1994:Q1-2007:Q4, excluding FOMC announcement on 9/17/2001. 95 and 68 percent confidence bands shown, using Newey and West (1987) standard errors. 


\section{H Data for Cross-Sectional Analysis}

Y-9C Filings. The data are collected from the Board of Governors' National Information Center database. Table H.1 lists the variables that are used. Given these variable definitions, the one-year income gap is computed as

$$
\text { Income gap }=\frac{(\text { bhck } 3197-(\text { bhck } 3296+\text { bhck } 3298+\text { bhck } 3408+\text { bhck } 3409)}{\text { bhck } 2170} .
$$

Table H.1: Variables from Y-9C filings.

\begin{tabular}{|c|l|}
\hline Variable Code & Variable Label \\
\hline \hline bhck 2170 & Total Assets \\
\hline bhck 3197 & Earning assets that reprice or mature within one year \\
\hline bhck 3296 & Interest-bearing deposit liabilities that reprice or mature within one year \\
\hline bhck 3298 & Long-term debt that reprices within one year \\
\hline bhck 3408 & Variable-rate preferred stock \\
\hline bhck 3409 & Long-term debt that matures within one year \\
\hline
\end{tabular}

Notes: The table lists the variables from the FR Y-9C filings that are used to compute the income gap as defined in (H.1). The FR Y-9C forms can be found at the websites of the Federal Reserve.

Call Reports. The data are collected from the Board of Governors' National Information Center database using the FFEIC 031 and the FFEIC 041 forms. Tables H.2-H.5 list the variables that are used.

Aggregation and Sample Restrictions. To aggregate bank subsidiaries to the BHC-level, I use a broad measure of ownership that allows for indirect connections and does not restrict the connection to a minimum percentage of equity owned. I checked and confirmed the robustness of my results to a more restrictive definition that only considers direct ownership with a minimum of 50 percent equity owned. To ensure that the aggregation gives a complete representation of the BHC's balance sheet, I further restrict the sample to observations that cover at least 95 percent of the BHC's total assets based on the Y-9C data. Following English, van den Heuvel and Zakrajšsek (2018), bank subsidiaries are also required to have loan-to-asset shares of 25 percent or larger. Apart from those restrictions, no further observations are excluded but I check the robustness of the results by dropping outliers as described in Appendix G.

Variables. To ensure that the results are not driven or influenced by the behavior of foreign subsidiaries, I focus on domestic data only. The associated variable codes in the Call Reports start with "RCON" for balance sheet items. 
Table H.2: Balance Sheet Variables from Call Reports.

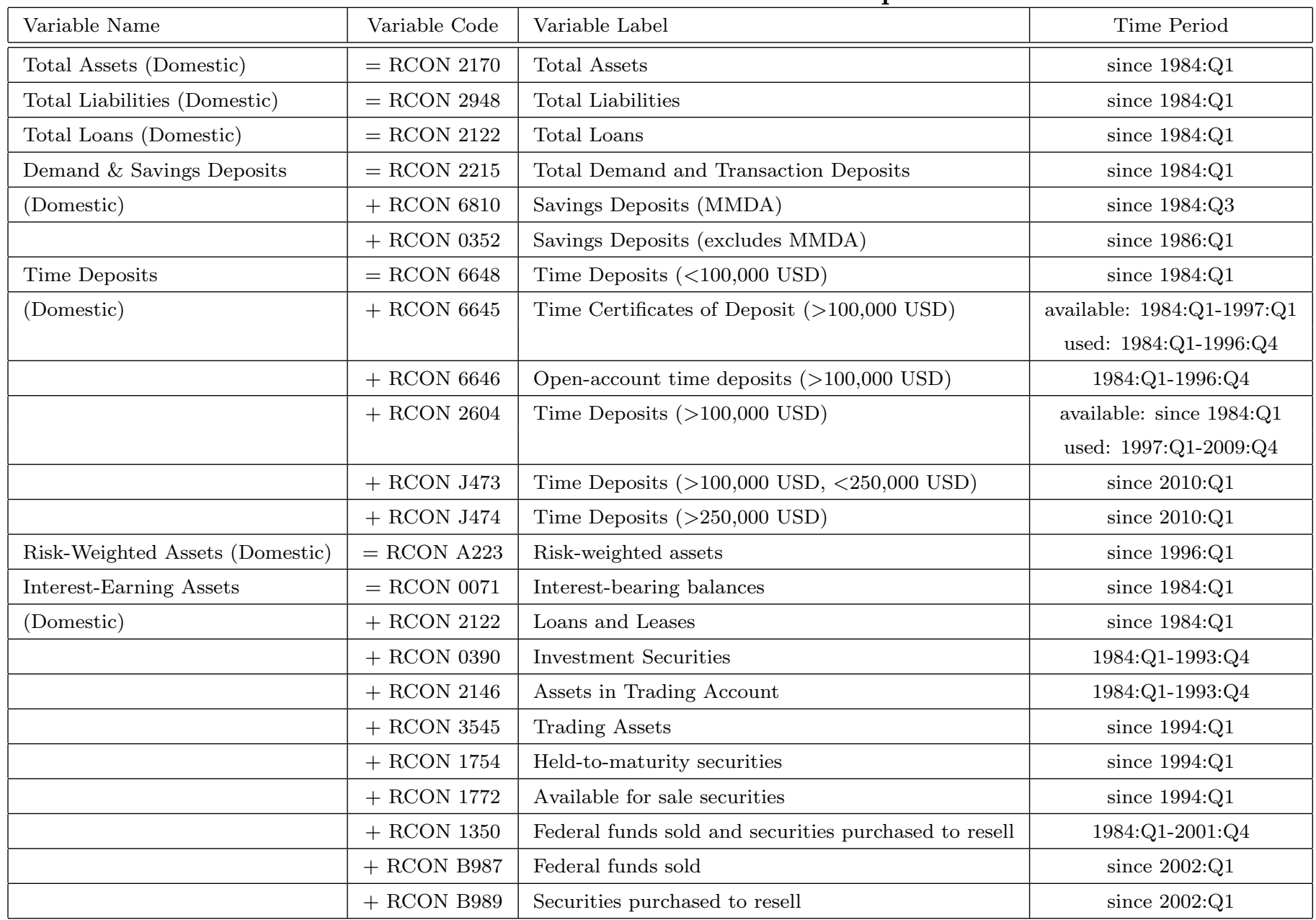

Notes: The table lists the balance sheet variables from the Call Reports that are used. "MMDA" stands for money market deposit accounts. Historical versions of the FFEIC 031 and the FFEIC 041 reporting forms can be found at:

https://www.ffiec.gov/forms031.htm https://www.ffiec.gov/forms041.htm 
Table H.3: Assets: Maturity / Repricing Data from Call Reports.

\begin{tabular}{|c|c|c|c|}
\hline Variable Name & Variable Code & Maturity / Repricing Range (Months) & Weighting (Months) \\
\hline Debt Securities (Domestic) & RCON A549 & $<3$ & 1.5 \\
\hline \multirow[t]{5}{*}{ (Government Agencies) } & RCON A550 & $3-12$ & 7.5 \\
\hline & RCON A551 & $12-36$ & 24 \\
\hline & RCON A552 & $36-60$ & 48 \\
\hline & RCON A553 & $60-180$ & 120 \\
\hline & RCON A554 & $>180$ & 240 \\
\hline Debt Securities (Domestic) & RCON A555 & $<3$ & 1.5 \\
\hline \multirow[t]{5}{*}{ (Mortgage Pass-through) } & RCON A556 & $3-12$ & 7.5 \\
\hline & RCON A557 & $12-36$ & 24 \\
\hline & RCON A558 & $36-60$ & 48 \\
\hline & RCON A559 & $60-180$ & 120 \\
\hline & RCON A560 & $>180$ & 240 \\
\hline Debt Securities (Domestic) & RCON A561 & $<36$ & 18 \\
\hline (Other Mortgage-Backed Securities) & RCON A562 & $>36$ & 60 \\
\hline Loans and Leases & RCON A564 & $<3$ & 1.5 \\
\hline \multirow[t]{5}{*}{ (Closed-end) } & RCON A565 & $3-12$ & 7.5 \\
\hline & RCON A566 & $12-36$ & 24 \\
\hline & RCON A567 & $36-60$ & 48 \\
\hline & RCON A568 & $60-180$ & 120 \\
\hline & RCON A569 & $>180$ & 240 \\
\hline Loans and Leases & RCON A570 & $<3$ & 1.5 \\
\hline \multirow[t]{5}{*}{ (Excluding closed-end) } & RCON A571 & $3-12$ & 7.5 \\
\hline & RCON A572 & $12-36$ & 24 \\
\hline & RCON A573 & $36-60$ & 48 \\
\hline & RCON A574 & $60-180$ & 120 \\
\hline & RCON A575 & $>180$ & 240 \\
\hline
\end{tabular}

Notes: The table lists the variables from the Call Reports that are used to compute the maturity gap. The data are available since 1997:Q2. Historical versions of the FFEIC 031 and the FFEIC 041 reporting forms can be found at: https://www.ffiec.gov/forms031.htm https://www.ffiec.gov/forms041.htm 
Table H.4: Liabilities: Maturity / Repricing Data from Call Reports.

\begin{tabular}{|l|c|c|c|c|}
\hline Variable Name & Variable Code & Maturity / Repricing Range (Months) & Weighting (Months) & Time Period \\
\hline \hline Time Deposits $<100 \mathrm{k}$ & RCON A579 & $<3$ & 1.5 & $1997: \mathrm{Q} 2-2016: \mathrm{Q} 4$ \\
\hline & RCON A580 & $3-12$ & 7.5 & 1997:Q2-2016:Q4 \\
\hline & RCON A581 & $12-36$ & 24 & $1997: \mathrm{Q} 2-2016: \mathrm{Q} 4$ \\
\hline & RCON A582 & $>36$ & 60 & $1997: \mathrm{Q} 2-2016: \mathrm{Q} 4$ \\
\hline Time Deposits $>100 \mathrm{k}$ & RCON A584 & $<3$ & 1.5 & $1997: \mathrm{Q} 2-2016: \mathrm{Q} 4$ \\
\hline & RCON A585 & $3-12$ & 24 & $1997: \mathrm{Q} 2-2016: \mathrm{Q} 4$ \\
\hline & RCON A586 & $12-36$ & 60 & $1997: \mathrm{Q} 2-2016: \mathrm{Q} 4$ \\
\hline & RCON A587 & $>36$ & 1.5 & $1997: \mathrm{Q} 2-2016: \mathrm{Q} 4$ \\
\hline Time Deposits $<250 \mathrm{k}$ & RCON HK07 & $<3$ & 24 & since 2017:Q1 \\
\hline & RCON HK08 & $3-12$ & since 2017:Q1 \\
\hline & RCON HK09 & $12-36$ & since 2017:Q1 \\
\hline & RCON HK10 & $>36$ & 1.5 & since 2017:Q1 \\
\hline Time Deposits $>250 \mathrm{k}$ & RCON HK12 & $<3$ & since 2017:Q1 \\
\hline & RCON HK13 & $3-12$ & 24 & since 2017:Q1 \\
\hline & RCON HK14 & $12-36$ & 60 & since 2017:Q1 \\
\hline & RCON HK15 & $>36$ & since 2017:Q1 \\
\hline
\end{tabular}

Notes: The table lists the variables from the Call Reports that are used to compute the maturity gap. Historical versions of the FFEIC 031 and the FFEIC 041 reporting forms can be found at: https://www.ffiec.gov/forms031.htm https://www.ffiec.gov/forms041.htm 
Table H.5: Variables from Income Statement in Call Reports.

\begin{tabular}{|c|c|c|c|}
\hline Variable Name & Variable Code & Variable Label & Time Period \\
\hline Net Income & $=$ RIAD 4340 & Net Income & since 1984:Q1 \\
\hline \multirow[t]{2}{*}{ (Domestic) } & - RIAD C914 & Net Income (Foreign) & since 2006:Q1 \\
\hline & - RIAD 4341 & Net Income (Foreign) & 1984:Q1-2005:Q4 \\
\hline Net Interest Margin & $=$ RIAD 4074 & Net Interest Income & since 1984:Q1 \\
\hline \multirow[t]{4}{*}{ (Domestic) } & - RIAD C899 & Interest Income (Foreign) & since 2006:Q1 \\
\hline & + RIAD C900 & Interest Expenses (Foreign) & since 2006:Q1 \\
\hline & - RIAD B525 & Net Interest Income (Foreign) & 2001:Q1-2005:Q4 \\
\hline & - RIAD 4842 & Net Interest Income (Foreign) & 1984:Q1-2000:Q4 \\
\hline Net Noninterest Income & $=\mathrm{RIAD} 4079$ & Total Noninterest Income & since 1984:Q1 \\
\hline \multirow[t]{8}{*}{ (Domestic) } & - RIAD 4093 & Total Noninterest Expenses & since 1984:Q1 \\
\hline & - RIAD C902 & Noninterest Income (Foreign) & since 2006:Q1 \\
\hline & - RIAD C903 & Noninterest Income (Foreign) & since 2006:Q1 \\
\hline & - RIAD C904 & Noninterest Income (Foreign) & since 2006:Q1 \\
\hline & - RIAD C905 & Noninterest Income (Foreign) & since 2006:Q1 \\
\hline & + RIAD C907 & Noninterest Expenses (Foreign) & since 2006:Q1 \\
\hline & - RIAD 4097 & Noninterest Income (Foreign) & 1984:Q1-2005:Q4 \\
\hline & + RIAD 4239 & Noninterest Expenses (Foreign) & 1984:Q1-2005:Q4 \\
\hline Provision for Loan Losses & $=-$ RIAD 4230 & Provision for Loan and Lease Losses & $\begin{array}{l}\text { available: since 1984:Q1 } \\
\text { used: 1984:Q1-2018:Q4 }\end{array}$ \\
\hline \multirow[t]{4}{*}{ (Domestic) } & - RIAD JJ33 & Provision for Loan and Lease Losses & since 2019:Q1 \\
\hline & + RIAD KW02 & Provision for Loan and Lease Losses (Foreign) & since 2019:Q1 \\
\hline & + RIAD C901 & Provision for Loan and Lease Losses (Foreign) & 2006:Q1-2018:Q4 \\
\hline & + RIAD 4235 & Provision for Loan and Lease Losses (Foreign) & 1984:Q1-2005:Q4 \\
\hline
\end{tabular}

Notes: The table lists the variables from the Income Statement in the Call Reports that are used. Historical versions of the FFEIC 031 and the FFEIC 041 reporting forms can be found at:

https://www.ffiec.gov/forms031.htm

https://www.ffiec.gov/forms041.htm 


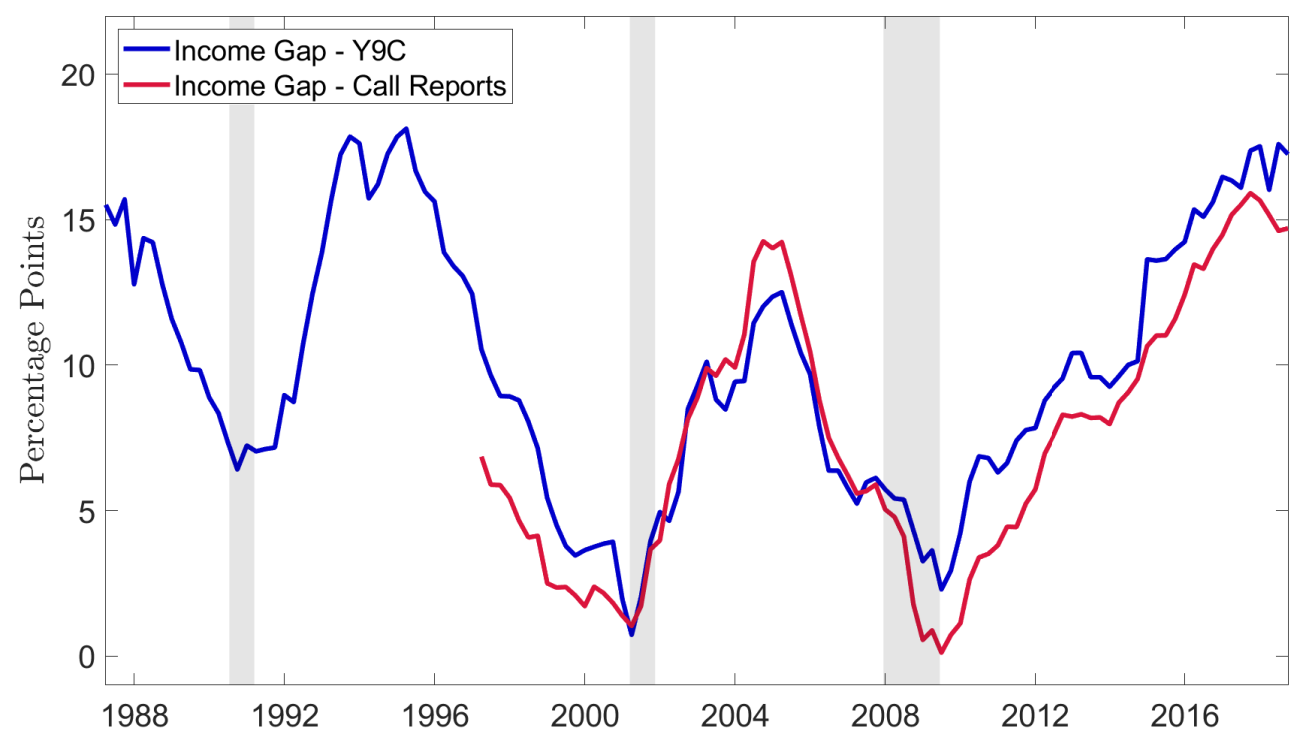

Figure H.1: Income Gap.

Notes: The graph shows the evolution of the average income gap across banks based on Y-9C and Call Report data.

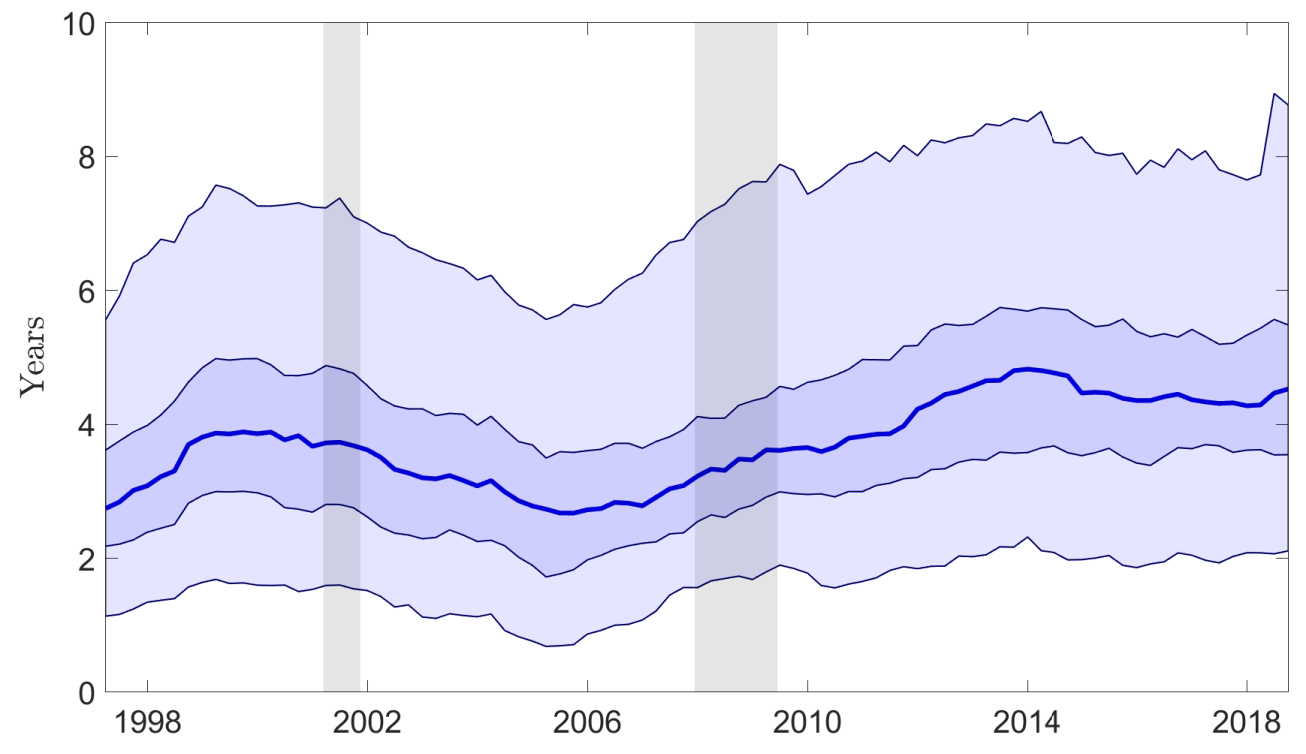

Figure H.2: Maturity Gap.

Notes: The graph shows the evolution of the maturity gap for the median, the 33rd and the 66th percentiles, and the 10th and the 90th percentiles across the distribution of banks at each point in time. 
Table H.6: Correlations of Measures of Maturity Mismatch.

\begin{tabular}{c|c|cccc}
\cline { 2 - 6 } & Y9C & \multicolumn{4}{|c}{ Call Reports } \\
\cline { 2 - 6 } & IG & IG $(<1$ Y $)$ & IG $(1 Y-3 Y)$ & IG $(>3 Y)$ & MG \\
\hline IG & 1 & & & & \\
IG $(<1 Y)$ & 0.43 & 1 & & & \\
IG $(1 Y-3 Y)$ & -0.07 & 0.19 & 1 & & \\
IG $(>3 Y)$ & -0.41 & -0.16 & 0.02 & 1 & \\
MG & -0.17 & -0.54 & -0.39 & 0.38 & 1 \\
\hline
\end{tabular}

Notes: The table reports the correlation coefficients between various measures of maturity mismatch. "IG" denotes the income gap based on Y-9C data as defined in equation (8.1). "IG(<1Y)" is the equivalent income gap based on data from the Call Reports. "IG(1Y-3Y)" is the income gap for assets and liabilities that reprice between one and three years and "IG( $>3 \mathrm{Y})$ " after three years based on data from the Call Reports. "MG" denotes the maturity gap as defined in equation (8.2).

Table H.7: Summary Statistics.

\begin{tabular}{lccccc}
\hline & Mean & SD & P5 & Median & P95 \\
\hline & & & & & \\
$\Delta Y_{t}^{3 M}$ & -0.012 & 0.065 & -0.14 & -0.01 & 0.09 \\
$\Delta Y_{t}^{2}$ & -0.005 & 0.07 & -0.131 & -0.001 & 0.108 \\
$\Delta Y_{t}^{5}$ & -0.003 & 0.069 & -0.116 & 0.002 & 0.119 \\
$\Delta Y_{t}^{10}$ & -0.002 & 0.058 & -0.105 & 0 & 0.089 \\
$\Delta E H_{t}^{2}$ & -0.006 & 0.043 & -0.084 & -0.001 & 0.07 \\
$\Delta E H_{t}^{5}$ & -0.004 & 0.03 & -0.062 & -0.002 & 0.041 \\
$\Delta E H_{t}^{10}$ & -0.003 & 0.023 & -0.047 & -0.003 & 0.034 \\
$\Delta T P_{t}^{2}$ & 0.001 & 0.033 & -0.055 & 0.002 & 0.06 \\
$\Delta T P_{t}^{5}$ & 0.001 & 0.042 & -0.072 & 0.002 & 0.068 \\
$\Delta T P_{t}^{10}$ & 0.001 & 0.042 & -0.065 & 0.002 & 0.063 \\
$M G_{i, t}$ & 3.773 & 2.308 & 0.896 & 3.32 & 8.145 \\
$I G_{i, t}$ & 0.099 & 0.195 & -0.189 & 0.092 & 0.402 \\
& & & & & \\
\hline
\end{tabular}

Notes: Summary statistics for regressors in regressions (4.1), (4.2), (8.3), and (8.4) for the sample of FOMC announcement days 1994:M1-2007:M12, excluding 9/17/2001 (118 meetings).

\section{Additional Evidence for Bank-Level Stock Returns}

In this appendix, I collect further evidence and robustness checks supporting the findings in Section 8.2. First, I compare the results in Tables 8.1 and 8.2 to the ones by English, van den Heuvel and Zakrajšek (2018). To this end, I estimate a simplified version of equation (5) in English, van den 
Heuvel and Zakrajšek (2018),

$$
\begin{aligned}
R_{i, t} & =\alpha_{i}+\beta_{1} \Delta Y_{t}^{3 M}+\beta_{2} \Delta\left(Y_{t}^{m}-Y_{t}^{3 M}\right)+\beta_{3} \Delta Y_{t}^{3 M} \cdot \operatorname{Gap}_{i, t} \\
& +\beta_{4} \Delta\left(Y_{t}^{m}-Y_{t}^{3 M}\right) \cdot \operatorname{Gap}_{i, t}+\beta_{5} \operatorname{Gap}_{i, t}+u_{i, t}
\end{aligned}
$$

where $G a p_{i, t}$ denotes either the income gap or the maturity gap of bank $i$ in the quarter before an FOMC meeting. Importantly, regression (I.1) does not distinguish between changes in expected short-term rates and changes in term premia.

The results are shown in Tables I.4 and I.5. In line with English, van den Heuvel and Zakrajšek (2018), the estimated coefficients $\hat{\beta}_{3}$ and $\hat{\beta}_{4}$ in (I.1) are negative for the income gap and positive for the maturity gap. These results suggest that banks that engage more heavily in maturity transformation benefit relatively more from a higher level and slope of the yield curve. Next, I disentangle changes in long-term yields into changes in expected short-term rates and changes in term premia, estimating

$$
\begin{aligned}
R_{i, t} & =\alpha_{i}+\beta_{1} \Delta Y_{t}^{3 M}+\beta_{2} \Delta\left(E H_{t}^{m}-Y_{t}^{3 M}\right)+\beta_{3} \Delta T P_{t}^{m} \\
& +\beta_{4} \Delta Y_{t}^{3 M} \cdot G_{a p}, t+\beta_{5} \Delta\left(E H_{t}^{m}-Y_{t}^{3 M}\right) \cdot G a p_{i, t}+\beta_{6} \Delta T P_{t}^{m} \cdot G_{a p}+,+\beta_{7} G_{a p}+, u_{i, t}
\end{aligned}
$$

which allows for the additional interactions $\Delta Y_{t}^{3 M} \cdot \operatorname{Gap}_{i, t}$ and $\Delta\left(E H_{t}^{m}-Y_{t}^{3 M}\right) \cdot$ Gap $_{i, t}$ compared with the baseline regressions in (8.3) and (8.4). For the 2-year maturity, Tables I.6 and I.7 show the results for regression (I.3) and two additional versions that either omit $\Delta Y_{t}^{3 M} \cdot G_{a p}$ or $\Delta\left(E H_{t}^{m}-Y_{t}^{3 M}\right) \cdot \operatorname{Gap}_{i, t}$.

For the income gap (see Table I.6), out of the interaction variables, only the one with respect to the term premium is statistically significant (and negative). In comparison with regression (I.1), it is therefore the term premium and not the change in expected short-term rates that explains the negative coefficient on $\Delta\left(Y_{t}^{m}-Y_{t}^{3 M}\right) \cdot I G_{i, t}$ in Table I.4. For the maturity gap (see Table I.7), the coefficient on $\Delta Y_{t}^{3 M} \cdot M G_{i, t}$ is negative, while the one associated with $\Delta\left(E H_{t}^{m}-Y_{t}^{3 M}\right) \cdot M G_{i, t}$ is positive. In comparison with (I.1), the interaction $\Delta\left(Y_{t}^{m}-Y_{t}^{3 M}\right) \cdot M G_{i, t}$ therefore masks two opposing effects. On one hand, banks with a larger maturity gap experience a relatively higher stock return when the slope of the yield curve steepens, if this change is driven by a higher term premium. On the other hand, if the steeper yield curve is actually due to an increase in expected future short-term rates, banks with a larger maturity gap see a relatively lower stock return. Intuitively, such banks are locked in for longer when their future cost of funding increases. On net, the term premium effect dominates in regression (I.1), providing an additional explanation for the findings in English, van den Heuvel and Zakrajšek (2018).

Second, the definition of the maturity gap in (8.2) slightly deviates from the one by English, van den Heuvel and Zakrajšek (2018). In comparison, English, van den Heuvel and Zakrajšek 
(2018) define the measured maturity gap as

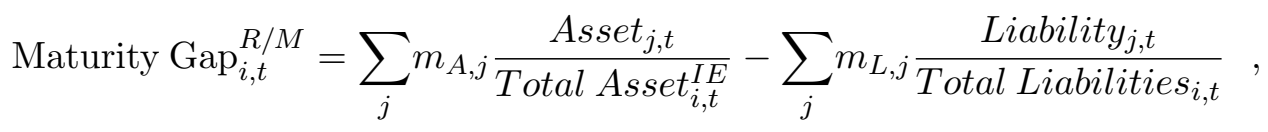

where the difference from equation (8.2) lies in the denominators. Equation (8.2) uses all assets and liabilities for which maturity data are available. In contrast, equation (I.4) divides by total interest-earning assets and total liabilities, respectively. The two definitions differ if the maturity data coverage is incomplete. English, van den Heuvel and Zakrajšek (2018) note that the "true" maturity gap is given by

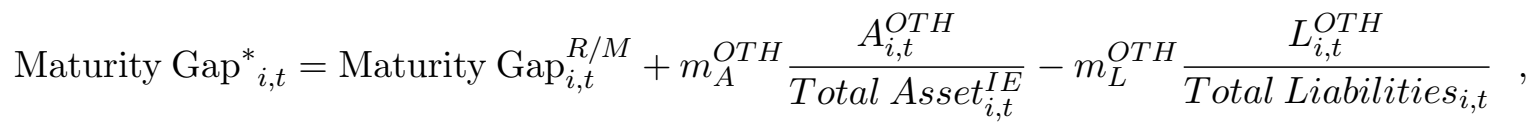

where $A_{i, t}^{O T H}$ and $L_{i, t}^{O T H}$ denote the differences between total interest-earning assets or liabilities, and their respective coverage in the maturity data. The parameters $m_{A}^{O T H}$ and $m_{L}^{O T H}$ are the associated average maturities, which are assumed to be constant over time.

English, van den Heuvel and Zakrajšek (2018) note that these parameters can be estimated by including the shares of uncovered assets and liabilities into the estimations. I follow this approach to approximate the true maturity gap in equation (I.5) and extend regression (8.4) to

$$
\begin{aligned}
R_{i, t} & =\alpha_{i}+\beta_{1} \Delta Y_{t}^{3 M}+\beta_{2}\left(\Delta E H_{t}^{m}-\Delta Y_{t}^{3 M}\right)+\beta_{3} \Delta T P_{t}^{m}+\beta_{4} \Delta T P_{t}^{m} \cdot M G_{i, t}^{R / M} \\
& +\beta_{5} \Delta T P_{t}^{m} \cdot \frac{A_{i, t}^{O T H}}{\text { Total Assets }{ }_{i, t}^{I E}}+\beta_{6} \Delta T P_{t}^{m} \cdot \frac{L_{i, t}^{\text {OTH }}}{\text { Total Liabilities } i, t}+u_{i, t} .
\end{aligned}
$$

where $M G_{i, t}^{R / M}$ denotes the measured maturity gap in equation (I.4). As noted by English, van den Heuvel and Zakrajšek (2018), the average maturity for the shares of other assets and liabilities, denoted $m_{A}^{O T H}$ and $m_{L}^{O T H}$ in equation (I.5), can then be obtained by $\hat{m}_{A}^{O T H}=\hat{\beta}_{5} / \hat{\beta}_{4}$ and $\hat{m}_{A}^{O T H}=\hat{\beta}_{6} / \hat{\beta}_{4}$, respectively. Based on these estimates, I compute the "true" maturity gap as in equation (I.5) and reestimate regression (8.4) using the new measure for the maturity gap. The results are shown in Table I.8. Compared with the findings in Table 8.2, the coefficients associated with the interaction between the term premium and the maturity gap are estimated to be even more positive. For example, for the 2-year maturity, the estimated coefficient $\hat{\beta}_{4}$ roughly doubles. Moreover, across the various bond maturities, the statistical significance also improves. The associated p-values are all below 0.01 .

Third, instead of the term premia estimates by Kim and Wright (2005), I use the bootstrap estimates based on the model by Adrian, Crump and Moench (2013) and reestimate regressions (8.3) and (8.4) (see Appendix D for the procedure). The results are shown in Tables I.9 and I.10. The estimated signs of the coefficients are largely unchanged. However, the absolute magnitudes are smaller and the statistical significance is lower, though the coefficients associated with the interaction term for the income gap in equation (8.3) remain statistically significant at standard confidence 
levels for various maturities. Again, a potential explanation for any difference compared with the results in Section 8.2 is the use of survey data in the model by Kim and Wright (2005), which aligns the short-term rates and term premia estimates with financial market expectations.

Fourth, I exclude several FOMC announcements associated with unscheduled meetings as listed in Section 4.1. The results are shown in Tables I.11 and I.12. While the estimated coefficients $\hat{\beta}_{1}$, $\hat{\beta}_{2}$, and $\hat{\beta}_{3}$ in equations (8.3) and (8.4) tend to be of smaller absolute magnitude and generally of lower statistical significance, the ones associated with the gap variables, $\hat{\beta}_{4}$, in fact remain similar in magnitude and statistical significance.

In unreported estimations, I find that the results in Tables 8.1 and 8.2 remain much the same when dropping various outliers: (i) observations below the 1st and above the 99th percentile in the sample distributions of the income gap, the maturity gap, or market leverage; (ii) observations with extreme asset growth of more than 20 percent in absolute terms from one quarter to the next; and (iii) banks with less than 7 years of consecutive data.

Table I.1: Response of Bank-Level Stock Returns to Yield Surprises.

\begin{tabular}{lccc}
\hline $\mathrm{m}=$ & 2-year & 5-year & 10-year \\
\hline$\Delta Y_{t}^{3 M}$ & -1.53 & -0.88 & -0.23 \\
& $(1.78)$ & $(1.86)$ & $(2.09)$ \\
$\Delta\left(Y_{t}^{m}-Y_{t}^{3 M}\right)$ & 0.49 & 1.26 & 1.80 \\
& $(1.69)$ & $(1.73)$ & $(1.91)$ \\
& & & \\
\hline$R^{2}$ & 0.03 & 0.03 & 0.03 \\
$N$ & 46,174 & 46,174 & 46,174 \\
Banks & 943 & 943 & 943 \\
Meetings & 118 & 118 & 118 \\
\hline
\end{tabular}

Notes: Estimation results for $R_{i, t}=\alpha_{i}+\beta_{1} \Delta Y_{t}^{3 M}+\beta_{2}\left(\Delta Y_{t}^{m}-\Delta Y_{t}^{3 M}\right)+u_{i, t}$, where $\alpha_{i}$ denotes a bank-specific fixed effect and $R_{i, t}$ is given by a bank-specific stock return. Sample: 1994:M12007:M12, excluding FOMC announcement on 9/17/2001. Standard errors in parentheses are two-way clustered by banks and meetings. ${ }^{* * *} p<0.01,{ }^{* *} p<0.05,{ }^{*} p<0.1$. 
Table I.2: Response of Bank-Level Stock Returns to Level, Slope, and Term Premia Surprises.

\begin{tabular}{lccc}
\hline $\mathrm{m}=$ & 2-year & 5 -year & 10 -year \\
\hline \multirow{2}{*}{$\Delta Y_{t}^{3 M}$} & $-7.52^{* *}$ & $-13.12^{* *}$ & $-16.93^{*}$ \\
& $(3.38)$ & $(6.45)$ & $(9.11)$ \\
$\Delta\left(E H_{t}^{m}-Y_{t}^{3 M}\right)$ & $-8.76^{* *}$ & $-14.67^{*}$ & $-18.40^{*}$ \\
& $(4.31)$ & $(7.75)$ & $(10.47)$ \\
$\Delta T P_{t}^{m}$ & $10.08^{* *}$ & $10.55^{* *}$ & $11.08^{* *}$ \\
& $(4.70)$ & $(4.77)$ & $(5.13)$ \\
& & & \\
\hline$R^{2}$ & 0.04 & 0.04 & 0.04 \\
$N$ & 46,174 & 46,174 & 46,174 \\
Banks & 943 & 943 & 943 \\
Meetings & 118 & 118 & 118 \\
\hline
\end{tabular}

Notes: Estimation results for $R_{i, t}=\alpha_{i}+\beta_{1} \Delta Y_{t}^{3 M}+\beta_{2}\left(\Delta E H_{t}^{m}-\Delta Y_{t}^{3 M}\right)+\beta_{3} \Delta T P_{t}^{m}+u_{i, t}$, where $\alpha_{i}$ denotes a bank-specific fixed effect, $R_{i, t}$ is given by a bank-specific stock return, and $\Delta E H_{t}^{m}$ and $\Delta T P_{t}^{m}$ are based on estimates from Kim and Wright (2005). Sample: 1994:M1-2007:M12, excluding FOMC announcement on $9 / 17 / 2001$. Standard errors in parentheses are two-way clustered by banks and meetings. ${ }^{* * *} p<0.01,{ }^{* *} p<0.05,{ }^{*} p<0.1$.

Table I.3: Response of Bank-Level Stock Returns - Top 10 Percent.

\begin{tabular}{lccc}
\hline $\mathrm{m}=$ & 2-year & 5-year & 10 -year \\
\hline \multirow{2}{*}{$\Delta Y_{t}^{3 M}$} & $-17.73^{* *}$ & $-32.36^{* *}$ & $-42.35^{* *}$ \\
& $(6.87)$ & $(13.20)$ & $(18.96)$ \\
$\Delta\left(E H_{t}^{m}-Y_{t}^{3 M}\right)$ & $-22.46^{* *}$ & $-37.81^{* *}$ & $-47.46^{* *}$ \\
& $(8.82)$ & $(16.07)$ & $(22.04)$ \\
$\Delta T P_{t}^{m}$ & $22.82^{* *}$ & $24.70^{* *}$ & $26.26^{* *}$ \\
& $(9.89)$ & $(9.96)$ & $(10.69)$ \\
& & & \\
\hline$R^{2}$ & 0.07 & 0.07 & 0.07 \\
$N$ & 4,617 & 4,617 & 4,617 \\
Banks & 82 & 82 & 82 \\
Meetings & 118 & 118 & 118 \\
\hline
\end{tabular}

Notes: Estimation results for $R_{i, t}=\alpha_{i}+\beta_{1} \Delta Y_{t}^{3 M}+\beta_{2}\left(\Delta E H_{t}^{m}-\Delta Y_{t}^{3 M}\right)+\beta_{3} \Delta T P_{t}^{m}+u_{i, t}$, where $\alpha_{i}$ denotes a bank-specific fixed effect, $R_{i, t}$ is given by a bank-specific stock return, and $\Delta E H_{t}^{m}$ and $\Delta T P_{t}^{m}$ are based on estimates from Kim and Wright (2005). Sample: 1994:M1-2007:M12, excluding FOMC announcement on $9 / 17 / 2001$, restricting the pooled sample to the top 10 percent based on market capitalization. Standard errors in parentheses are two-way clustered by banks and meetings. ${ }^{* * *} p<0.01,{ }^{* *} p<0.05,{ }^{*} p<0.1$. 
Table I.4: Response of Stock Returns - Term Spread (Income Gap).

\begin{tabular}{lccc}
\hline $\mathrm{m}=$ & 2-year & 5 -year & 10-year \\
\hline$\Delta Y_{t}^{3 M}$ & -1.44 & -0.77 & -0.03 \\
& $(1.70)$ & $(1.76)$ & $(1.94)$ \\
$\Delta\left(Y_{t}^{m}-Y_{t}^{3 M}\right)$ & 0.69 & 1.40 & 2.02 \\
& $(1.62)$ & $(1.61)$ & $(1.77)$ \\
$\Delta Y_{t}^{3 M} \cdot I G_{i, t}$ & -0.28 & -0.53 & $-0.81^{*}$ \\
& $(0.38)$ & $(0.42)$ & $(0.48)$ \\
$\Delta\left(Y_{t}^{m}-Y_{t}^{3 M}\right) \cdot I G_{i, t}$ & $-0.64^{* *}$ & $-0.80^{* *}$ & $-1.09^{* * *}$ \\
& $(0.31)$ & $(0.31)$ & $(0.38)$ \\
& & & \\
\hline$R^{2}$ & 0.04 & 0.04 & 0.04 \\
$N$ & 34,231 & 34,231 & 34,231 \\
Banks & 852 & 852 & 852 \\
Meetings & 118 & 118 & 118 \\
\hline
\end{tabular}

Notes: Estimation results for $R_{i, t}=\alpha_{i}+\beta_{1} \Delta Y_{t}^{3 M}+\beta_{2}\left(\Delta Y_{t}^{m}-\Delta Y_{t}^{3 M}\right)+\beta_{3} \Delta Y_{t}^{3 M} \cdot I G_{i, t}+$ $\beta_{4}\left(\Delta Y_{t}^{m}-\Delta Y_{t}^{3 M}\right) \cdot I G_{i, t}+\beta_{5} I G_{i, t}+u_{i, t}$, where $\Delta Y_{t}^{m}$ are based on Gürkaynak, Sack and Wright (2007). $I G_{i, t}$ is normalized to standard deviation one and mean zero for each estimation. Sample: 1994:M1-2007:M12, excluding FOMC announcements on 9/17/2001. Standard errors in parentheses are two-way clustered by banks and meetings. ${ }^{* * *} p<0.01,{ }^{* *} p<0.05,{ }^{*} p<0.1$.

Table I.5: Response of Stock Returns - Term Spread (Maturity Gap).

\begin{tabular}{lccc}
\hline $\mathrm{m}=$ & 2-year & 5-year & 10-year \\
\hline$\Delta Y_{t}^{3 M}$ & -1.10 & 0.01 & 1.41 \\
& $(2.27)$ & $(2.45)$ & $(2.67)$ \\
$\Delta\left(Y_{t}^{m}-Y_{t}^{3 M}\right)$ & 1.28 & 2.33 & 3.58 \\
& $(1.99)$ & $(2.02)$ & $(2.29)$ \\
$\Delta Y_{t}^{3 M} \cdot M G_{i, t}$ & $1.01^{* * *}$ & $1.29^{* * *}$ & $1.42^{* * *}$ \\
& $(0.33)$ & $(0.34)$ & $(0.39)$ \\
$\Delta\left(Y_{t}^{m}-Y_{t}^{3 M}\right) \cdot M G_{i, t}$ & 0.54 & $0.65^{* *}$ & $0.69^{*}$ \\
& $(0.34)$ & $(0.31)$ & $(0.41)$ \\
& & & \\
\hline$R^{2}$ & 0.03 & 0.03 & 0.04 \\
$N$ & 27,938 & 27,938 & 27,938 \\
Banks & 731 & 731 & 731 \\
Meetings & 90 & 90 & 90 \\
\hline
\end{tabular}

Notes: Estimation results for $R_{i, t}=\alpha_{i}+\beta_{1} \Delta Y_{t}^{3 M}+\beta_{2}\left(\Delta Y_{t}^{m}-\Delta Y_{t}^{3 M}\right)+\beta_{3} \Delta Y_{t}^{3 M} \cdot M G_{i, t}+$ $\beta_{4}\left(\Delta Y_{t}^{m}-\Delta Y_{t}^{3 M}\right) \cdot M G_{i, t}+\beta_{5} M G_{i, t}+u_{i, t}$, where $\Delta Y_{t}^{m}$ are based on Gürkaynak, Sack and Wright (2007). $M G_{i, t}$ is normalized to standard deviation one and mean zero for each estimation. Sample: 1997:M4-2007:M12, excluding FOMC announcements on 9/17/2001. Standard errors in parentheses are two-way clustered by banks and meetings. ${ }^{* * *} p<0.01,{ }^{* *} p<0.05,{ }^{*} p<0.1$. 
Table I.6: Response of Stock Returns - Additional Interactions (Income Gap).

\begin{tabular}{lccc}
\hline & Level & Slope & Level + Slope \\
\hline \multirow{2}{*}{$\Delta Y_{t}^{3 M}$} & $-6.76^{* *}$ & $-6.77^{* *}$ & $-6.77^{* *}$ \\
$\Delta\left(E H_{t}^{2 Y}-Y_{t}^{3 M}\right)$ & $(3.28)$ & $(0.04)$ & $(0.04)$ \\
& $-7.62^{*}$ & $-7.64^{*}$ & $-7.64^{*}$ \\
$\Delta T P_{t}^{2 Y}$ & $(4.12)$ & $(0.07)$ & $(0.07)$ \\
& $9.36^{* *}$ & $9.37^{* *}$ & $9.37^{* *}$ \\
$\Delta T P_{t}^{2 Y} \cdot I G_{i, t}$ & $(4.37)$ & $(0.03)$ & $(0.04)$ \\
& $-1.50^{* *}$ & $-1.44^{*}$ & -1.43 \\
$\Delta Y_{t}^{3 M} \cdot I G_{i, t}$ & $(0.62)$ & $(0.06)$ & $(0.15)$ \\
& 0.03 & & -0.00 \\
$\Delta\left(E H_{t}^{2 Y}-Y_{t}^{3 M}\right) \cdot I G_{i, t}$ & $(0.28)$ & & $(0.99)$ \\
& & -0.07 & -0.07 \\
$R^{2}$ & & $(0.82)$ & $(0.93)$ \\
$N$ & & & \\
Banks & 0.04 & 0.04 & 0.04 \\
Meetings & 34,231 & 34,231 & 34,231 \\
\hline
\end{tabular}

Notes: Estimation results for regression (I.3), where $\Delta E H_{t}^{2 Y}$ and $\Delta T P_{t}^{2 Y}$ are based on estimates from Kim and Wright (2005) (2-year maturity). $I G_{i, t}$ is normalized to standard deviation one and mean zero for each estimation. Sample: 1994:M1-2007:M12, excluding FOMC announcement on $9 / 17 / 2001$. Standard errors in parentheses are two-way clustered by banks and meetings. ${ }^{* * *} p<$ $0.01,{ }^{* *} p<0.05,{ }^{*} p<0.1$. 
Table I.7: Response of Stock Returns - Additional Interactions (Maturity Gap).

\begin{tabular}{lccc}
\hline & Level & Slope & Level + Slope \\
\hline & & & \\
$\Delta Y_{t}^{3 M}$ & $-7.72^{* *}$ & $-7.63^{* *}$ & $-7.68^{* *}$ \\
$\Delta\left(E H_{t}^{2 Y}-Y_{t}^{3 M}\right)$ & $(3.44)$ & $(0.03)$ & $(0.03)$ \\
& $-9.54^{* *}$ & $-9.43^{* *}$ & $-9.48^{* *}$ \\
$\Delta T P_{t}^{2 Y}$ & $(4.36)$ & $(0.03)$ & $(0.03)$ \\
& $12.92^{* * *}$ & $12.79^{* * *}$ & $12.87^{* * *}$ \\
$\Delta T P_{t}^{2 Y} \cdot M G_{i, t}$ & $(4.61)$ & $(0.01)$ & $(0.01)$ \\
$\Delta Y_{t}^{3 M} \cdot M G_{i, t}$ & $1.08^{* *}$ & $2.02^{* * *}$ & 1.38 \\
& $(0.50)$ & $(0.00)$ & $(0.15)$ \\
$\Delta\left(E H_{t}^{2 Y}-Y_{t}^{3 M}\right) \cdot M G_{i, t}$ & $0.84^{* *}$ & & 0.64 \\
& $(0.34)$ & & $(0.34)$ \\
$R^{2}$ & & $-1.17^{* * *}$ & -0.39 \\
$N$ & & $(0.01)$ & $(0.66)$ \\
Banks & & & \\
Meetings & 0.04 & 0.04 & 0.04 \\
& 27,938 & 27,938 & 27,938 \\
& 718 & 718 & 718 \\
& 90 & 90 & 90 \\
\hline
\end{tabular}

Notes: Estimation results for regression (I.3), where $\Delta E H_{t}^{2 Y}$ and $\Delta T P_{t}^{2 Y}$ are based on estimates from Kim and Wright (2005) (2-year maturity). $M G_{i, t}$ is normalized to standard deviation one and mean zero for each estimation. Sample: 1997:M4-2007:M12, excluding FOMC announcement on $9 / 17 / 2001$. Standard errors in parentheses are two-way clustered by banks and meetings. ${ }^{* * *} p<$ $0.01,{ }^{* *} p<0.05,{ }^{*} p<0.1$. 
Table I.8: Response of Stock Returns - Maturity Gap Definition.

\begin{tabular}{lccc}
\hline $\mathrm{m}=$ & 2-year & 5-year & 10-year \\
\hline & & & \\
$\Delta Y_{t}^{3 M}$ & $-7.54^{* *}$ & $-12.38^{*}$ & -14.58 \\
& $(3.41)$ & $(6.89)$ & $(10.48)$ \\
$\Delta\left(E H_{t}^{m}-Y_{t}^{3 M}\right)$ & $-9.35^{* *}$ & $-14.26^{*}$ & -16.21 \\
& $(4.32)$ & $(8.32)$ & $(12.05)$ \\
$\Delta T P_{t}^{m}$ & $12.73^{* * *}$ & $12.05^{* *}$ & $12.05^{* *}$ \\
& $(4.53)$ & $(4.61)$ & $(5.09)$ \\
$\Delta T P_{t}^{m} \cdot M G_{i, t}$ & $2.14^{* * *}$ & $1.92^{* * *}$ & $2.08^{* * *}$ \\
& $(0.68)$ & $(0.52)$ & $(0.46)$ \\
& & & \\
\hline$R^{2}$ & 0.04 & 0.04 & 0.04 \\
$N$ & 27,942 & 27,942 & 27,942 \\
Banks & 718 & 718 & 718 \\
Meetings & 90 & 90 & 90 \\
\hline
\end{tabular}

Notes: Estimation results for regression (8.4), where $\Delta E H_{t}^{m}$ and $\Delta T P_{t}^{m}$ are based on estimates from Kim and Wright (2005). $M G_{i, t}$ is estimated as described in Section I and normalized standard deviation one and mean zero for each estimation. Sample: 1997:M4-2007:M12, excluding FOMC announcement on $9 / 17 / 2001$. Standard errors in parentheses are two-way clustered by banks and meetings. ${ }^{* * *} p<0.01,{ }^{* *} p<0.05,{ }^{*} p<0.1$.

Table I.9: Response of Stock Returns - Adrian, Crump and Moench (2013) (Income Gap).

\begin{tabular}{lccc}
\hline $\mathrm{m}=$ & 2-year & 5 -year & 10-year \\
\hline \multirow{2}{*}{$\Delta Y^{3 M_{-} t}$} & $-1.82^{* * *}$ & $-2.20^{* * *}$ & $-3.43^{* * *}$ \\
& $(0.00)$ & $(0.00)$ & $(0.00)$ \\
$\Delta\left(E H^{m} \_t-Y^{3 M}{ }_{-} t\right)$ & -0.18 & -0.70 & $-2.04^{* * *}$ \\
& $(0.39)$ & $(0.16)$ & $(0.01)$ \\
$\Delta T P^{m} \_t$ & $3.13^{*}$ & $2.29^{*}$ & $2.56^{* * *}$ \\
& $(0.07)$ & $(0.05)$ & $(0.01)$ \\
$\Delta T P^{m} \_t \cdot I G_{-} i, t$ & $-0.79^{* * *}$ & $-0.73^{* * *}$ & $-1.06^{* * *}$ \\
& $(0.01)$ & $(0.00)$ & $(0.00)$ \\
& & & \\
\hline$R^{2}$ & 0.04 & 0.04 & 0.04 \\
$\mathrm{~N}$ & 34246 & 34246 & 34246 \\
Banks & 852 & 852 & 852 \\
Meetings & 118 & 118 & 118 \\
\hline
\end{tabular}

Notes: Estimation results for regression (D.3), where $\hat{R}_{t}^{b}$ is given by the predicted return of the KBW Bank Index or the S\&P 500 (excluding banks), and $\Delta E H_{t}^{m, b}$ and $\Delta T P_{t}^{m, b}$ are bootstrapped estimates based on a reestimation of the model by Adrian, Crump and Moench (2013) for the sample 1990:M7-2007:M12 (see Appendix D for details). The table shows the median of the estimated parameters, the cumulative probability $(c p)$ above zero (for $\hat{\beta}_{1}, \hat{\beta}_{2}$, and $\hat{\beta}_{4}$ ) and below zero (for $\left.\hat{\beta}_{3}\right)$ is shown in parentheses. Sample: 1994:M1-2007:M12, excluding FOMC announcement on 9/17/2001. ${ }^{* * *} c p<0.01,{ }^{* *} c p<0.05,{ }^{*} c p<0.1$. 
Table I.10: Response of Stock Returns - Adrian, Crump and Moench (2013) (Maturity Gap).

\begin{tabular}{lccc}
\hline $\mathrm{m}=$ & 2-year & 5-year & 10-year \\
\hline & & & \\
$\Delta Y^{3 M} \_t$ & $-1.27^{* * *}$ & $-1.63^{* *}$ & $-3.02^{* *}$ \\
& $(0.00)$ & $(0.02)$ & $(0.02)$ \\
$\Delta\left(E H^{m} \_t-Y^{3 M_{-}} t\right)$ & 0.28 & -0.40 & -1.89 \\
& $(0.27)$ & $(0.31)$ & $(0.10)$ \\
$\Delta T P^{m}{ }_{-}$ & $4.90^{* *}$ & $3.70^{* * *}$ & $4.53^{* * *}$ \\
& $(0.03)$ & $(0.01)$ & $(0.00)$ \\
$\Delta T P^{m} \_t \cdot M G_{-} i, t$ & $0.64^{* *}$ & $0.49^{* * *}$ & $0.54^{* *}$ \\
& $(0.02)$ & $(0.01)$ & $(0.03)$ \\
& & & \\
\hline$R^{2}$ & 0.04 & 0.04 & 0.04 \\
$\mathrm{~N}$ & 27951 & 27951 & 27951 \\
Banks & 731 & 731 & 731 \\
Meetings & 90 & 90 & 90 \\
\hline
\end{tabular}

Notes: Estimation results for regression (D.3), where $\hat{R}_{t}^{b}$ is given by the predicted return of the KBW Bank Index or the S\&P 500 (excluding banks), and $\Delta E H_{t}^{m, b}$ and $\Delta T P_{t}^{m, b}$ are bootstrapped estimates based on a reestimation of the model by Adrian, Crump and Moench (2013) for the sample 1990:M7-2007:M12 (see Appendix D for details). The table shows the median of the estimated parameters, the cumulative probability $(c p)$ above zero (for $\hat{\beta}_{1}$ and $\hat{\beta}_{2}$ ) and below zero (for $\hat{\beta}_{3}$ and $\left.\hat{\beta}_{4}\right)$ is shown in parentheses. Sample: 1994:M1-2007:M12, excluding FOMC announcement on 9/17/2001. ${ }^{* * *} c p<0.01,{ }^{* *} c p<0.05,{ }^{*} c p<0.1$. 
Table I.11: Response of Stock Returns - Excluding Unscheduled Meetings (Income Gap).

\begin{tabular}{lccc}
\hline $\mathrm{m}=$ & 2-year & 5 -year & 10-year \\
\hline \multirow{2}{*}{$\Delta Y_{t}^{3 M}$} & $-6.00^{*}$ & -8.26 & -7.94 \\
& $(3.53)$ & $(6.50)$ & $(8.86)$ \\
$\Delta\left(E H_{t}^{m}-Y_{t}^{3 M}\right)$ & -5.85 & -7.82 & -6.97 \\
& $(4.19)$ & $(7.39)$ & $(9.68)$ \\
$\Delta T P_{t}^{m}$ & 6.85 & 6.33 & 5.73 \\
$\Delta T P_{t}^{m} \cdot I G_{i, t}$ & $(4.68)$ & $(4.73)$ & $(4.94)$ \\
& $-1.57^{* *}$ & $-1.31^{* * *}$ & $-1.39^{* * *}$ \\
& $(0.60)$ & $(0.47)$ & $(0.48)$ \\
\hline$R^{2}$ & & & \\
$N$ & 0.04 & 0.04 & 0.04 \\
Banks & 33,359 & 33,359 & 33,359 \\
Meetings & 852 & 852 & 852 \\
\hline
\end{tabular}

Notes: Estimation results for regression (8.3), where $\Delta E H_{t}^{m}$ and $\Delta T P_{t}^{m}$ are based on estimates from Kim and Wright (2005). $I G_{i, t}$ is normalized to standard deviation one and mean zero for each estimation. Sample: 1994:M1-2007:M12, excluding FOMC announcements on 10/15/1998, 9/17/2001, 08/10/2007, and $08 / 17 / 2007$. Standard errors in parentheses are two-way clustered by banks and meetings. ${ }^{* * *} p<0.01$, ${ }^{* *} p<0.05,{ }^{*} p<0.1$.

Table I.12: Response of Stock Returns - Excluding Unscheduled Meetings (Maturity Gap).

\begin{tabular}{lccc}
\hline $\mathrm{m}=$ & 2-year & 5-year & 10-year \\
\hline \multirow{2}{*}{$\Delta Y_{t}^{3 M}$} & $-6.84^{*}$ & -9.19 & -7.35 \\
& $(3.71)$ & $(7.15)$ & $(10.38)$ \\
$\Delta\left(E H_{t}^{m}-Y_{t}^{3 M}\right)$ & $-7.30^{*}$ & -9.09 & -6.31 \\
& $(4.38)$ & $(8.24)$ & $(11.48)$ \\
$\Delta T P_{t}^{m}$ & $9.72^{*}$ & $8.45^{*}$ & 7.23 \\
& $(4.96)$ & $(4.92)$ & $(5.12)$ \\
$\Delta T P_{t}^{m} \cdot M G_{i, t}$ & $1.34^{* * *}$ & $1.08^{* * *}$ & $0.91^{* *}$ \\
& $(0.42)$ & $(0.36)$ & $(0.43)$ \\
& & & \\
\hline$R^{2}$ & 0.04 & 0.04 & 0.04 \\
$N$ & 27,066 & 27,066 & 27,066 \\
Banks & 731 & 731 & 731 \\
Meetings & 87 & 87 & 87 \\
\hline
\end{tabular}

Notes: Estimation results for regression (8.4), where $\Delta E H_{t}^{m}$ and $\Delta T P_{t}^{m}$ are based on estimates from Kim and Wright (2005). $M G_{i, t}$ is normalized to standard deviation one and mean zero for each estimation. Sample: 1997:M4-2007:M12, excluding FOMC announcements on 10/15/1998, 9/17/2001, 08/10/2007, and $08 / 17 / 2007$. Standard errors in parentheses are two-way clustered by banks and meetings. ${ }^{* * *} p<0.01$, ${ }^{* *} p<0.05,{ }^{*} p<0.1$. 